\title{
Predator presence affects activity patterns but not food consumption or growth of juvenile corkwing wrasse (Symphodus melops)
}

Norin, Tommy; Sundin, Josefin; Morgan, Rachael; Andreassen, Anna H.; Amcoff, Mirjam; SpeersRoesch, Ben; Jutfelt, Fredrik; Binning, Sandra A.; Roche, Dominique G.; Clark, Timothy D.

Published in:

Behavioral Ecology and Sociobiology

Link to article, DOI:

$10.1007 / \mathrm{s} 00265-020-02947-5$

Publication date:

2021

Document Version

Peer reviewed version

Link back to DTU Orbit

Citation (APA):

Norin, T., Sundin, J., Morgan, R., Andreassen, A. H., Amcoff, M., Speers-Roesch, B., Jutfelt, F., Binning, S. A., Roche, D. G., \& Clark, T. D. (2021). Predator presence affects activity patterns but not food consumption or growth of juvenile corkwing wrasse (Symphodus melops). Behavioral Ecology and Sociobiology, 75(1), [14]. https://doi.org/10.1007/s00265-020-02947-5

\section{General rights}

Copyright and moral rights for the publications made accessible in the public portal are retained by the authors and/or other copyright owners and it is a condition of accessing publications that users recognise and abide by the legal requirements associated with these rights.

- Users may download and print one copy of any publication from the public portal for the purpose of private study or research.

- You may not further distribute the material or use it for any profit-making activity or commercial gain

- You may freely distribute the URL identifying the publication in the public portal 
1 Predator presence affects activity patterns but not food consumption or growth of juvenile corkwing wrasse (Symphodus melops)

3

4 Tommy Norin ${ }^{1, *}$, Josefin Sundin ${ }^{2,3}$, Rachael Morgan ${ }^{4}$, Anna H. Andreassen ${ }^{4}$, Mirjam

5 Amcoff $^{5}$, Ben Speers-Roesch ${ }^{6}$, Fredrik Jutfelt ${ }^{4}$, Sandra A. Binning ${ }^{7}$, Dominique G. Roche ${ }^{8,9}$,

6 Timothy D. Clark ${ }^{10}$

7

$8{ }^{1}$ DTU Aqua: National Institute of Aquatic Resources, Technical University of Denmark, Kgs. Lyngby,

9 Denmark

$10{ }^{2}$ Department of Aquatic Resources, Swedish University of Agricultural Sciences, Drottningholm,

11 Sweden

$12{ }^{3}$ Department of Neuroscience, Uppsala University, Uppsala, Sweden

$13{ }^{4}$ Department of Biology, Norwegian University of Science and Technology, Trondheim, Norway

$14{ }^{5}$ Department of Zoology/Functional Zoomorphology Stockholm University, Stockholm, Sweden

$15{ }^{6}$ Department of Biological Sciences, University of New Brunswick, Saint John, New Brunswick, 16 Canada

$17 \quad{ }^{7}$ Département de sciences biologiques, Université de Montréal, Montréal, Québec, Canada

$18{ }^{8}$ Department of Biology, Carleton University, Ottawa, Ontario, Canada

$19{ }^{9}$ Institut de biologie, Université de Neuchâtel, Neuchâtel, Switzerland

$20{ }^{10}$ School of Life and Environmental Sciences, Deakin University, Geelong, Victoria, Australia 21

*Corresponding author (tnor@aqua.dtu.dk)

23

24

25 Keywords: Fish, behaviour, digestion, metabolic rate, specific dynamic action, predation risk 
Indirect effects of predators can manifest themselves as changes in prey behaviour and physiology. Given that digestion requires energy, it has been suggested that prey will choose to eat smaller meals under predation risk to reserve a larger portion of the aerobic metabolic scope they have available for energetically-demanding tasks more critical than digestion, such as escape. To test this prediction, we quantified food consumption and growth of juvenile corkwing wrasses (Symphodus melops) over 11 days in the presence or absence of a predator (Atlantic cod, Gadus morhua). We then quantified behaviour and food consumption of the same wrasses in behavioural arenas with a predator. All food consumption was examined in the context of the aerobic scope that would have been available during the digestive period. Overall, there was no effect of predator exposure on food consumption or growth, yet predator-exposed wrasses were more consistent in their daily food consumption, lending some support to our prediction of prey bet-hedging on meal size under predation risk. The lack of a clear pattern may have resulted from a relatively low percentage of aerobic scope $(\sim 20-27 \%)$ being occupied by digestion, such that fish retained ample capacity for activities other than digestion. In the subsequent behavioural trials, predator-exposed wrasses were more active and spent more time near the cod than predator-naïve wrasses, suggesting the former had habituated to predation threat and were more risk-taking. Our results highlight the complex and often counter-intuitive effects that predator presence can have on prey populations beyond direct consumption.

\section{$47 \quad$ Significance statement}

48 Predators affect the behaviour of prey species by simply being present in the environment. Such intimidation by predators can change activity patterns of prey and be as important as direct predation for ecosystem dynamics. However, compared to behavioural changes, we know little about how predators indirectly affects prey physiology. We investigated if fish deliberately eat 
less food when a predator is present, in order to retain sufficient physiological capacity for avoiding a potential attack, on top of the energetically-costly process of digesting. While our study confirms that predator encounters reduce prey activity, prey fish appeared to rapidly habituate to predator presence and we did not see reduced food consumption in predatorexposed fish; these were, however, more consistent than unexposed fish in their daily food consumption, suggesting that fish may still be mindful about protecting their aerobic capacity under predation risk.

\section{Introduction}

Predators eat prey. Although this relationship sounds straightforward, the dynamics between animals higher up the food chain and the species they consume are, in fact, much more complicated. The mere presence of predators in an environment can have dramatic effects on the behaviour, physiology, and life-history of potential prey (Preisser et al. 2005), including in fishes (Lima and Dill 1990; Dugatkin and Godin 1992; Hawlena and Schmitz 2010a; Gallagher et al. 2016; Hasenjager and Dugatkin 2017). Such non-consumptive effects of predators on prey are thought to be at least as strong as direct consumptive effects, especially in aquatic systems (Preisser et al. 2005), and can have cascading effects on prey demographics and ecosystem processes (Preisser et al. 2005; Hawlena and Schmitz 2010a). An example is the growthpredation risk trade-off, where the presence of predators reduces the foraging behaviour of prey species, resulting in reduced growth due to lost feeding opportunities (Lima and Dill 1990; Houston et al. 1993; Brown and Kotler 2004; McPeek 2004; Verdolin 2006). This cost is offset by increased survival as predators are less likely to detect potential prey when prey are less active and, similarly, prey are more likely to detect and respond early to the presence of a predator when they are not distracted by feeding. Although the growth-predation risk trade-off is generally supported by the available experimental evidence (Dugatkin and Godin 1992; 
Brown and Kotler 2004; Verdolin 2006), some studies have found that prey can maintain normal growth rates despite reduced foraging activity, due to compensatory changes in their underlying physiology (McPeek 2004; Thaler et al. 2012).

Predation risk affects the physiology of prey by inducing stress (Boonstra et al. 1998; Hawlena and Schmitz 2010a; Sheriff et al. 2009; Boonstra 2013), changing metabolic rate (Steiner and Van Buskirk 2009; Hall and Clark 2016; Lagos and Herberstein 2017), increasing oxidative damage (Janssens and Stoks 2013; Culler et al. 2014; Manzur et al. 2014; Jermacz et al. 2020), and altering the assimilation of nutrients (McPeek 2004; Hawlena and Schmitz 2010a, b; Thaler et al. 2012; Dalton and Flecker 2014). The latter is deemed an important mechanism through which prey may compensate for adverse impacts of predation risk (e.g. reduced foraging opportunities and food consumption; Hawlena and Schmitz 2010b; Thaler et al. 2012), including compensating for the (transient) increase in prey metabolic rate that is often observed in the presence of predators (Steiner and Van Buskirk 2009; Hawlena and Schmitz 2010b; Okuyama 2015; Hall and Clark 2016; Lagos and Herberstein 2017). Nonetheless, the consequences of predation risk on prey physiology can be complex and variable (Thaler et al. 2012; Handelsman et al. 2013; Tigreros et al. 2018), and the growth-predation risk trade-off may manifest itself via a range of different physiological pathways. For example, previous work has found that fish eating relatively large meals benefit from a higher digestion and growth efficiency, compared to fish eating smaller meals, but are disadvantaged by the metabolic cost of digestion (i.e. 'specific dynamic action', SDA; Secor 2009) occupying a larger portion of the aerobic scope available for activities other than digestion (Norin and Clark 2017). Aerobic scope is the difference between an animal's aerobic maximum metabolic rate (MMR) and its standard (resting) metabolic rate (SMR), and represents the capacity to increase oxygen uptake rate above baseline levels to support energy-demanding activities (Clark et al. 2013). Therefore, animals should preferentially eat large meals in the absence of predators (i.e. in an environment 
perceived to be safe) to reap the associated growth benefits, but smaller meals in the presence

103 of predators to conserve a portion of their aerobic scope in case energetically costly behaviours 104 are abruptly required to avoid or escape predators.

105 Here, we tested these ideas in a laboratory setting using juvenile corkwing wrasses 106 (Symphodus melops) exposed to a natural predator, the Atlantic cod (Gadus morhua). Wrasses, 107 including S. melops, are common prey for cod (Nordeide and Salvanes 1991; Salvanes and 108 Nordeide 1993). We conducted three sets of experiments, where we: (1) fed wrasses meals of 109 different sizes and quantified their metabolic cost of digestion (SDA) using respirometry in the 110 absence of cod; (2) recorded growth and food consumption of wrasses kept in holding tanks 111 with or without a cod for 11 days; and (3) transferred wrasses from their holding tanks to 112 behavioural arenas and quantified their behaviour and food consumption with a cod present.

113 We predicted that: (1) SDA from larger meals would occupy a greater percentage of the 114 wrasses' aerobic scope; (2) predator-exposed wrasses would eat smaller meals than wrasses 115 held without predators; and (3) wrasses held without predators would display lower food 116 consumption and activity when acutely confronted with a predator in a behavioural arena 117 compared to wrasses that had been previously housed with a predator.

\section{Methods}

120 Fish collection and holding conditions

121 All experiments were performed at the Kristineberg Marine Research Station, University of 122 Gothenburg, located on the west coast of Sweden, in June 2017. Juvenile corkwing wrasses 123 (Symphodus melops) of unknown sex were collected on June 7-8 using a beach seine pulled by 124 hand in bays of the Gullmar Fjord near Kristineberg $\left(58^{\circ} 15^{\prime} \mathrm{N}, 11^{\circ} 28^{\prime} \mathrm{E}\right)$. Wrasses were initially 125 housed in groups of $\sim 10$ individuals in laboratory holding aquaria [58 $\times 30 \times 36 \mathrm{~cm}$ (length $\times$ 126 width $\times$ height)] receiving flow-through, filtered seawater pumped into the station from a depth 
of $7 \mathrm{~m}$ (surface water supply). Artificial plastic plants were provided to all fish for shelter.

Wrasses were fed live shrimp (Crangon crangon and Palaemon adspersus) and thawed chironomid larvae ("bloodworms") ad libitum once every second day. Temperature and salinity in the aquaria followed natural conditions in the area (means \pm SDs: temperature, $14.9 \pm 0.92^{\circ} \mathrm{C}$;

131 salinity, $27.6 \pm 2.15$ PSU; data from the continuous monitoring system at the research station, 132 June 7-30, 2017: http://www.weather.loven.gu.se/kristineberg/en/data.shtml). The photoperiod was set to $18 \mathrm{~h}$ light and $6 \mathrm{~h}$ darkness to mimic natural conditions, regulated by small lights on a timer from 06:00 to 24:00 in both holding and experimental rooms. Additional room lighting was manually switched on at $\sim 08: 00$ and off at $\sim 22: 00$.

Juvenile Atlantic cod (Gadus morhua) of unknown sex were cage-caught by local

137 fishers in the waters off Lysekil, Sweden, in June 2017, and brought by boat to the research

138 station. At the station, the cod were kept in four $1000 \mathrm{~L}$ tanks receiving thermo-regulated, flow139 through, filtered seawater pumped from a depth of $32 \mathrm{~m}$ (deep water supply). The water 140 temperature was increased from $10.7^{\circ} \mathrm{C}$ (the natural deep-water temperature at the time of 141 capture) to a target temperature of $\sim 14^{\circ} \mathrm{C}$ over a period of 3 days (actual mean \pm SD temperature 142 during cod holding: $13.5 \pm 1.15^{\circ} \mathrm{C}$ ). The cod were fed cooked blue mussels (Mytilus edulis) and 143 shrimp (Pandalus borealis) once every second day. Artificial plastic plants and cut plastic pipes 144 were provided in the tanks for shelter. The light cycle was the same as described for the wrasses.

147 To understand how digestion affects the available aerobic scope of wrasses, the metabolic rate 148 of 20 individuals (mean \pm SD body mass: $3.92 \pm 0.94 \mathrm{~g}$ ) was estimated as the rate of oxygen 149 uptake $\left(\dot{M}_{O_{2}}\right)$ during and after the postprandial process (SDA), using intermittent-closed respirometry. 

chambers submerged in a $40 \mathrm{~L}$ (water volume) tank receiving flow-through normoxic surface seawater maintained at $15.4 \pm 0.5^{\circ} \mathrm{C}$ (mean \pm range) and at a salinity following the natural conditions in the area (mean \pm SD: $28.4 \pm 1.71$ PSU; June 20-30, 2017). Each respirometry 155 chamber had an in-line pump (miniature DC pump; Loligo Systems, Viborg, Denmark) that 156 continuously recirculated water through the chamber and past an optical oxygen probe 157 (PyroScience GmbH, Aachen, Germany) in a closed loop of PVC tubing. The oxygen probe 158 was connected to an oxygen meter (FireStingO 2 ; PyroScience GmbH, Aachen, Germany) that 159 recorded the oxygen concentration of the water every 2 s. Another set of eight miniature DC 160 pumps was controlled by a timer and was turned on for $3 \mathrm{~min}$ in every $7 \mathrm{~min}$ intermittent 161 respirometry cycle to flush the chambers with clean and normoxic water from the ambient tank.

162 The decrease in oxygen recorded over the other 4 min closed (sealed) period was used for 163 calculating $\dot{M}_{\mathrm{O}_{2}}$ by multiplying the slope for the decrease in oxygen concentration over time $164\left(\mathrm{mg} \mathrm{O}_{2} \mathrm{~L}^{-1} \mathrm{~s}^{-1}\right)$ with the volume of the respirometry chamber after subtracting the volume of 165 the fish (assuming a fish density of $1 \mathrm{~g} \mathrm{~mL}^{-1}$ ). The day before a respirometry experiment, wrasses were moved from their holding 167 aquaria and placed in individual compartments $[22 \times 12 \times 10 \mathrm{~cm}$ (length $\times$ width $\times$ height) $]$ 168 receiving flow through water at the conditions described above. After $\sim 24 \mathrm{~h}$ with no food 169 available, wrasses were fed between 10 and 60 bloodworms and given about 30-45 min to eat. 170 All fish were monitored with a webcam to determine precisely when they started eating. The 171 wrasses were then gently moved (in a water-filled container) to the respirometry chambers, and $172 \dot{M}_{\mathrm{O}_{2}}$ recordings were started between 38 and $54 \mathrm{~min}$ after the fish had started eating. Any 173 uneaten worms were counted to calculate the final amount eaten by each individual, which 174 ranged between two and 60 worms. The fish remained in the respirometry chambers for 38.5 175 to $43.2 \mathrm{~h}$ until $\dot{M}_{\mathrm{O}_{2}}$ had plateaued at baseline values, yielding between 330 and $370 \dot{M}_{\mathrm{O}_{2}}$ 
recordings per fish. We used these recordings to quantify the wrasses' specific dynamic action

177 (SDA) responses using a modified version of the SDA script provided by Chabot et al. (2016).

178 Upon completion of these initial $\dot{M}_{\mathrm{O}_{2}}$ recordings, the wrasses were gently removed from the 179 respirometry chambers and placed in a tub with water at the same conditions as for the respirometry trials. The fish were then chased by hand for 2 min by an experimenter before being immediately reintroduced to the respirometry chambers for another 6-10 $\dot{M}_{\mathrm{O}_{2}}$ recordings, of which the highest measurement (the first measurement for all but one fish) was taken to represent the MMR of the fish (cf. Norin and Clark 2016). bleach in 100 parts water) before each new respirometry trial (excluding the oxygen probes, which were cleaned in ethanol). Background (microbial) respiration was therefore near zero at the start of a trial. The mean of three background recordings taken at the end of a trial, after removal of the fish, was used to correct the $\dot{M}_{\mathrm{O}_{2}}$ of the wrasses for the increase in background respiration during the trial by assuming a linear increase between zero at the start of a trial and the mean background value at the end of the trial.

The SDA script was used to calculate the SMR of the fish as the 0.05-quantile of all the $\dot{M}_{\mathrm{O}_{2}}$ values for each fish (which always occurred towards the end of the respirometry trial once

193 SDA was complete). The script was also used to calculate peak net SDA (the peak $\dot{M}_{O_{2}}$ during 194 digestion, above SMR), time to peak SDA (the time to reach peak $\dot{M}_{\mathrm{O}_{2}}$ from time of feeding; corrections for handling effects outlined in supplementary material), SDA duration (the time it took to complete the SDA response and reach SMR), and SDA magnitude (the total amount of 197 oxygen used in digesting the meal, i.e. the area under the SDA curve but above SMR). Aerobic 198 scope was calculated as the absolute difference between MMR and SMR. Out of the 20 wrasses, two had to be excluded from the final dataset. One because the recirculation pump malfunctioned during the recording of MMR (meaning that aerobic scope 
201 could not be calculated), and another due to a loose connection to one of the oxygen probes that 202 resulted in erratic oxygen recordings, as noted during the experiment. Final sample sizes are 203 given in Fig. 1. Further details of the SDA analyses are given in the supplementary material 204 along with all $\dot{M}_{\mathrm{O}_{2}}$ profiles (graphs of $\dot{M}_{\mathrm{O}_{2}}$ over time during digestion, annotated with SDA 205 variables; Fig. S1).

blind at the time of the experiment; the subsequent calculations of each individual's $\dot{M}_{O_{2}}$ and SDA were done blinded (i.e. without knowing how much each fish had eaten until after the raw data analyses had been completed).

\section{Food consumption and growth in holding tanks in the presence or absence of a predator}

212 We quantified food consumption and growth of wrasses being held in the presence or absence of a predator (cod) for 11 days. Fish were fasted for $24 \mathrm{~h}$ before the experiment began. were weighed and transferred to individual, transparent plastic boxes $[18 \times 16 \times 14 \mathrm{~cm}$ (length $\times$ width $\times$ height)]. Four boxes were placed in each of six larger holding tanks [glass aquaria measuring $61 \times 40 \times 37 \mathrm{~cm}$ (length $\times$ width $\times$ height) $]($ Fig. S2), three of which contained a cod

218 ('predator-habituated' treatment; mean \pm SD wrasse body mass: $4.20 \pm 0.39 \mathrm{~g}$; mean \pm SD cod 219 body mass: $87.0 \pm 6.46 \mathrm{~g}$ ), and three of which did not ('predator-naïve' treatment; mean \pm SD 220 wrasse body mass: $4.04 \pm 0.63 \mathrm{~g}$ ). Each wrasse-box had several $\sim 5 \mathrm{~mm}$ holes on all sides (see 221 photo in Fig. S2) to allow water exchange between the box and the surrounding holding tank. 222 These boxes separated the wrasses physically from the cod but allowed for both chemical and 223 visual cue exchange between predator and prey. Each of the six holding tanks received flow224 through surface water and had an air stone for aeration and four artificial plastic plants. Each 225 wrasse-box also contained an opaque plastic tube for shelter $(9.5 \mathrm{~cm}$ long, $\varnothing 3 \mathrm{~cm})$. There was 
no significant difference in the initial mass of wrasses between the two treatments $\left(\mathrm{t}_{22}=0.75\right.$,

$227 \mathrm{p}=0.463)$.

To measure food consumption and growth, each wrasse was initially given 40

229 bloodworms in the afternoon of the first day of the experiment, followed by an additional 230 maximum 40 bloodworms if the initial 40 were consumed within $1 \mathrm{~h}$. The next morning, all 231 remaining bloodworms were siphoned from each of the wrasse-boxes into individual buckets and counted. This initial trial allowed us to establish 80 bloodworms as the satiation limit for wrasses of this size. We subsequently gave each wrasse a total of 80 bloodworms in the morning of each day. Uneaten bloodworms were siphoned and counted each morning before the fish were fed fresh bloodworms. Data from the first feeding event for three wrasses were excluded due to technical issues preventing us from accurately quantifying food consumption (e.g. we accidentally siphoned bloodworms onto the floor, preventing the data from being included, as some worms could have gone down the drain).

We also quantified the sheltering behaviour of the wrasses by noting whether individuals were sheltering or not (sheltering defined as more than $\sim 90 \%$ of the fish being inside the shelter) at the time of observation. Visual observations were made three times on the second 242 day of the experiment (at approximately 09:00, 15:00, and 18:00), four times per day on the 243 following nine days (at approximately 09:00, 12:00, 15:00, and 18:00), and three times on the 244 last day (at approximately 09:00, 15:00, and 18:00) before trials in the behavioural arenas 245 commenced (see next section). The cod were fed cooked shrimp (Pandalus borealis) every 246 second day. Temperature and salinity followed the natural conditions of surface seawater in the 247 area (June 12-23, 2017, means \pm SDs: temperature, $14.5 \pm 0.97^{\circ} \mathrm{C}$; salinity, $\left.28.0 \pm 2.25 \mathrm{PSU}\right)$. Food consumption and sheltering was quantified directly from each transparent holding 249 tank with the predator visible, and thus not recorded blind. 
252 To quantify whether being exposed to a predator or not had an effect on the behaviour and food consumption of wrasses in the presence of a predator, we conducted video-recorded behavioural trials in a novel behavioural arena.

Four glass aquaria measuring $60 \times 38 \times 35 \mathrm{~cm}$ (length $\times$ width $\times$ height; water depth $\sim 20 \mathrm{~cm}$ ) were used simultaneously as behavioural arenas (Fig. S3). Each arena was divided into two sections with a transparent glass plate glued (with silicone) to the sides of the aquaria with a small $(3 \mathrm{~mm})$ gap at the bottom, allowing for water exchange between sections. A predator (cod; different individuals than used previously) was placed in one section of the arena [40 $\times$

$26038 \mathrm{~cm}($ length $\times$ width)], with a wrasse placed in the other section $[20 \times 38 \mathrm{~cm}($ length $\times$ width $)]$.

261 The walls of the aquaria were covered with white waterproof paper to prevent fish in the four 262 separate behavioural arenas from seeing each other. Each of the four cod had a shelter (opaque 263 plastic pipe; $12.5 \mathrm{~cm}$ long, $\varnothing 7 \mathrm{~cm}$ ) placed at the opposite end of the aquaria to the wrasse 264 section. Each wrasse section also had a shelter (opaque plastic pipe; $8 \mathrm{~cm}$ long, $\varnothing 4.5 \mathrm{~cm}$ ) placed 265 on the opposite side relative to the cod section. Cod were housed in the behavioural arenas for 266 the duration of the trials (two days). Wrasses were placed in the arenas at the start of a trial and 267 given $\sim 6$ min to settle (mean \pm SD: $5.8 \pm 0.8 \mathrm{~min}$ ), during which time they were video recorded 268 with a USB camera (Kurokesu C1; Kurokesu, Vilnius, Lithuania) mounted above the aquaria. 269 After this habituation period, a dish containing 40 bloodworms was added to each wrasse 270 section at the end opposite from the shelter (dish placement in all four arenas complete within $2714 \mathrm{~min}$; mean $\pm \mathrm{SD}: 2.1 \pm 1.2 \mathrm{~min}$ ), and the wrasses were monitored for another $\sim 30$ min (mean $272 \pm$ SD: $31.2 \pm 1.0 \mathrm{~min}$ ) before the trial was ceased and any uneaten bloodworms were counted.

273 Water temperature and salinity followed natural surface water conditions in the area (June 2427425,2017 , means \pm SDs: temperature, $16.3 \pm 0.14^{\circ} \mathrm{C}$; salinity, $\left.27.0 \pm 0.19 \mathrm{PSU}\right)$. 
276 France). For the wrasses, we quantified time spent in four zones both before and after the food

277 was added to the arena: zone 1, within proximity to food but away from the predator; zone 2,

278 within proximity to food but close to the predator; zone 3, in or near the shelter but away from

279 the predator; and zone 4, anywhere along the glass divider near the predator section but away

280 from the food (Fig. S3). We also measured latency to inspect the food (defined as the fish being

281 within $\sim 1 \mathrm{~cm}$ of the food dish and facing the food), latency to feed (duration from food addition

282 to consumption of first bloodworm), and percentage of bloodworms consumed (out of 40). In

283 two instances, a wrasse never inspected the food and ate nothing; these fish were assigned the

284 maximum run time of their respective trial after the addition of food (31.2 and 31.9 min) for

285 both latency to inspect food and latency to feed. For both wrasses and cod, we quantified 286 activity as swimming distance over time before and after the food was added. For the cod, time spent in two zones was analysed: zone 1, close to the wrasse; and zone 2, away from the wrasse (Fig. S3).

Three of the 24 wrasses (two from the predator-naïve treatment, one from the predatorhabituated treatment) exhibited abnormal behaviour (constantly swimming in an atypical manner at the surface) after being transferred to the behavioural arenas and were therefore excluded from these trials. We had not observed any abnormal behaviour of these fish while in their holding tanks, and they do not stand out as outliers in the data analyses (see diagnostics in

294 data analysis script). The fish were therefore kept in the analyses of the holding tank data.

Predator treatment history was known at the time of the trials, however the trials were

296 video recorded and the subsequent video analyses were done blinded using automated tracking 297 software. 
To convert the number of bloodworms eaten by the wrasses into a percentage of the wrasses' body mass, we weighed 13 replicates of 80 bloodworms (i.e. 1040 bloodworms in total) on an analytical balance both before and after drying the worms for $26 \mathrm{~h}$ at $70^{\circ} \mathrm{C}$. From this, we

303 calculated the overall mean mass of one bloodworm, which was $7.144 \mathrm{mg}$ wet mass or 3.884 304 mg dry mass. Herein, we use wet bloodworm mass to express food consumption as a percentage 305 of fish body mass.

Statistical analyses

308 All statistical analyses were performed in R v. 4.0.2 (R Core Team 2020).

The effect of digestion on metabolic rate was examined with two general linear models

310 (LMs) with either the SDA magnitude or the percentage of aerobic scope occupied at the peak

311 of SDA as the response variable, and meal size (as percent of body mass) and wrasse body mass as predictor variables.

The effect of predator (cod) presence or absence on wrasse food consumption and

314 sheltering in the holding tank was examined with two linear mixed-effects models (LMEs)

315 using the package lme4 (Bates et al. 2015). P-values were estimated using lmerTest

316 (Kuznetsova et al. 2017). These models included either the amount of bloodworms eaten

317 (percent of body mass) or the percentage time spent sheltering as the response variable;

318 treatment (predator present or absent), time (day of the experiment), and wrasse body mass

319 were included as predictor variables; fish ID was nested within holding tank and included as a 320 random effect.

321 The growth of wrasses was calculated as their specific growth rate (SGR; \% day ${ }^{-1}$ ) 322 across their time in the holding tanks. This was determined as $\mathrm{SGR}=\left[\ln \left(\mathrm{BM}_{f}\right)-\ln \left(\mathrm{BM}_{i}\right)\right] \times t^{-}$ $323{ }^{1} \times 100$, where $\mathrm{BM}_{f}$ is final body mass, $\mathrm{BM}_{i}$ is initial body mass, and $t$ is the time (days) over 324 which the fish were growing. These data were analysed with an LME with SGR as the response 
variable and treatment, mean daily food consumption, and mean wrasse body mass across the

326 growth period as predictor variables; holding tank was included as a random effect. We

327 calculated how consistent the fish were in the amount they ate across the experiment by 328 computing the adjusted repeatability $\left(\mathrm{R}_{\mathrm{adj}}\right.$, the repeatability after controlling for fixed effects; 329 Nakagawa and Schielzeth 2010) of meal sizes using the same model structure as above in the 330 package $r p t R$ (Stoffel et al. 2017). Adjusted repeatability was also calculated for each treatment 331 group separately, without treatment as a predictor variable. Uncertainty in the repeatability estimates was evaluated by running 1000 parametric bootstraps.

For the behavioural arena trials, the effect of predator treatment (predator-habituated $v s$.

334 predator-naïve wrasses) on wrasse activity (distance moved over time), time spent near vs. far 335 from food and/or predator (i.e. time spent in each of the four zones of the behavioural arena), 336 and food consumption in the presence of a predator were analysed with six LMEs. These models had percentage time spent in a given zone, activity, or amount of bloodworms eaten in 338 the behavioural arena as a response variable; treatment, presence of food (before $v s$. after food 339 was added to the arena), wrasse body mass, and cod behaviour (time spent close to the wrasse) 340 were included as predictor variables in all models; behavioural arena number was specified as 341 a random effect. Latency to inspect food and latency to feed in the behavioural arenas were analysed 343 using two mixed-effects Cox proportional hazards models (COXME) with the package coxme 344 (Therneau 2020): latency to either inspect food or to feed were included as the response 345 variable; treatment, wrasse body mass, and cod behaviour were included as predictor variables; 346 behavioural arena number was specified as a random effect. Individual fish were censored in 347 these models if they never inspected the food or never fed. 
fit model. Results presented in the text below are model-predicted estimates for each treatment

351 (predator present or absent in holding tanks), evaluated at the means of the other predictor

354 show the raw data.

\section{Results}

Aerobic scope and metabolic cost of digestion

The total increase in metabolic rate during digestion of a meal (the SDA magnitude) increased with meal size (LM, effect of meal size: $\left.\mathrm{F}_{1,16}=8.973, \mathrm{p}=0.0086\right)$ (Fig. 1A). Similarly, the amount of aerobic scope occupied at the peak of the SDA response increased with meal size

361 (LM, effect of meal size: $F_{1,16}=6.716, p=0.0197$ ), with wrasses fed between 0.4 and $8.4 \%$ of their body mass having, on average, between 11.4 and $36.1 \%$ of their aerobic scope occupied by the postprandial process (Fig. 1B).

Food consumption and growth in holding tanks in the presence or absence of a predator

366 In the holding tank trials, an average-size ( $4.2 \mathrm{~g})$ wrasse ate a model-predicted meal of $4.4 \pm$ $0.7 \%$ of its body mass (predator present) or $5.5 \pm 0.7 \%$ of its body mass (predator absent) (26

$368 \pm 4.0$ or $33 \pm 4.0$ bloodworms, respectively) on the first day of the 11-day trial (Fig. 2 ). If the bloodworms had been consumed as one meal, digestion would have occupied an average 23.6 or $27.1 \%$ of the fish's aerobic scope, respectively, at the peak of the SDA response (based on

371 the relationship established between meal size and $\dot{M}_{\mathrm{O}_{2}}$ at peak SDA; Fig. 1B). Food 372 consumption tended to increase slightly by $0.1 \%$ of the wrasses' body mass ( 0.6 worms $)$ per 373 day throughout the experiment (LME, effect of day: $\mathrm{t}_{236.2}=1.905, \mathrm{p}=0.058$ ), with no difference 374 between treatments in this increase (supported by the non-significant and dropped interaction; 
LME, day $\times$ treatment: $\left.\mathrm{t}_{233.0}=0.348, \mathrm{p}=0.728\right)($ Fig. $2 \mathrm{~A})$. The overall difference in food consumption between treatment groups across the 11 days was not significant (LME, effect of treatment: $\left.\mathrm{t}_{22.05}=-1.322, \mathrm{p}=0.200\right)$. Specific growth rates also did not differ between predator treatments (LME, effect of treatment: $\left.\mathrm{t}_{20.00}=0.487, \mathrm{p}=0.632\right)($ Fig. $2 \mathrm{~B})$. Individual wrasses were consistent in their food consumption throughout the experiment and across treatments $\left(\mathrm{R}_{\mathrm{adj}}=0.360\right.$ [95\% $\left.\left.\mathrm{CI}=0.186-0.519\right], \mathrm{p}<0.0001\right)$. Interestingly, within treatments, wrasses being held with predators were more than twice as consistent (repeatable) in the amount of food they ate each day $\left(\mathrm{R}_{\mathrm{adj}}=0.480[0.226-0.674], \mathrm{p}<0.0001\right)$ compared to wrasses not exposed to predators $\left(\mathrm{R}_{\mathrm{adj}}=0.227[0.046-0.408], \mathrm{p}<0.0001\right)$.

An average-size wrasse held in the presence or absence of a predator spent a modelpredicted $60 \pm 8.1 \%$ or $48 \pm 8.1 \%$ of its time sheltering on the first day of the 11-day experiment, respectively. Time spent sheltering decreased significantly thereafter by $3.9 \%$ per day (LME, effect of day: $\mathrm{t}_{239.0}=8.502, \mathrm{p}<0.0001$ ), with no difference between treatments in this decrease

(supported by the non-significant and dropped interaction; LME, day $\times$ treatment: $\mathrm{t}_{238.3}=$ $-1.062, p=0.289)$. The overall difference in sheltering between treatments was not significant (LME, effect of treatment: $\left.\mathrm{t}_{4.000}=1.172, \mathrm{p}=0.306\right)$.

Behaviour and food consumption in behavioural arenas in the presence of a predator

393 In the behavioural arena trials, the predator treatment (predator-habituated $v s$. predator-naïve 394 wrasses) had no effect on the time wrasses spent near the food, regardless of whether the 395 wrasses were directly adjacent to the predator section (time in zone 2; LME, effect of treatment: $396 \mathrm{t} 38.00=-1.548, \mathrm{p}=0.130$ ) or on the far side of the food dish (time in zone 1; LME, effect of treatment: $\left.\mathrm{t}_{35.76}=0.523, \mathrm{p}=0.604\right)($ Table 1$)$. However, the predator-habituated wrasses spent 398 less time in or near the shelter (time in zone 3; LME, effect of treatment: $t_{38.00}=2.023, p=$ 399 0.050) and more time closer to the predator but away from the food (time in zone 4; LME, 
effect of treatment: $\left.\mathrm{t}_{37.11}=-2.294, \mathrm{p}=0.028\right)$ compared to the predator-naïve wrasses (Table

401 1).

Predator-habituated wrasses were most active in the behavioural trials (LME, effect of treatment: $\left.\mathrm{t}_{40.00}=-2.734, \mathrm{p}=0.0093\right)$, swimming $252 \pm 18.6 \mathrm{~cm} \mathrm{~min}^{-1}$ compared to $179 \pm 19.5$ $\mathrm{cm} \min ^{-1}$ for predator-naïve wrasses (Fig. 3).

Predator-habituated and predator-naïve wrasses did not differ significantly in the time they took to inspect the food (COXME, effect of treatment: $z=1.49, p=0.14$ ) (Fig. 4A) or to feed (COXME, effect of treatment: $\mathrm{z}=1.01, \mathrm{p}=0.31)($ Fig. 4B).

Food consumption in the behavioural arenas also did not differ between treatments (LME, effect of treatment: $\left.\mathrm{t}_{19.00}=1.100, \mathrm{p}=0.285\right)$, with predator-habituated wrasses eating $3.3 \pm 0.6 \%$ of their body mass, while predator-naïve wrasses ate $4.3 \pm 0.6 \%$ of their body mass. Digestion of this food would have occupied an average 20.3 or $23.2 \%$ of the wrasses' aerobic scope at the peak of their SDA, respectively (cf. Fig. 1B).

\section{Discussion}

Corkwing wrasses exposed to a predator (Atlantic cod) for 11 days ate $20 \%$ less than wrasses being held without a predator, but this difference was not statistically significant $(p=0.200)$ and therefore does not support our prediction that predator-exposed fish would significantly reduce food consumption compared to fish being held in the absence of predators. We also predicted that a reduction in food consumption would occur in the presence of predators as a mechanism used by prey to reserve a larger portion of their aerobic scope for energetically costly behaviours associated with predator avoidance and recovery from a possible predator attack. However, a 20\% lower food consumption would only have reduced the portion of aerobic scope occupied by digestion from, on average, 27.1 to $23.6 \%$ at the peak of the digestive (SDA) response if the food was eaten as one meal. This suggests that the wrasses would have 
gained little by reducing their food consumption, possibly explaining why we did not observe

426 a stronger response to the presence of a predator. While reduced food consumption under 427 perceived predation risk is often reported (Dugatkin and Godin 1992; Benard 2004; Thaler et al. 2012), there are also reports that foraging does not decrease under predation risk (McPeek 2004). Similarly, some studies have found that the effects of predators on prey foraging and

430 food consumption is highly context-dependent, for instance, occurring only at certain (high) temperatures (Culler et al. 2014) or for certain prey sizes (Veldhuis et al. 2020). Since the SDA response is expected to be completed faster but have a higher peak at warmer temperatures, thus occupying an increasing portion of aerobic scope with increasing temperature (Jutfelt et 434 al., 2020), it is possible that our results would have been different had we performed the 435 experiment at higher temperatures. Another possibility is that our prediction of differential 436 feeding in predator-exposed vs. unexposed fish might hold more strongly in prey fishes that 437 tend to eat large meals rapidly (e.g. juvenile carnivores) rather than species that graze on smaller food items, such as the wrasses used here.

Some studies have found that food consumption and growth can be decoupled in prey when exposed to predators (McPeek 2004; Steiner 2007; Thaler et al. 2012), because predator 441 exposure induces a change in the intake, storage, and/or use of nutrients (Hawlena and Schmitz 2010a, 2010b; Thaler et al. 2012). However, we found no differences in growth rate between wrasses being held with or without predators, in line with our results for food consumption.

444 The relatively short duration of our experiments (11 days) may not have been long enough to 445 detect differences in growth between treatments in this species, although the lack of such an 446 effect of predators on prey growth rates has also been reported in several other studies, 447 particularly in experiments lasting more than only a couple of days (Benard 2004; Van Dievel 448 et al. 2016). These results suggest that, even if food consumption and growth is initially reduced 449 under predation risk, animals, including fishes, often have the capacity for compensatory 
growth later on (Maclean and Metcalfe 2001; Metcalfe and Monaghan 2001), although this may eventually trade off with lifespan (Inness and Metcalfe 2008; Lee et al. 2013). We found that wrasses exposed to predators in their holding tanks were more than twice as consistent in how much food they ate each day, compared to wrasses not exposed to predators $(\operatorname{Radj}=0.480$ vs. 0.227 , respectively $)$. This interesting result lends some support to our prediction that prey will adjust meal size to protect their aerobic scope, as inconsistent meal sizes, including eating a very large meal on a given day, could compromise aerobic scope on that day; the largest amount of food eaten in one day by an individual wrasse was $14 \%$ of the wrasse's body mass, which would have occupied an estimated $53 \%$ of aerobic scope if eaten as one meal (cf. Fig. 1B). In comparison, southern catfish (Silurus meridionalis) require $\sim 44 \%$ of their aerobic scope at the peak of SDA to digest a meal corresponding to $16 \%$ of the fish's body mass; this energetic cost caused a significant reduction in the catfish's maximum swimming speed by 14\% (Fu et al. 2011; non-fasted treatment group), which could impair escape from predators (Billerbeck et al. 2001; Lankford et al. 2001). Temporal consistency in the size of a meal eaten in predator presence may be an important behavioural adjustment in prey that warrants further investigation.

In the behavioural arena trials with predators present, predator-habituated wrasses were more active (Fig. 3) and spent more time away from the shelter and near the predator than predator-naïve conspecifics (Table 1). The lower activity of predator-naïve fish when exposed to a predator is in general agreement with the findings of other studies. For example, Trinidadian guppies (Poecilia reticulata) and killifish (Hart's rivulus, Rivulus hartii) that infrequently experience predators in their natural stream habitats decrease activity and hide more when presented with both live and model predators (Fraser and Gilliam 1987). Reduced activity under predation risk is also a common response in many other animal species (reviewed in Lima and Dill 1990; Laurila 2000; Takahara et al. 2012). Although lower activity levels are 
sometimes associated with reduced foraging opportunities, we did not observe any measurable cost to reduced activity in terms of food consumption. In fact, although the difference was not statistically significant, predator-habituated wrasses consumed $23 \%$ less food than fish from the predator-naïve treatment during the $\sim 30$ min behavioural arena trials. Other predator-prey studies have also shown that activity levels are unrelated to food consumption, suggesting that cautious individuals may gain from being risk-averse while also not suffering from lost foraging opportunities (McPeek 2004; Steiner 2007).

Predator-habituated fish also spent more time away from the shelter and near the predator than predator-naïve individuals. Although predator inspection is common in fishes as a way for to assess predation risk (Pitcher et al. 1986; Lima and Dill 1990; Dugatkin and Godin 1992), and may lead to increased mortality in the prey-species (Dugatkin 1992), our results rather suggest that more time spent out of a shelter and near a predator reflects habituation to a predator threat rather than risk assessment. Increased risk-taking behaviour and boldness in predator-experienced fish is a common observation (Fraser and Gilliam 1987; Kelley and Magurran 2003; Brown et al. 2005, 2007; Riesch et al. 2009; Sommer-Trembo et al. 2016). However, displaying more risky behaviours may be costly to the individual as the extra time spent near the predator may result in a greater mortality risk. Increased activity also elevates metabolic rate (Speers-Roesch et al. 2018) which, in the absence of compensatory food consumption, points to the more active predator-habituated wrasses being at an energetic disadvantage.

Why, then, did the wrasses behave as they did? Fish and other animals have the ability to gauge when a predator is likely to attack (rather than simply pass by) and respond accordingly by adjusting their behaviour (e.g. freezing) or initiating escape (Stankowich and Blumstein 2005; McGhee et al. 2013; Lagos et al. 2014). Since the wrasses in the present study were always separated from the cod by a transparent divider, the prey was never in direct contact 
with the predator. The predator-habituated wrasses may have learned this, thus no longer

501 perceiving the cod as an immediate threat. Such habituation to the presence of a predator has previously been found to reduce the perception of fear in prey (Stankowich and Blumstein 2005). Our results are also consistent with the idea that prey continuously living in the presence

504 of predators simply have to accept the greater risk, as being chronically scared and hiding would 505 trade-off with foraging and mating opportunities (Lima and Bednekoff 1999; Brown et al. 506 2005), with resulting fitness consequences if prey over-respond to predator presence. Overall, our results add to a growing body of literature suggesting that non-consumptive (indirect) effects of predators on prey are complex, sometimes counter-intuitive, and important to consider in the context of behavioural and eco-physiological research.

\section{Acknowledgments}

512 We thank Bengt Lundve and the Royson family for fish collection, and the staff at the 513 University of Gothenburg's Kristineberg Marine Research Station for technical assistance. We 514 also thank the editor and two anonymous reviewers for their comments.

\section{Funding}

517 This work was funded by the Royal Swedish Academy of Sciences (JS: grant no. 518 FOA14SLC027; JS, FJ, BSR, DGR, SAB, MA, TDC: grant no. FOA17SLC), the Swedish 519 Research Council VR (MA: grant no. 637-2014-449), the Swedish Research Council Formas 520 (JS: grant no. 2013-947), the Natural Sciences and Engineering Research Council of Canada 521 (BSR, SAB), the Danish Council for Independent Research (TN: grant no. DFF-4181-00297), 522 the European Union's Horizon 2020 research and innovation programme under the Marie 523 Skłodowska-Curie grant agreement (TN: grant no. 713683), the Carl Trygger Foundation (Carl 524 Tryggers Stiftelse för Vetenskaplig Forskning; MA: grant no. 14:15), and the Australian 
525 Research Council Future Fellowship programme (TDC: grant no. FT180100154) funded by the

526 Australian Government.

527

528 Conflicts of interest

529 We have no conflicts of interest to declare.

530

\section{$531 \quad$ Ethics approval}

532 All experiments were conducted in accordance with license Dnr103-2014 (held by FJ) from the

533 Swedish Board of Agriculture. All applicable international, national, and/or institutional 534 guidelines for the use of animals were followed.

535

\section{Consent for publication}

537 All authors approve of the publication of this work.

538

\section{Author contributions}

540 TN, TDC, and JS conceived and designed the study; all authors performed the experiments;

541 TN, JS, TDC, RM, and AHA analysed the data; TN, JS, and TDC drafted the manuscript; all 542 authors revised the manuscript.

543

\section{Data availability}

545 The data and analysis script for this study are archived in the repository figshare and were made

546 available to editors and reviewers upon initial submission:

547 https://doi.org/10.6084/m9.figshare.13180616 (Norin et al. 2020).

548

549 References 
Bates D, Maechler M, Bolker B, Walker S (2015) Fitting linear mixed-effects models using lme4. J Stat Softw 67:1-48.

Benard MF (2004) Predator-induced phenotypic plasticity in organisms with complex life histories. Annu Rev Ecol Evol Syst 35:651-673.

Billerbeck JM, Lankford TE Jr, Conover DO (2001) Evolution of intrinsic growth and energy acquisition rates. I. Trade-offs with swimming performance in Menidia menidia. Evolution 55:1863-1872.

Boonstra R, Hik D, Singleton GR, Tinnikov A (1998) The impact of predator-induced stress on the snowshoe hare cycle. Ecol Monogr 79:371-394.

Boonstra R (2013) Reality as the leading cause of stress: rethinking the impact of chronic stress in nature. Funct Ecol 27:11-23.

Brown JS, Kotler BP (2004) Hazardous duty pay and foraging cost of predation. Ecol Lett 7:999-1014.

Brown C, Jones F, Braithwaite V (2005) In situ examination of boldness-shyness traits in the tropical poeciliid, Brachyraphis episcopi. Anim Behav 70:1003-1009.

565 Brown C, Jones F, Braithwaite VA (2007) Correlation between boldness and body mass in natural populations of the poeciliid Brachyraphis episcopi. J Fish Biol 71:1590-1601.

Chabot D, Koenker R, Farrell AP (2016) The measurement of specific dynamic action in fishes. J Fish Biol 88:152-172.

569 Clark TD, Sandblom E, Jutfelt F (2013) Aerobic scope measurements of fishes in an era of climate change: respirometry, relevance and recommendations. J Exp Biol 216:2771-2782.

571 Culler LE, McPeek MA, Ayres MP (2014) Predation risk shapes thermal physiology of a predaceous damselfly. Oecologia 176:653-660.

573 Dalton CM, Flecker AS (2014) Metabolic stoichiometry and the ecology of fear in Trinidadian 574 guppies: consequences for life histories and stream ecosystems. Oecologia 176:691-701. 
575 Dugatkin LA (1992) Tendency to inspect predators predicts mortality risk in the guppy (Poecilia reticulata). Behav Ecol 3:124-127.

577 Dugatkin LA, Godin JGJ (1992) Predator inspection, shoaling and foraging under predation hazard in the Trinidadian guppy, Poecilia reticulata. Environ Biol Fishes 34:265-276.

Fraser DF, Gilliam JF (1987) Feeding under predation hazard: response of the guppy and Hart's rivulus from sites with contrasting predation hazard. Behav Ecol Sociobiol 21:203-209.

Fu S-J, Pang X, Cao Z-D, Peng J-L, Yan G (2011) The effects of fasting on the metabolic interaction between digestion and locomotion in juvenile southern catfish (Silurus meridionalis). Comp Biochem Physiol A, 158:498-505.

Gallagher AJ, Lawrence MJ, Jain-Schlaepfer MR, Wilson DM, Cooke SJ (2016) Avian predators transmit fear along the air-water interface influencing prey and their parental care. Can J Zool 94:863-870.

Hall AE, Clark TD (2016) Seeing is believing: metabolism provides insight into threat perception for a prey species of coral reef fish. Anim Behav 115:117-126.

Handelsman CA, Broder ED, Dalton CM, Ruell EW, Myrick CA, Reznick DN, Ghalambor CK (2013) Predator-induced phenotypic plasticity in metabolism and rate of growth: rapid adaptation to a novel environment. Integr Comp Biol 53:975-988.

Hasenjager MJ, Dugatkin LA (2017) Fear of predation shapes social network structure and the acquisition of foraging information in guppy shoals. Proc R Soc B 284:20172020.

Hawlena D, Schmitz OJ (2010a) Physiological stress as a fundamental mechanism linking predation to ecosystem functioning. Am Nat 176:537-556.

Hawlena D, Schmitz OJ (2010b) Herbivore physiological response to predation risk and implications for ecosystem nutrient dynamics. Proc Natl Acad Sci USA 107:15503-15507. between gaining energy and avoiding predators. Phil Trans R Soc B 341:375-397. 
Inness CLW, Metcalfe NB (2008) The impact of dietary restriction, intermittent feeding and compensatory growth on reproductive investment and lifespan in a short-lived fish. Proc $\mathrm{R}$ Soc B 275:1703-1708.

603

Janssens L, Stoks R (2013) Predation risk causes oxidative damage in prey. Biol Lett

604 9:20130350.

605

Jermacz Ł, Nowakowska A, Kletkiewicz H, Kobak, J (2020) Experimental evidence for the 606

607 adaptive reponse of aquatic invertebrates to chronic predation risk. Oecologia 192:341-

\section{8} 350.

Jutfelt F, Norin T, Åsheim ER, Rowsey LE, Andreassen AH, Morgan R, Clark TD, SpeersRoesch B (2020) Aerobic scope protection reduces ectotherm growth under warming. Preprint: EcoEvoRxiv. https://doi.org/doi:10.32942/osf.io/zc3bm.

611 Kelley JL, Magurran AE (2003) Learned predator recognition and antipredator responses in fishes. Fish Fish 4:216-226.

613 Kuznetsova A, Brockhoff PB, Christensen RHB (2017) lmerTest package: tests in linear mixed effects models. J Stat Softw 82:1-26.

Lagos PA, Ebensperger LA, Herberstein ME (2014) A quantitative test of the 'economic' and 'optimal' models of escape behaviour. Anim Behav 97:221-227.

Lagos PA, Herberstein ME (2017) Are males more scared of predators? Differential change in metabolic rate between males and females under predation risk. Physiol Behav 173:110115.

620 Lankford TE Jr, Billerbeck JM, Conover DO (2001) Evolution of intrinsic growth and energy acquisition rates. II. Trade-offs with vulnerability to predation in Menidia menidia.

623 Laurila A (2000) Behavioural responses to predator chemical cues and local variation in 624 antipredator performance in Rana temporaria tadpoles. Oikos 88:159-168. 
Lee W-S, Monaghan P, Metcalfe NB (2013) Experimental demonstration of the growth rate lifespan trade-off. Proc R Soc B 280:20122370.

Lima SL, Dill LM (1990) Behavioural decisions made under the risk of predation: a review and prospectus. Can J Zool 68:619-640.

Lima SL, Bednekoff PA (1999) Temporal variation in danger drives antipredator behavior: the predation risk allocation hypothesis. Am Nat 153:649-659.

631

Lüdecke D (2018) ggeffects: tidy data frames of marginal effects from regression models. J Open Source Softw 3:772.

\section{3}

Maclean A, Metcalfe NB (2001) Social status, access to food, and compensatory growth in juvenile Atlantic salmon. J Fish Biol 58:1331-1346.

Manzur T, Vidal F, Pantoja JF, Fernández M, Navarrete SA (2014) Behavioural and physiological responses of limpet prey to a seastar predator and their transmission to basal trophic levels. J Anim Ecol 83:923-933.

McGhee KE, Pintor LM, Bell AM (2013) Reciprocal behavioral plasticity and behavioral types during predator-prey interactions. Am Nat 182:704-717.

McPeek MA (2004) The growth/predation risk trade-off: so what is the mechanism? Am Nat 163:E88-E111.

Metcalfe NB, Monaghan P (2001) Compensation for a bad start: grow now, pay later? Trends Ecol Evol 16:254-260.

644 Nakagawa S, Schielzeth H (2010) Repeatability for Gaussian and non-Gaussian data: a practical guide for biologists. Biol Rev 85:935-956.

646 Nordeide JT, Salvanes AGV (1991) Observations on reared newly released and wild cod (Gadus morhua L.) and their potential predators. ICES Mar Sci Symp 192:139-146.

Norin T, Clark TD (2016) Measurement and relevance of maximum metabolic rate in fishes. J Fish Biol 88:122-151. 
Norin T, Clark TD (2017) Fish face a trade-off between 'eating big' for growth efficiency and 'eating small' to retain aerobic capacity. Biol Lett 13:20170298.

652

653

654

655

656

657

658

659

660

661

662

663

664

665

666

667

668

669

670

671

672

673

674

Norin T, Sundin J, Morgan R, Andreassen AH, Amcoff M, Speers-Roesch B, Jutfelt F, Binning SA, Roche DG, Clark TD (2020) Data and R script for: Predator presence affects activity patterns but not food consumption or growth of juvenile corkwing wrasse (Symphodus melops). https://doi.org/10.6084/m9.figshare.13180616.

Okuyama T (2015) Metabolic responses to predation risk in a jumping spider. J Zool 297:9-14.

Pitcher TJ, Green DA, Magurran AE (1986) Dicing with death: predator inspection behaviour in minnow shoals. J Fish Biol 28:439-448.

Preisser EL, Bolnick DI, Benard MF (2005) Scared to death? The effects of intimidation and consumption in predator-prey interactions. Ecology 86:501-509.

R Core Team (2020) R: a language and environment for statistical computing. R Foundation for Statistical Computing, Vienna, Austria. https://www.R.project.org/.

Riesch R, Duwe V, Herrmann N, Padur L, Ramm A, Scharnweber K, Schulte M, SchulzMirbach T, Ziege M, Plath M (2009) Variation along the shy-bold continuum in extremophile fishes (Poecilia mexicana, Poecilia sulphuraria). Behav Ecol Sociobiol 63:1515-1526.

Salvanes AGV, Nordeide JT (1993) Dominating sublittoral fish species in a west Norwegian fjord and their trophic links to cod (Gadus morhua L.). Sarsia 78:221-234.

Secor SM (2009) Specific dynamic action: a review of the postprandial metabolic response. J Comp Physiol B 179:1-56.

Sheriff MJ, Krebs CJ, Boonstra R (2009) The sensitive hare: sublethal effects of predator stress on reproduction in showshoe hares. J Anim Ecol 78:1249-1258.

Sommer-Trembo C, Zimmer C, Jourdan J, Bierbach D, Plath M (2016) Predator experience homogenizes consistent individual differences in predator avoidance. J Ethol 34:155-165. 
675 Speers-Roesch B, Norin T, Driedzic WR (2018) The benefit of being still: energy savings during winter dormancy in fish come from inactivity and the cold, not from metabolic rate depression. Proc R Soc B 285:20181593.

678 Stankowich T, Blumstein DT (2005) Fear in animals: a meta-analysis and review of risk assessment. Proc R Soc B 272:2627-2634.

680 Steiner UK (2007) linking antipredator behaviour, ingestion, gut evacuation and costs of 681 predator-induced responses in tadpoles. Anim Behav 74:1473-1479.

682

Steiner UK, Van Buskirk J (2009) Predator-induced changes in metabolism cannot explain the growth/predation risk tradeoff. PLoS ONE 4:e6160.

684 Stoffel MA, Nakagawa S, Schielzeth H (2017) rptR: repeatability estimation and variance decomposition by generalized linear mixed-effects models. Methods Ecol Evol 8:16391644.

Takahara T, Kohmatsu Y, Maruyama A, Doi H, Yamanaka H, Yamaoka R (2012) Inducible defence behaviour of an anuran tadpole: cue-detection range and cue types used against predator. Behav Ecol 23:863-868.

Thaler JS, McArt SH, Kaplan I (2012) Compensatory mechanisms for ameliorating the 691 fundamental trade-off between predator avoidance and foraging. Proc Natl Acad Sci USA 109:12075-12080.

Therneau TM (2020) coxme: mixed effects Cox models. R package version 2.2-16. https://CRAN.R-project.org/package=coxme.

Tigreros N, Wang EH, Thaler JS (2018) Prey nutritional state driver divergent behavioural and physiological responses to predation risk. Funct Ecol 32:982-989.

Van Dievel M, Janssens L, Stoks R (2016) Short- and long-term behavioural, physiological and stoichiometric responses to predation risk indicate chronic stress and compensatory mechanisms. Oecologia 181:347-357. 
700 Veldhuis MP, Hofmeester TR, Balme G, Druce DJ, Pitman RT, Cromsigt JPGM (2020)

701 Predation risk constrains herbivores' adaptive capacity to warming. Nat Ecol Evol 4:1069$702 \quad 1074$

703 Verdolin JL (2006) Meta-analysis of foraging and predation risk trade-offs in terrestrial $704 \quad$ systems. Behav Ecol Sociobiol 60:457-464.

705 

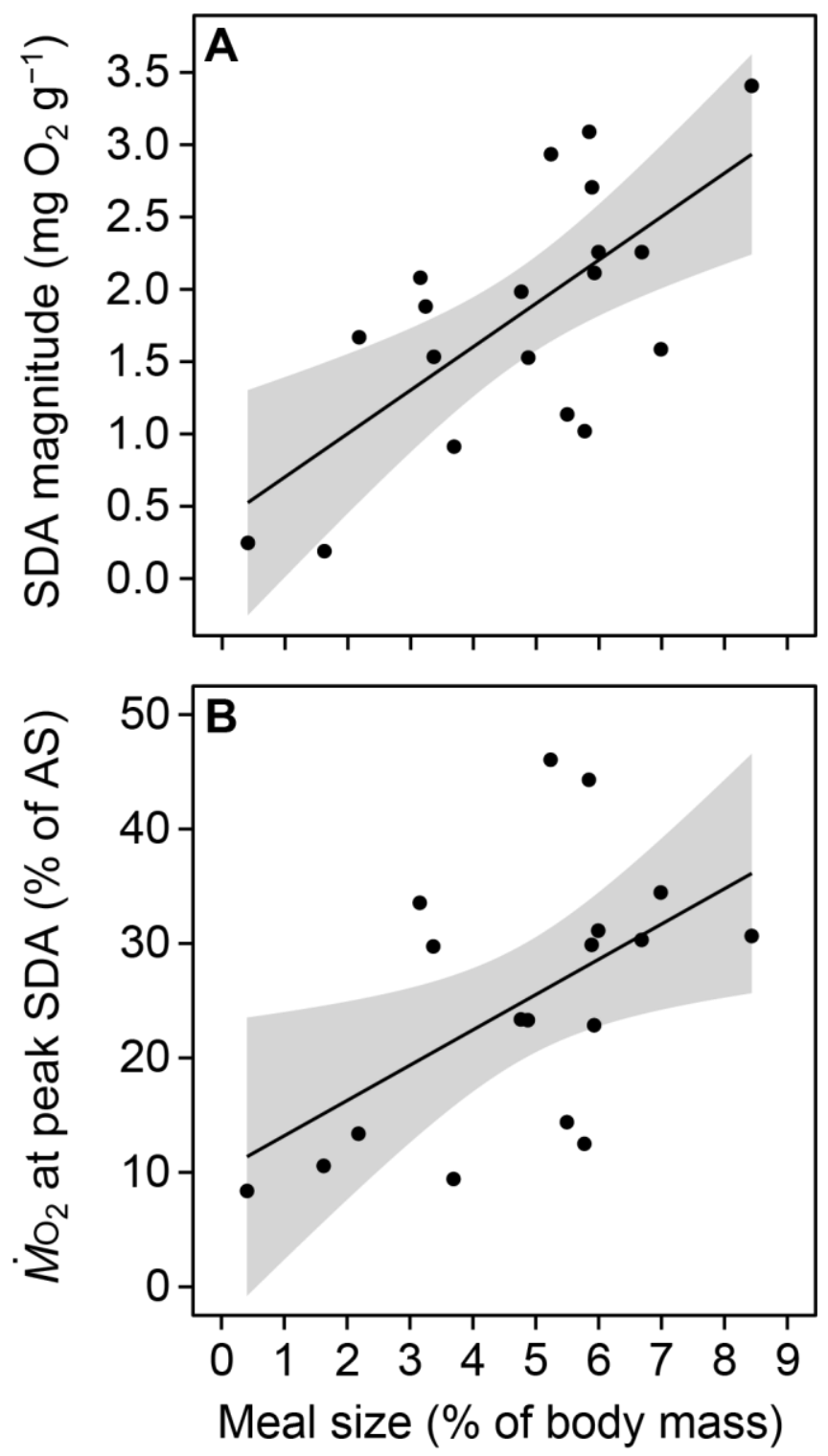

709 Fig. 1. Specific dynamic action (SDA) responses of juvenile corkwing wrasses fed different meal sizes

710 of chironomid larvae ("bloodworms"). The overall cost of digestion per gram of fish (i.e. the SDA

711 magnitude $)$ increased with meal size $\left(A ; F_{2,16}=6.050, p=0.011, r^{2}=0.431 ; n=19\right)$, and so did the

712 oxygen uptake rate $\left(\dot{M}_{O_{2}}\right)$ at peak SDA, thus occupying a larger percentage of the fish's aerobic scope

713 (AS) at the peak of the digestive response $\left(\mathbf{B} ; \mathrm{F}_{1,16}=6.716, \mathrm{p}=0.020, \mathrm{r}^{2}=0.296 ; \mathrm{n}=18\right)$. Shaded areas 714 are $95 \%$ confidence bands. 


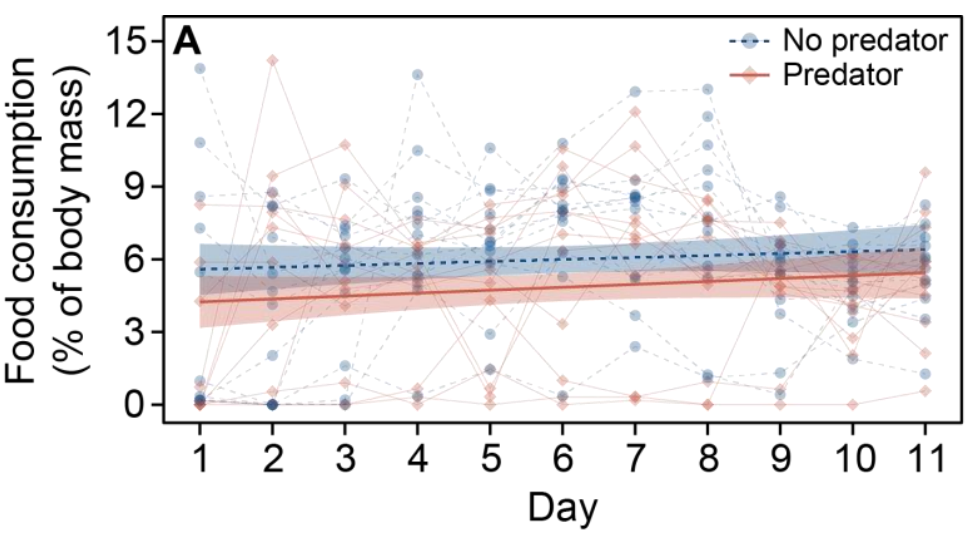

715

716

717 Fig. 2. Daily food consumption (A) and resulting specific growth rates (SGR; B) of juvenile corkwing

718 wrasses being held in the presence (red) or absence (blue) of a predator (cod) in their holding tanks for

71911 days. Diamonds (predator) and circles (no predator) represent data for individual fish. Shaded areas 720 are $95 \%$ confidence bands.

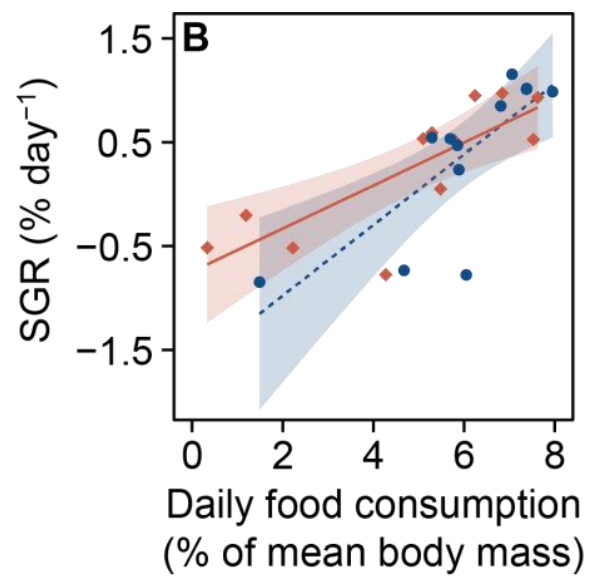




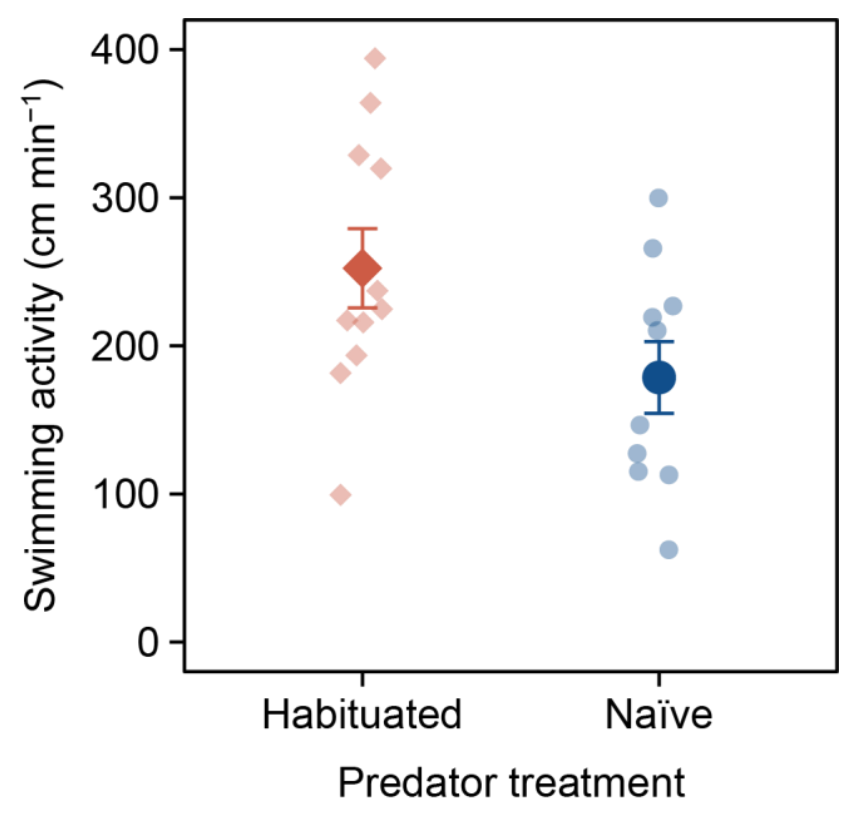

722

723 Fig. 3. Swimming activity of juvenile corkwing wrasses in behavioural arenas with a predator present

724 (behind a glass wall). Larger symbols with error bars are means \pm SEs, while smaller and semi-

725 transparent symbols represent individual fish. Predator treatment [habituated $(\mathrm{n}=11)$ or naïve $(\mathrm{n}=10)$ ]

726 refer to the two treatments (wrasses being previously exposed to cod or not in the holding tanks); there

727 was always a cod present in the behavioural arenas. 

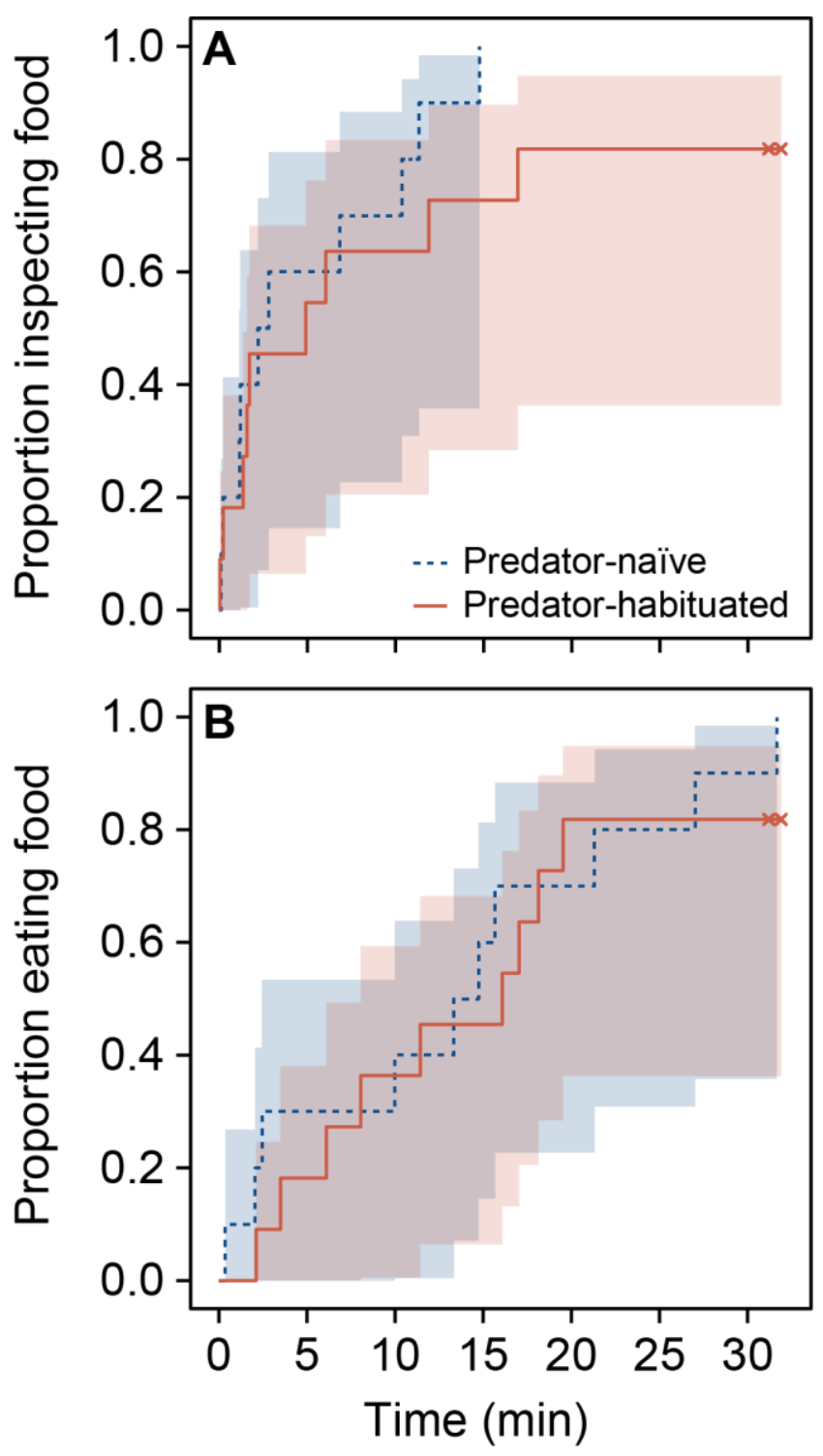

730 Fig. 4. Latency to inspect food and to start feeding by juvenile corkwing wrasses in behavioural arenas

731 with a predator present (behind a glass wall). The data are shown as the proportion of fish inspecting 732 food (A) or eating food (B) at a given time since food was introduced to the arena. 'Predator-habituated' $733(\mathrm{n}=11)$ or 'Predator-naïve' $(\mathrm{n}=10)$ refer to the two treatments (wrasses being previously exposed to 734 cod or not in the holding tanks); there was always a cod present in the behavioural arenas. A cross 735 indicates censoring (two fish never inspected and never ate any food). 
736 Table 1. Time spent by wrasses in different zones of the behavioural arenas (means \pm SEs). 'Predator-

737 habituated' or 'Predator-naïve' refer to the two treatments (wrasses being previously exposed to cod or 738 not in the holding tanks); there was always a cod present in the behavioural arenas. The combined values 739 for zones $1,2,3$, and 4 do not necessarily sum up to $100 \%$, as these are model predicted values.

740 Significant differences $(\mathrm{p} \leq 0.05)$ between treatments are indicated with an asterisk.

\begin{tabular}{|c|c|c|c|}
\hline \multirow[t]{2}{*}{ Zone of behavioural arena } & \multicolumn{3}{|c|}{ Time spent in zone (\% of total) } \\
\hline & $\begin{array}{l}\text { Predator- } \\
\text { habituated }\end{array}$ & & $\begin{array}{c}\text { Predator- } \\
\text { naïve }\end{array}$ \\
\hline Zone 1 (near food, far from predator) & $3.9 \pm 0.6$ & & $4.7 \pm 0.6$ \\
\hline Zone 2 (near food, near predator) & $11.5 \pm 0.4$ & & $6.7 \pm 0.4$ \\
\hline Zone 3 (in or near shelter, far from predator) & $55.6 \pm 4.7$ & * & $69.5 \pm 5.0$ \\
\hline Zone 4 (far from food and shelter, near predator) & $24.4 \pm 4.3$ & $*$ & $14.1 \pm 4.4$ \\
\hline
\end{tabular}




\section{SUPPLEMENTARY MATERIAL}

Predator presence affects activity patterns but not food consumption or growth of juvenile corkwing wrasse (Symphodus melops). Behavioral Ecology and Sociobiology

Tommy Norin 1,*, Josefin Sundinn ${ }^{2,3}$, Rachael Morgan ${ }^{4}$, Anna H. Andreassen ${ }^{4}$, Mirjam Amcoff ${ }^{5}$, Ben Speers-Roesch ${ }^{6}$, Fredrik Jutfelt ${ }^{4}$, Sandra A. Binning ${ }^{7}$, Dominique G. Roche ${ }^{8,9}$, Timothy D. Clark ${ }^{10}$

${ }^{1}$ DTU Aqua: National Institute of Aquatic Resources, Technical University of Denmark, Kgs. Lyngby, Denmark

${ }^{2}$ Department of Aquatic Resources, Swedish University of Agricultural Sciences, Drottningholm, Sweden

${ }^{3}$ Department of Neuroscience, Uppsala University, Uppsala, Sweden

${ }^{4}$ Department of Biology, Norwegian University of Science and Technology, Trondheim, Norway

${ }^{5}$ Department of Zoology/Functional Zoomorphology Stockholm University, Stockholm, Sweden

${ }^{6}$ Department of Biological Sciences, University of New Brunswick, Saint John, New Brunswick, Canada

${ }^{7}$ Département de sciences biologiques, Université de Montréal, Montréal, Québec, Canada

${ }^{8}$ Department of Biology, Carleton University, Ottawa, Ontario, Canada

${ }^{9}$ Institut de biologie, Université de Neuchâtel, Neuchâtel, Switzerland

${ }^{10}$ School of Life and Environmental Sciences, Deakin University, Geelong, Victoria, Australia

*Corresponding author (tnor@aqua.dtu.dk) 
Details on specific dynamic action (SDA) analyses

We had initially planned to have at least seven unfed fish that could be used to adjust for any elevations in oxygen uptake rate $\left(\dot{M}_{\mathrm{O}_{2}}\right)$ caused by handling when introducing the fish to the respirometry chambers. However, we had several issues with malfunctioning of the miniature pumps (miniature DC pump; Loligo Systems, Viborg, Denmark), which resulted in a reduced sample size of 20 fed and only one unfed fish. This unfed fish (fish '7_290617' in Fig. S1 below) reached its standard metabolic rate (SMR) $1.6 \mathrm{~h}$ after being introduced to the respirometry chamber, indicating that any effect of handling on $\dot{M}_{\mathrm{O}_{2}}$ was ephemeral and did not influence estimation of peak net SDA, which always occurred later. $\dot{M}_{\mathrm{O}_{2}}$ data were therefore analysed without any adjustments for initial handling, but after excluding the initial $1.9 \mathrm{~h}$ after feeding in the fit of the SDA curve and assuming a linear increase between SMR at time $0 \mathrm{~h}$ post-feeding and the peak of the SDA response (Fig. S1, top panels), as recommended by Chabot et al. (2016).

Figure S1 (below). Graphs of oxygen uptake rate $\left(\dot{M}_{O_{2}}\right)$ over time produced by the SDA script (cf. Chabot et al. 2016), annotated with SDA variables and SMR values. The solid red line shows the fitted SDA curve, with the semi-transparent red area under the curve representing the SDA magnitude. The left-most dashed vertical line shows the SDA peak (the height represents peak net SDA and the position represents peak SDA time), while the right-most dashed vertical line represents the end of the SDA response (the SDA duration). The dashed horizontal line indicates SMR. The label centered above each graph in bold is fish ID, with data for each fish shown twice on each page; top panels show data not adjusted for any initial increase in $\dot{M}_{O_{2}}$ caused by handling, which are the data used in all subsequent analyses, while bottom panels show handling-adjusted $\dot{M}_{O_{2}}$ based on the one unfed fish (fish 7_290617). This handling-adjustment was done by subtracting net $\dot{M}_{O_{2}}$ (i.e. $\dot{M}_{O_{2}}$ above SMR) of the unfed fish for the initial $1.6 \mathrm{~h}$ from the net $\dot{M}_{\mathrm{O}_{2}}$ of all other fish. The handling-adjusted data are shown for visual comparison only and are not used in any analyses. 


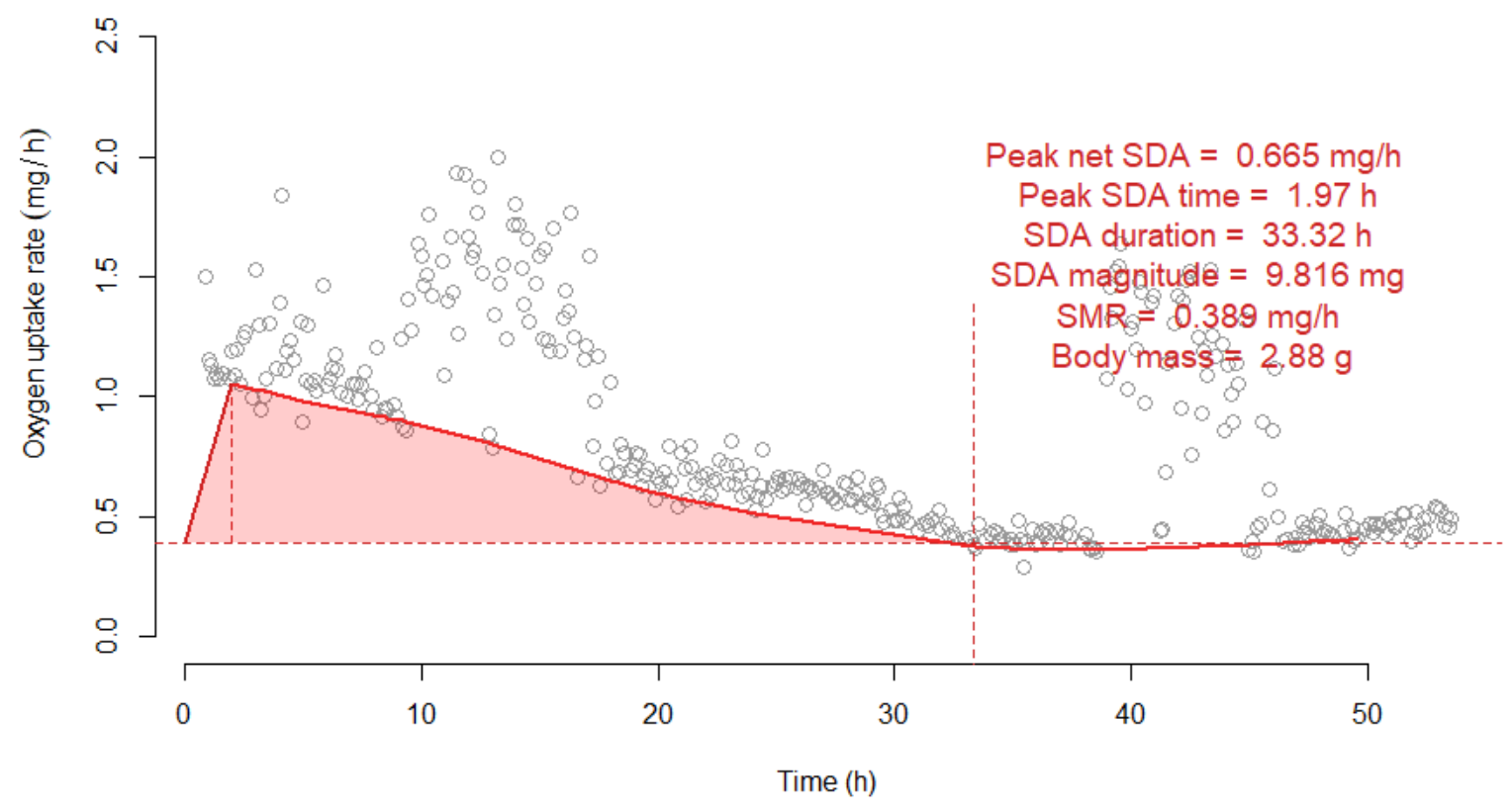

1_200617

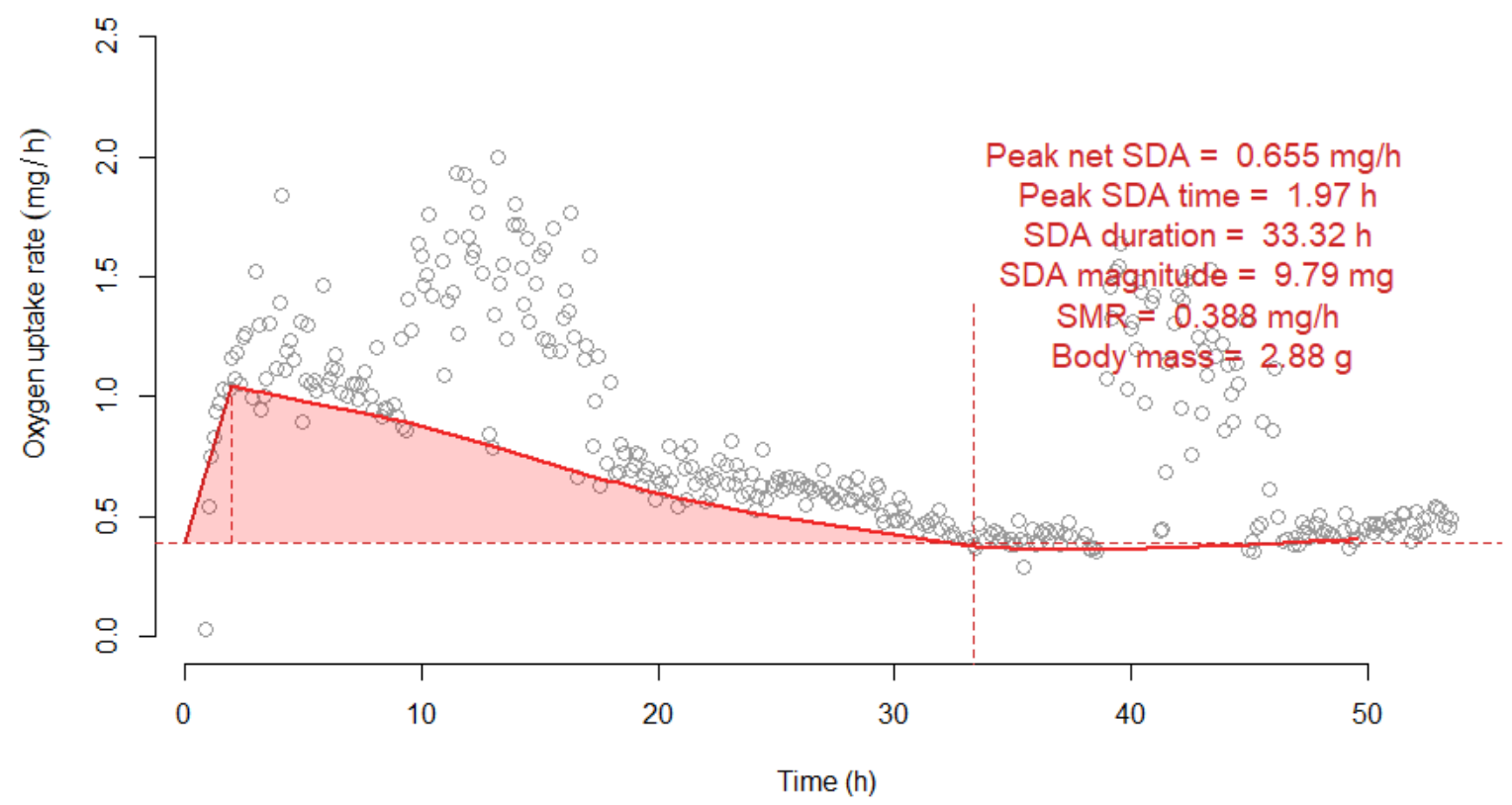

Page 3 of 25 


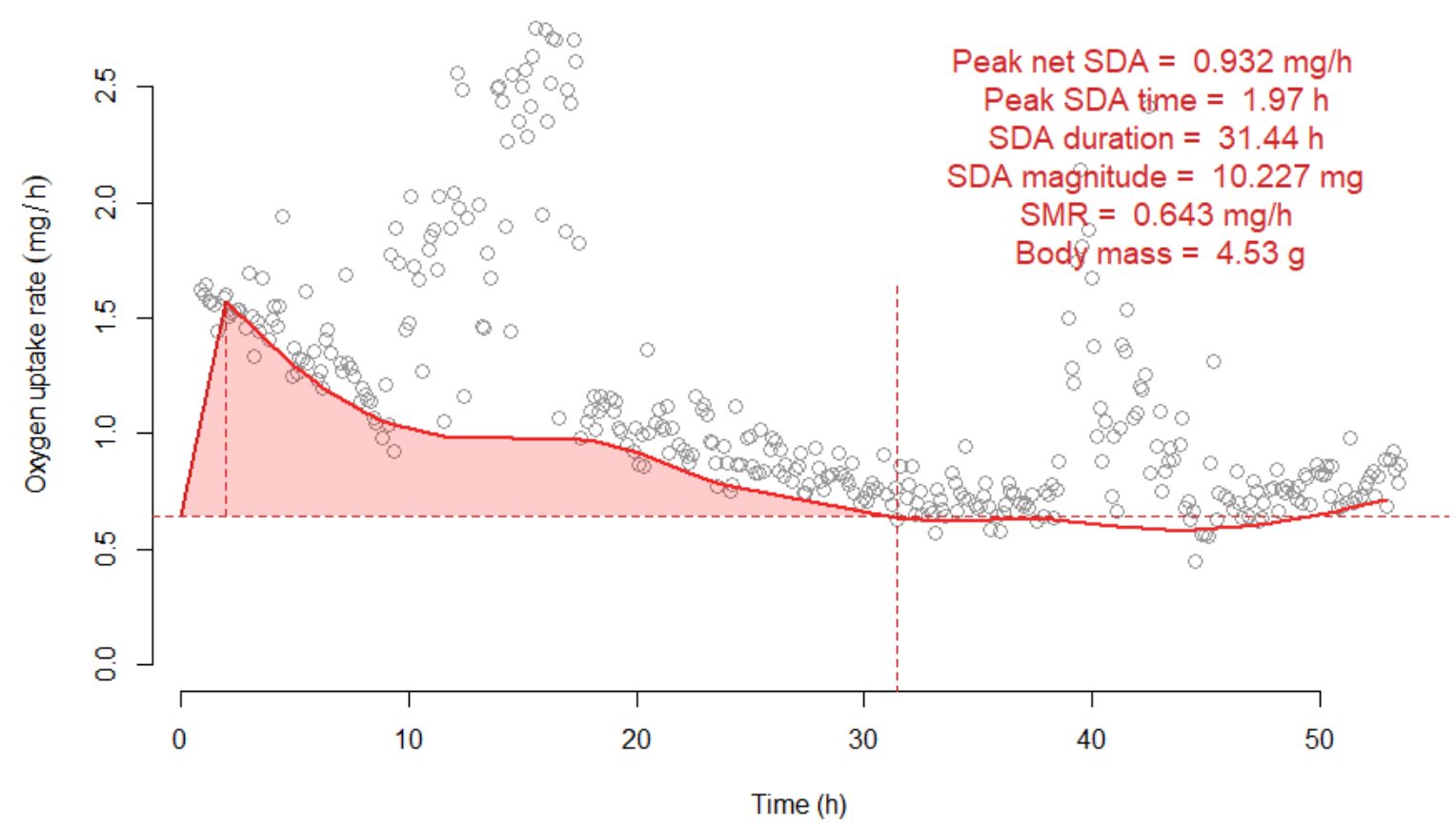

2_200617

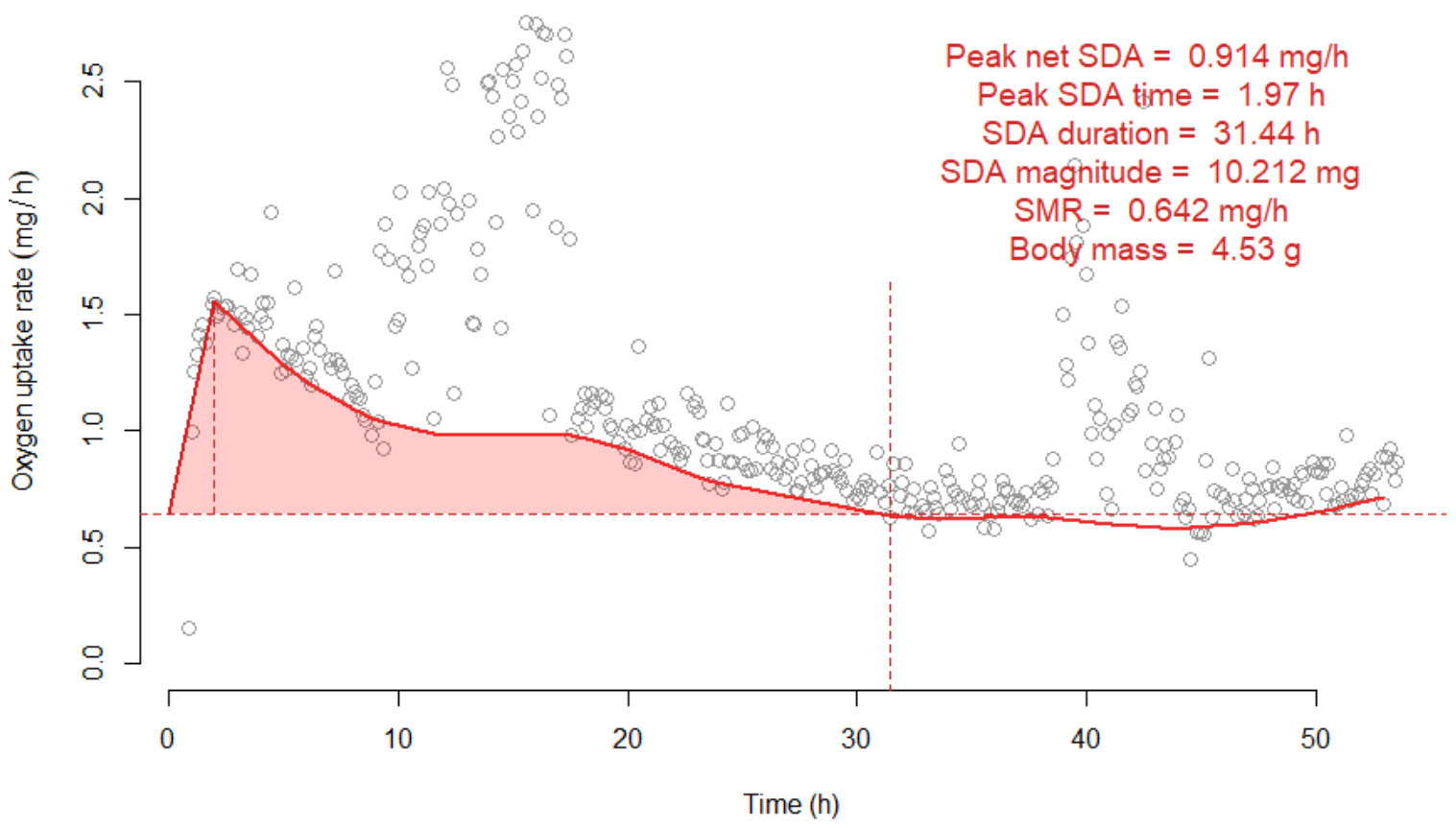




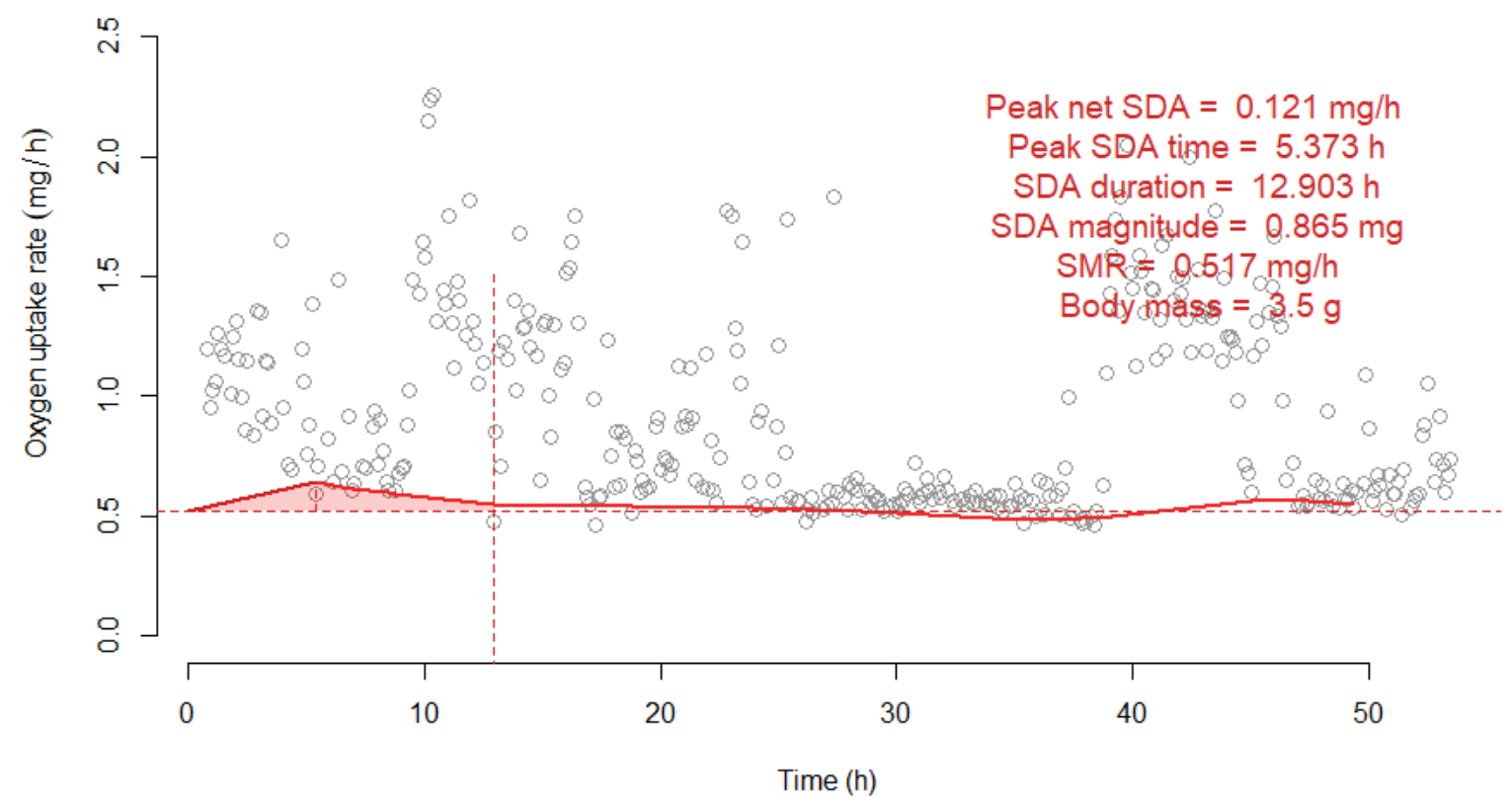

4_200617

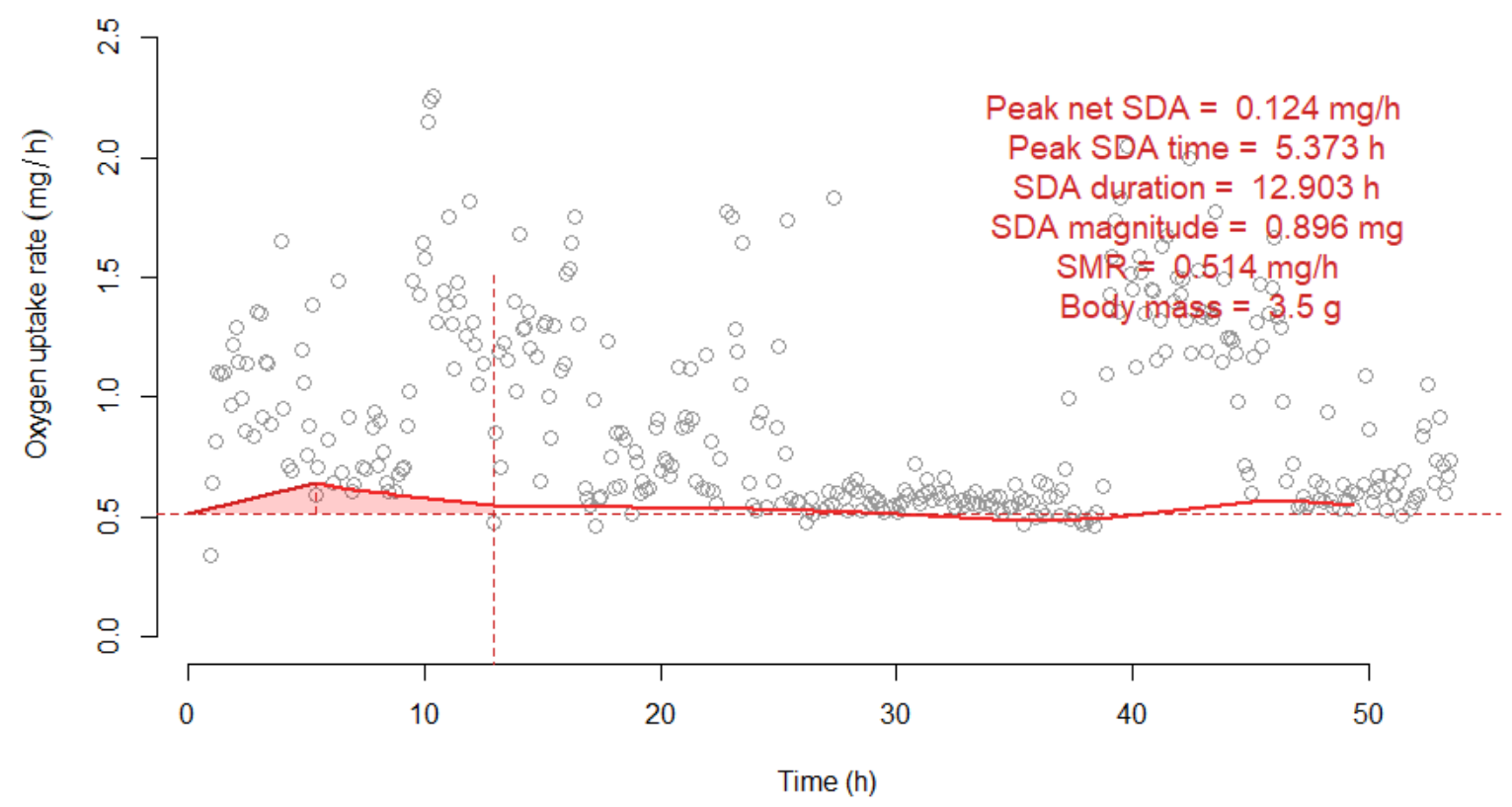




\section{5_200617}

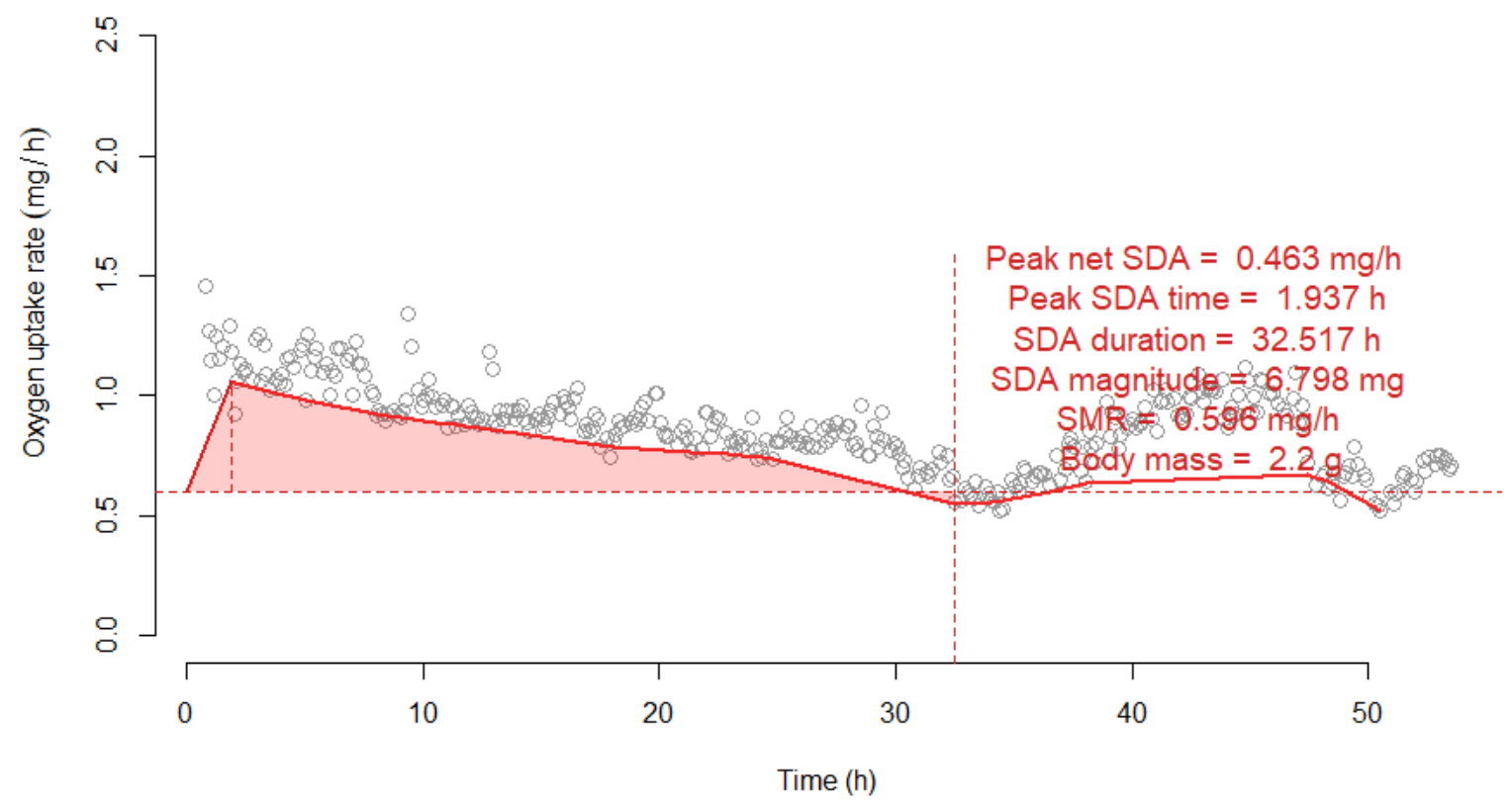

5_200617

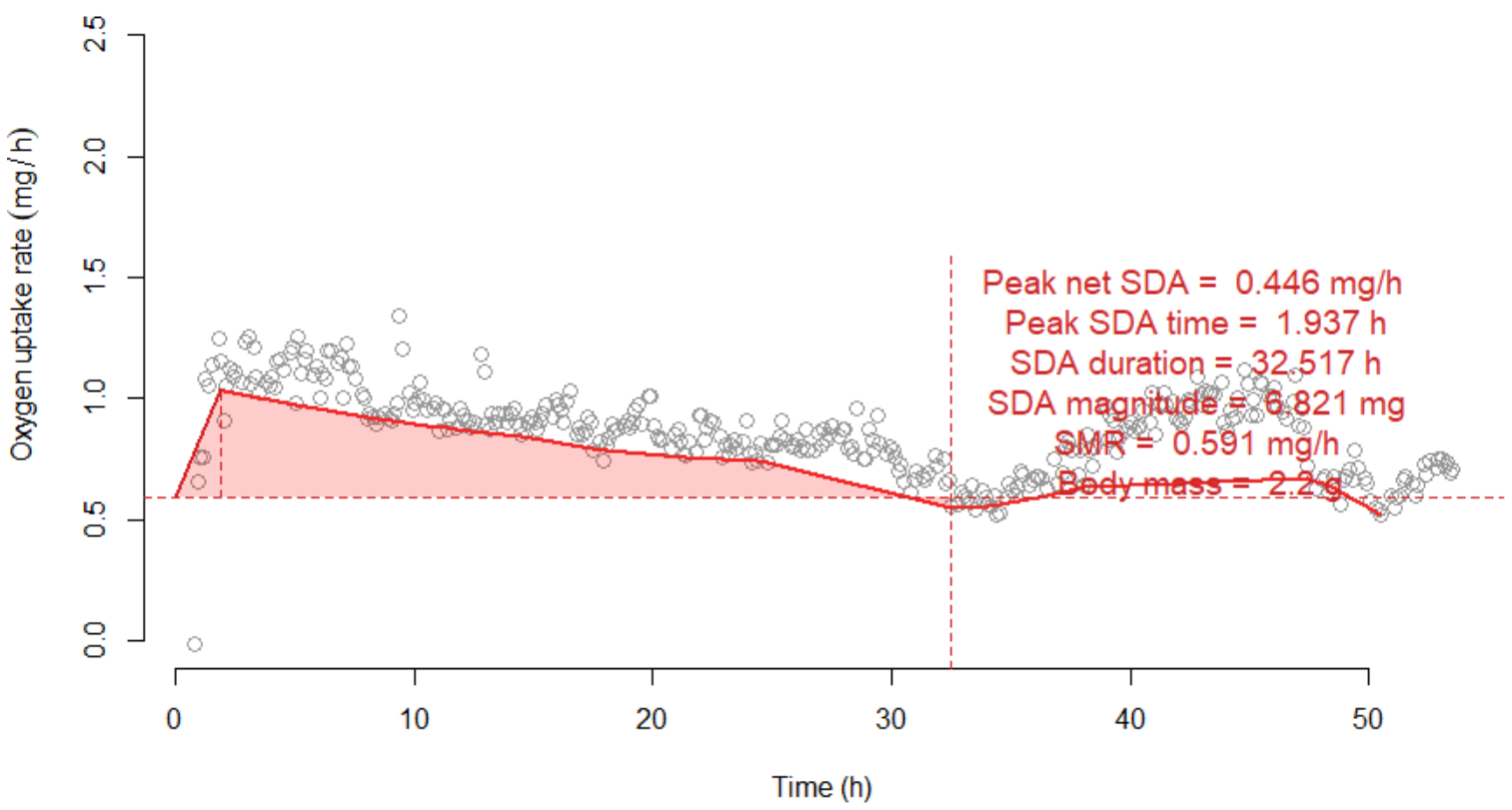




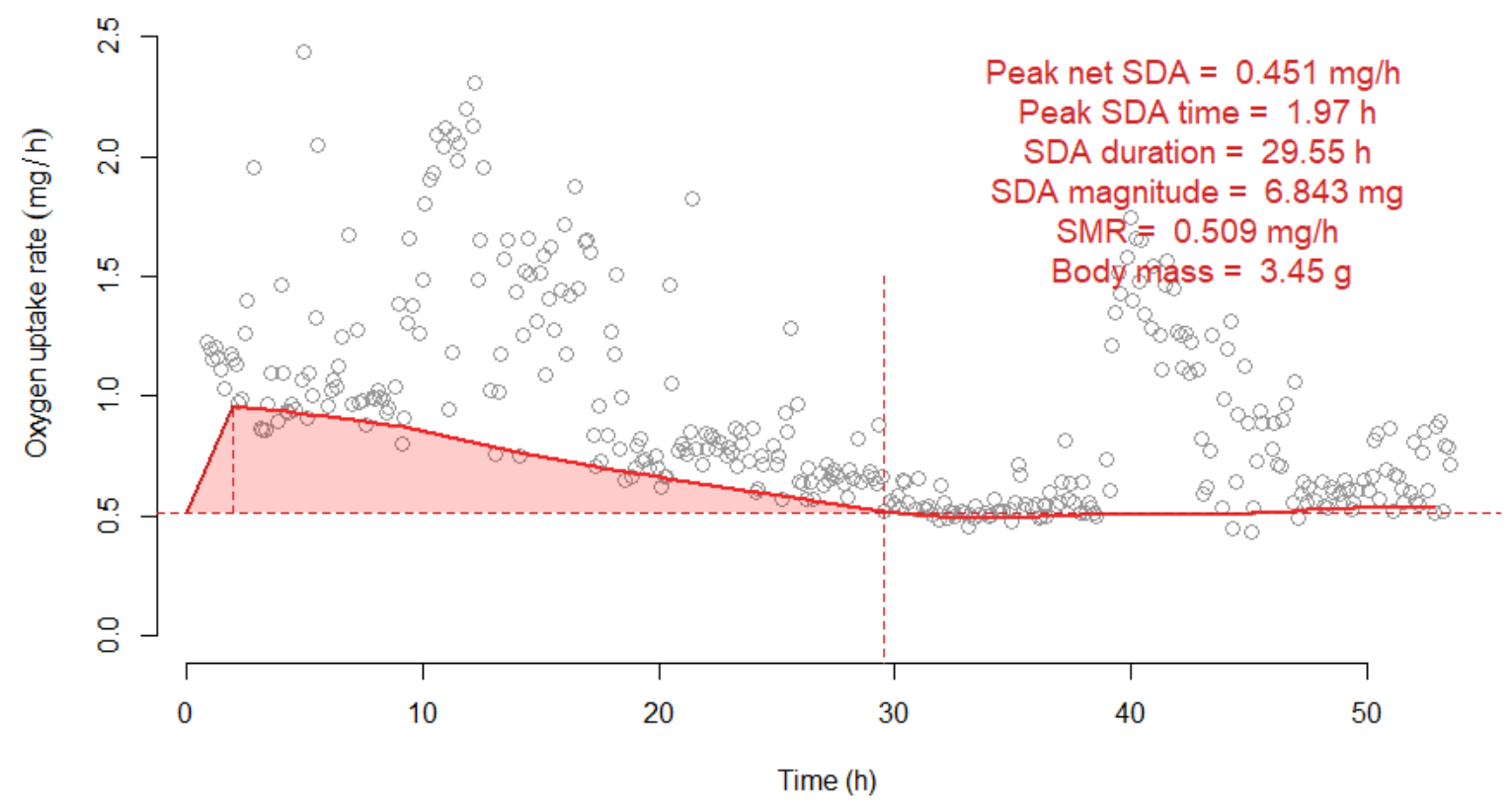

6_200617

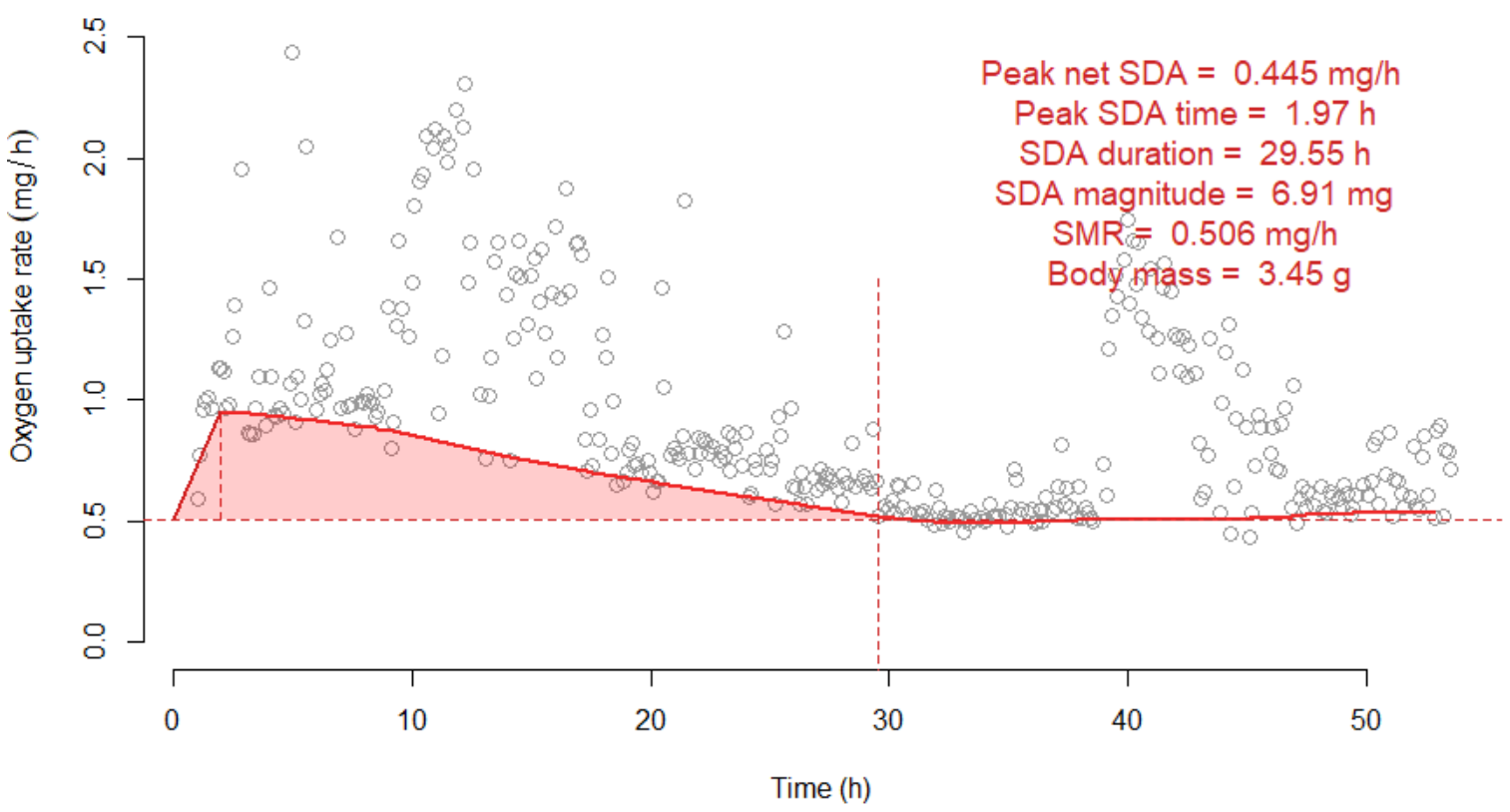




\section{7_200617}

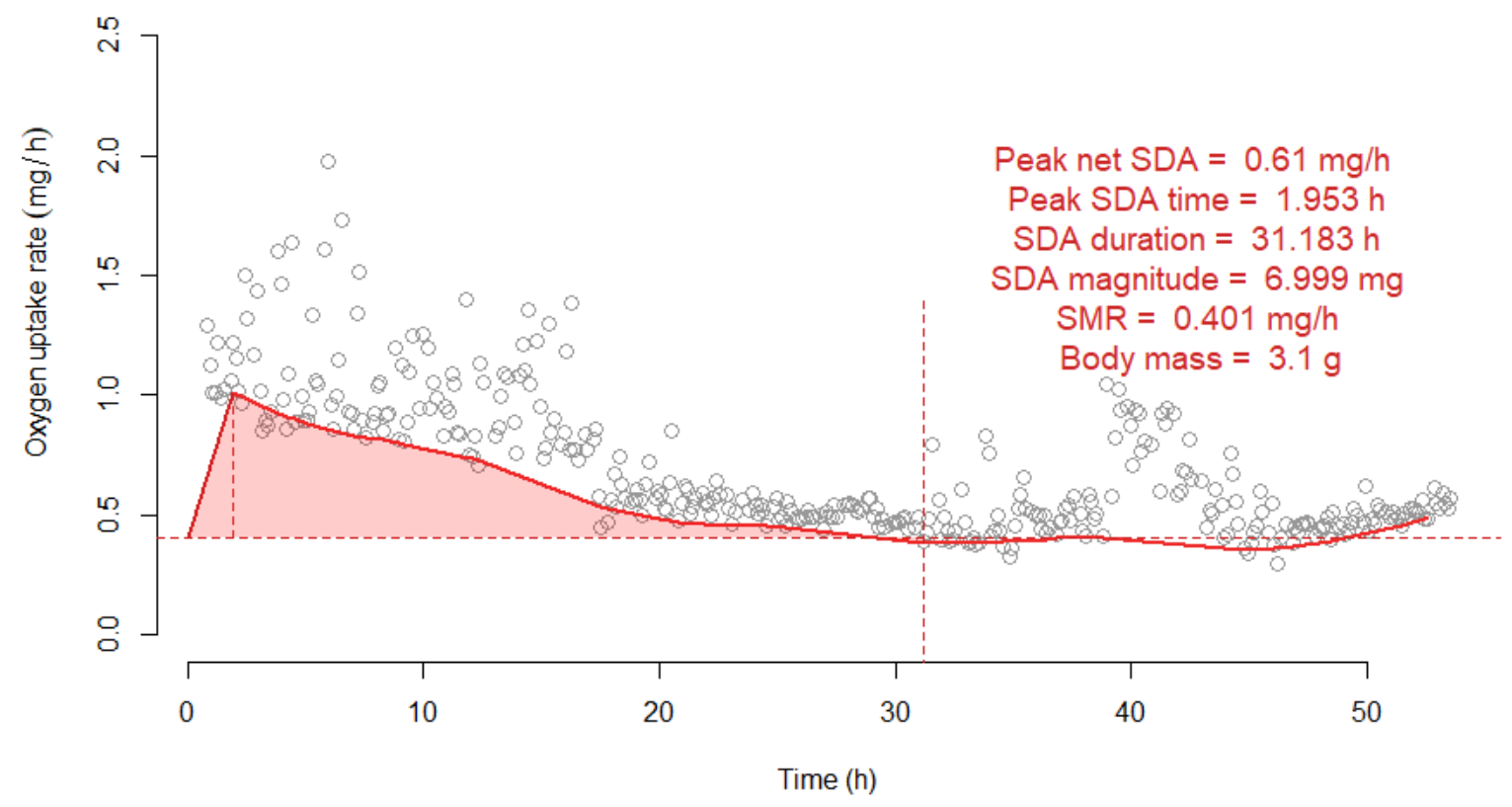

7_200617

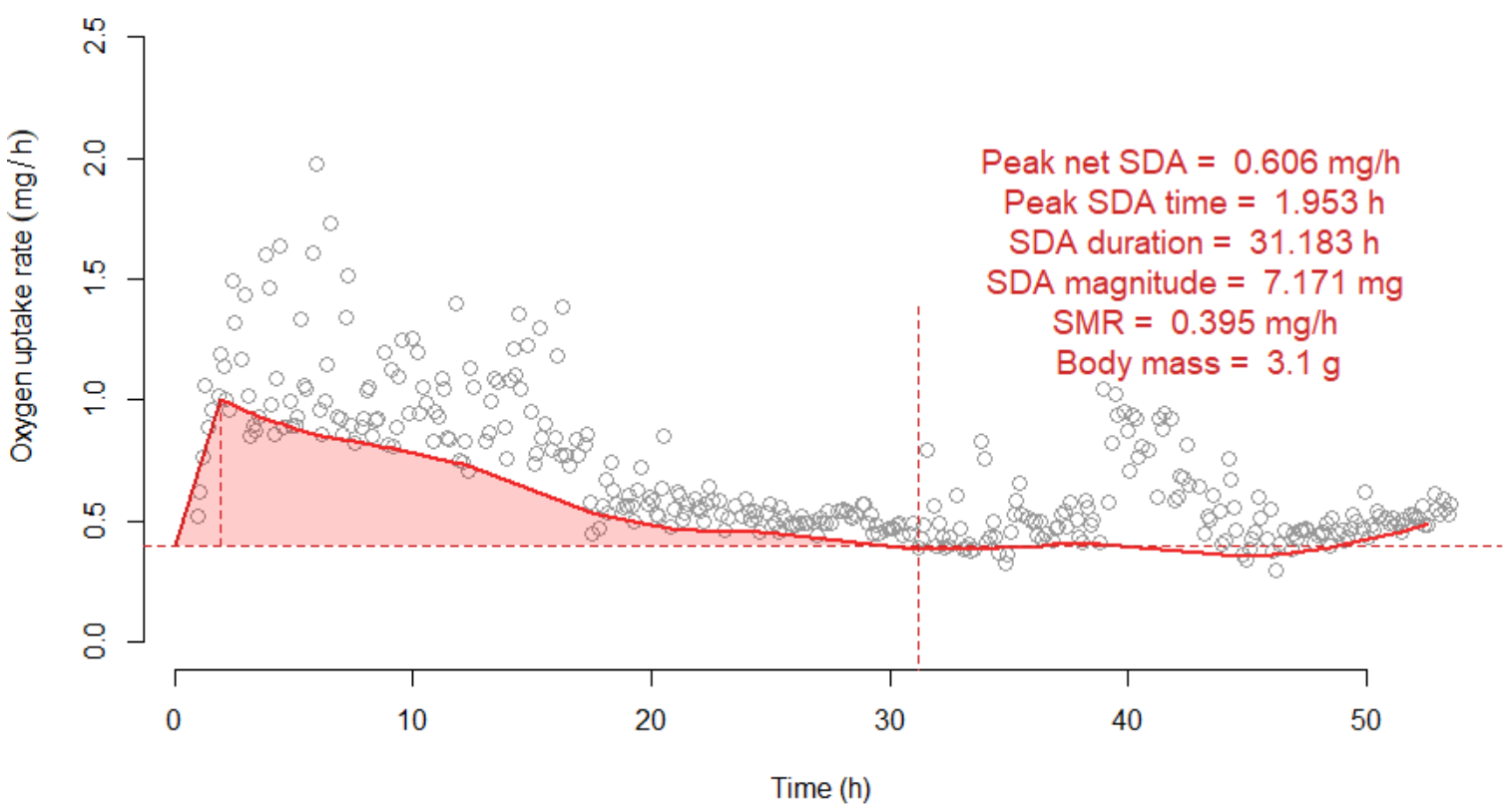

Page 8 of 25 


\section{1_250617}

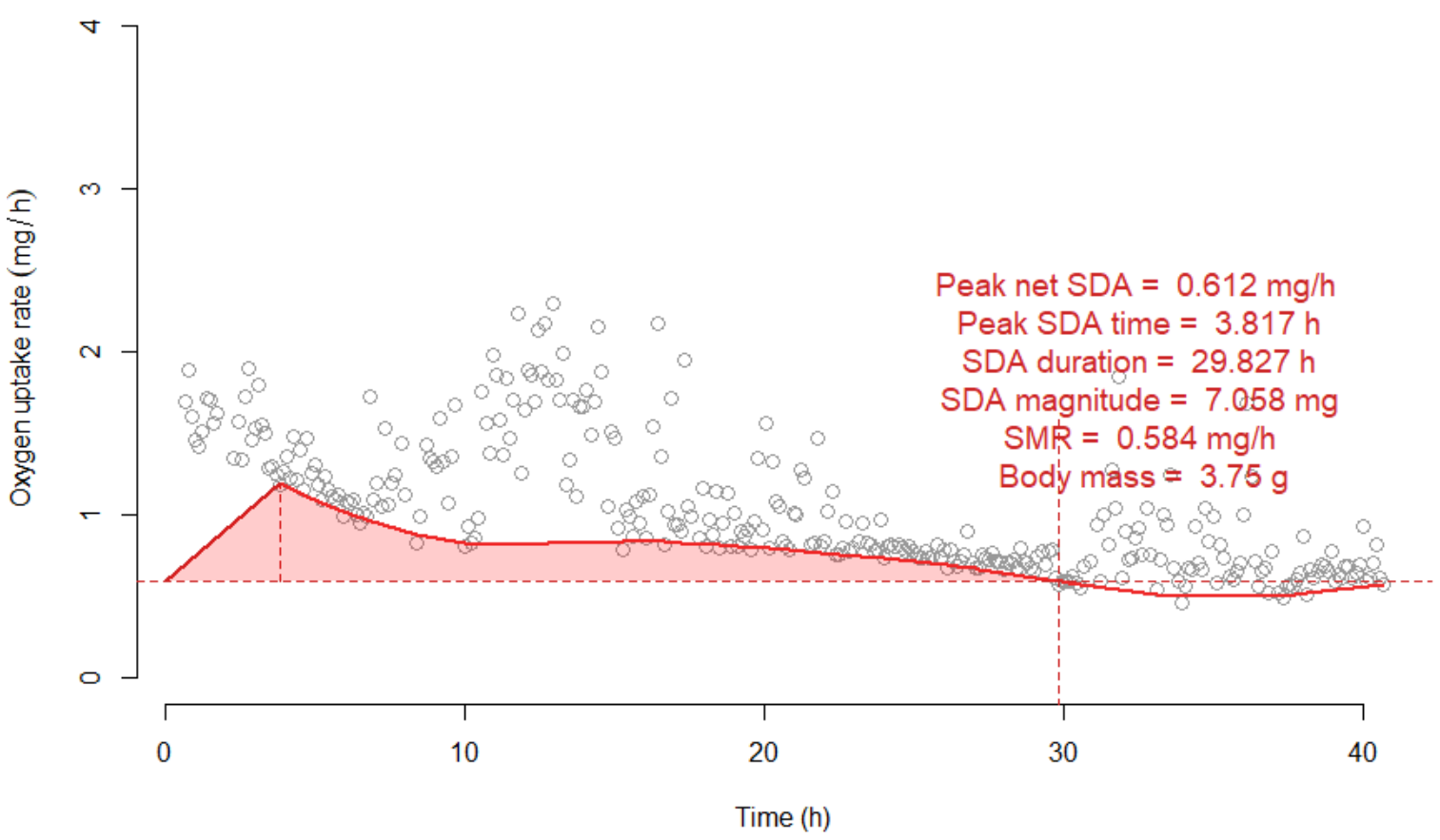

1_250617

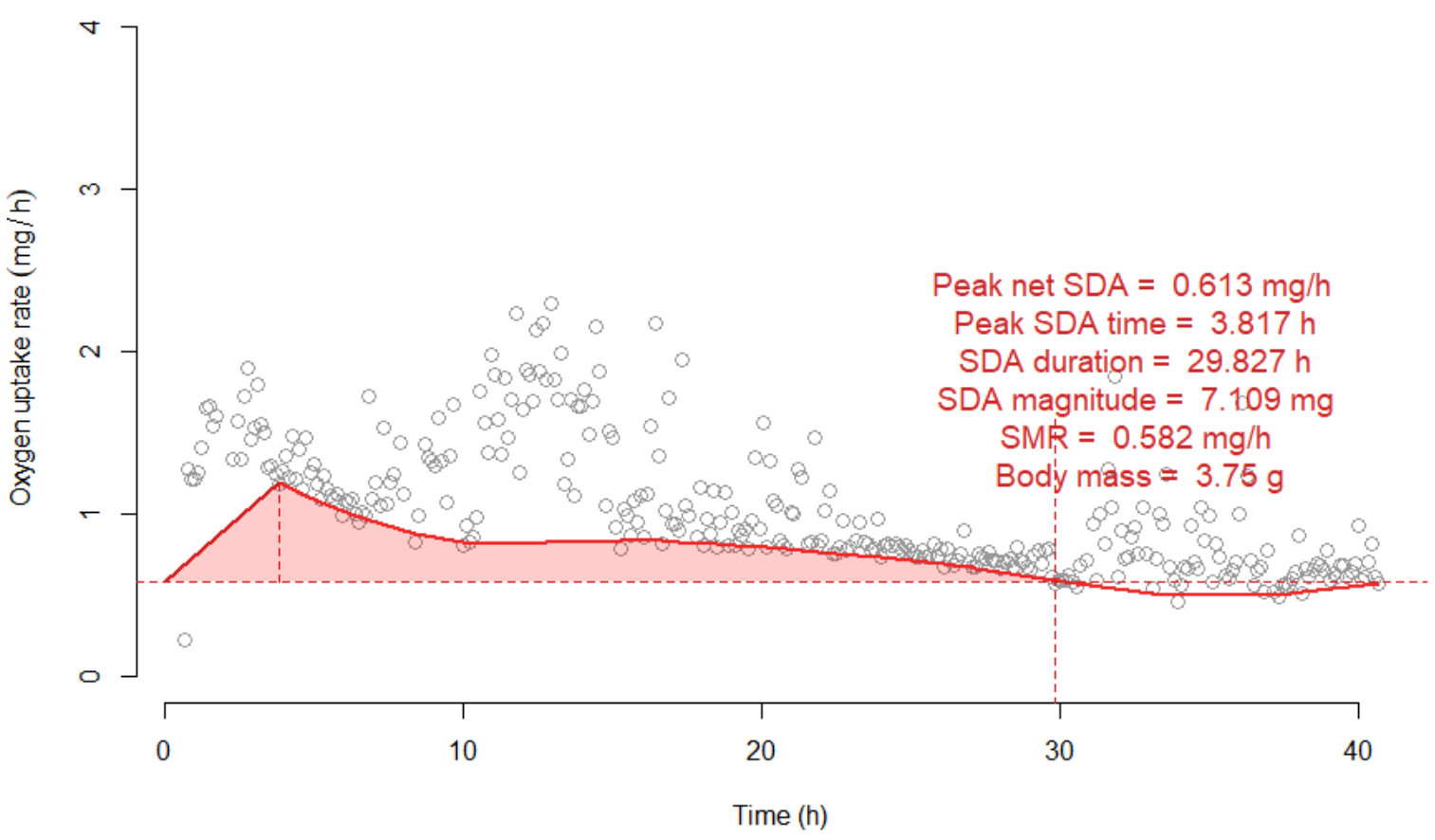




\section{2_250617}

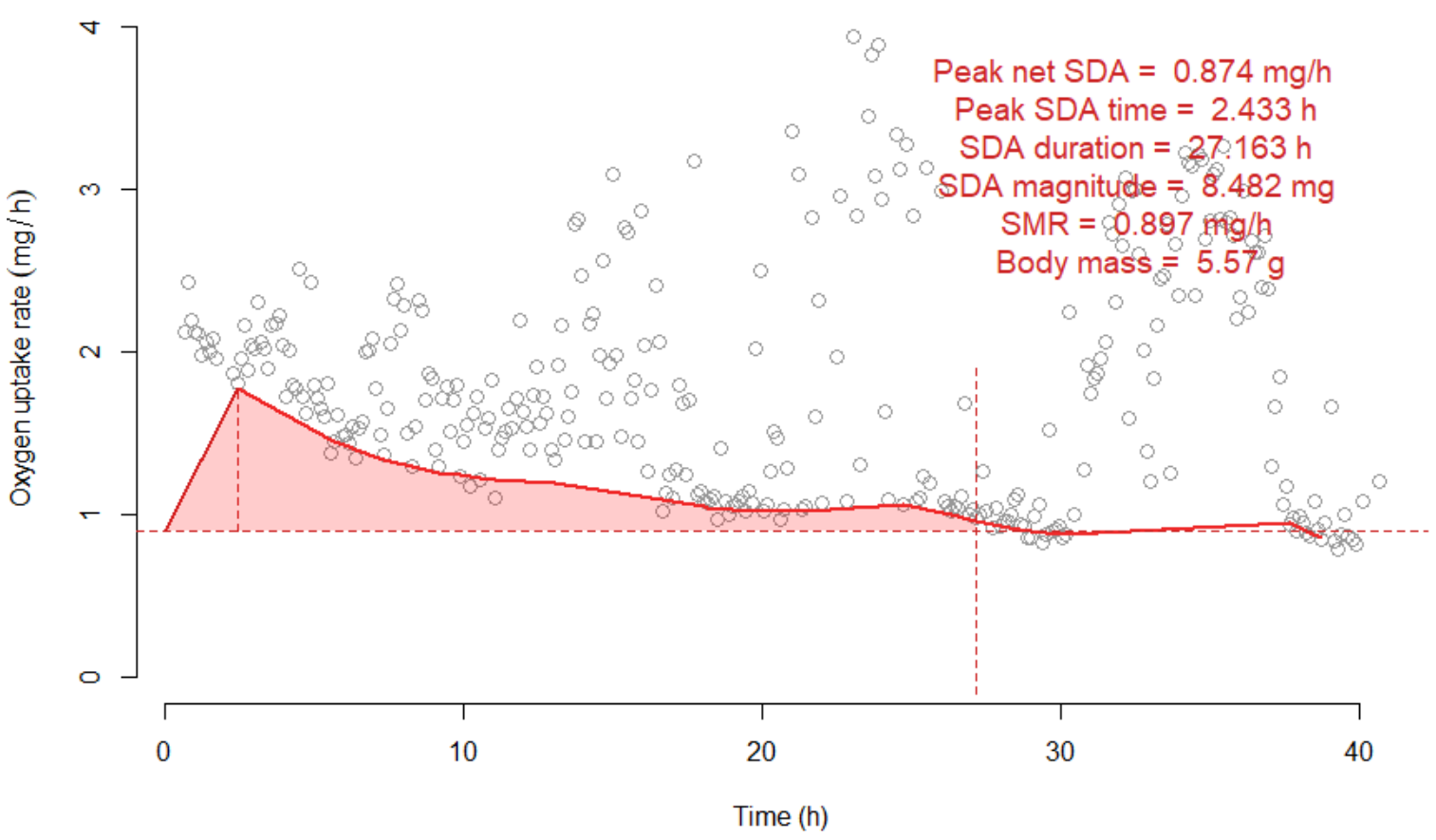

2_250617

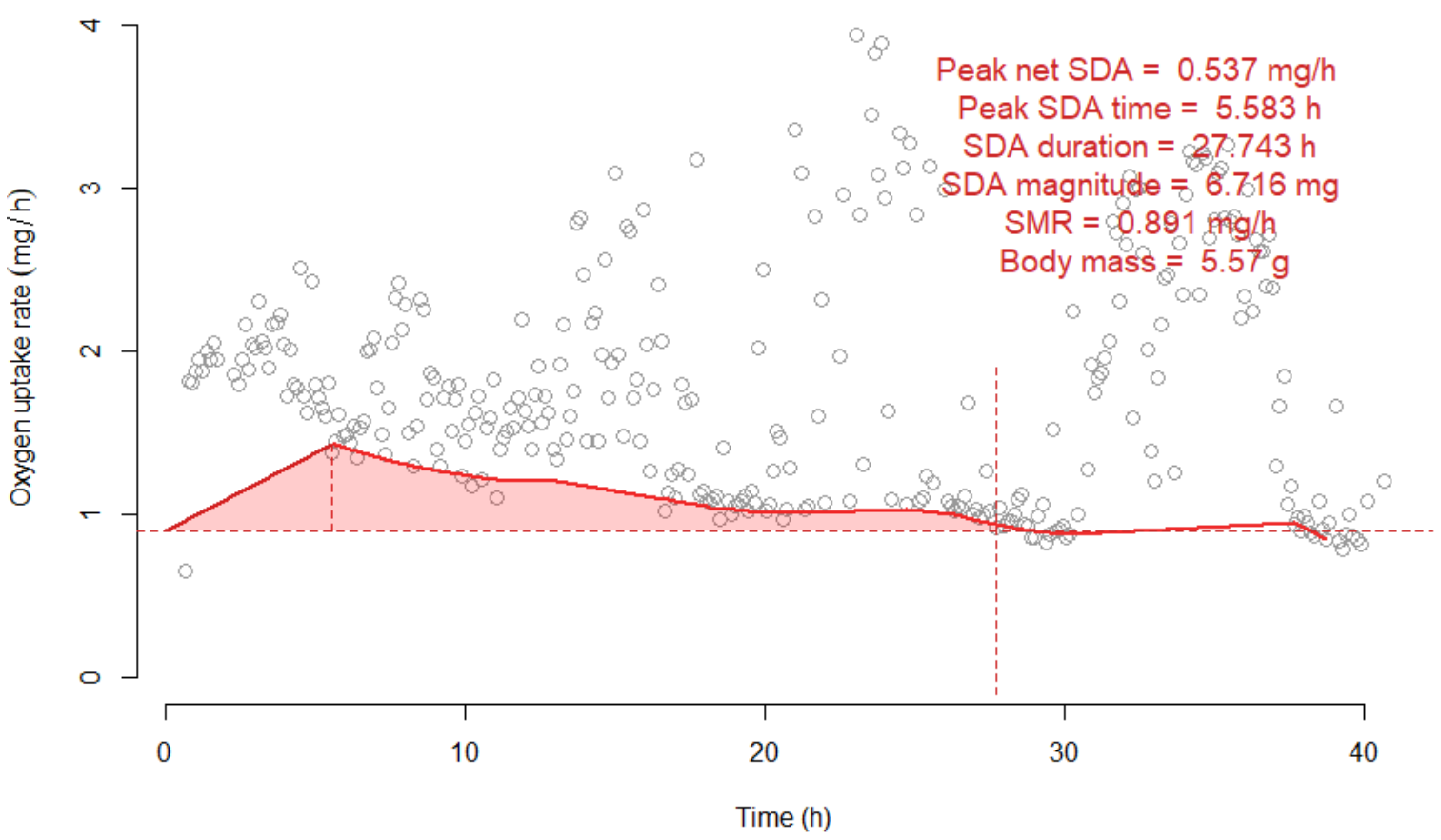




\section{3_250617}

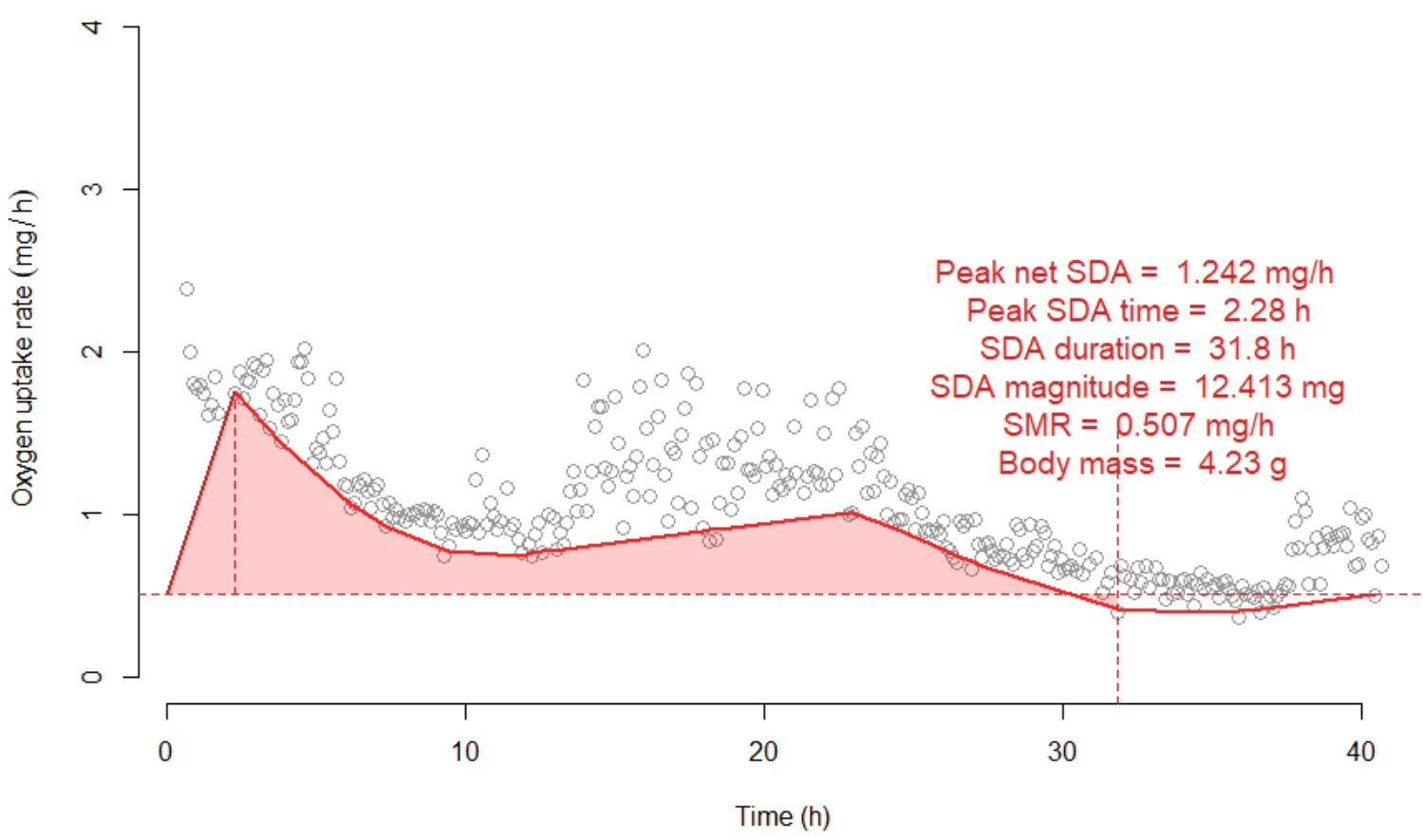

3_250617

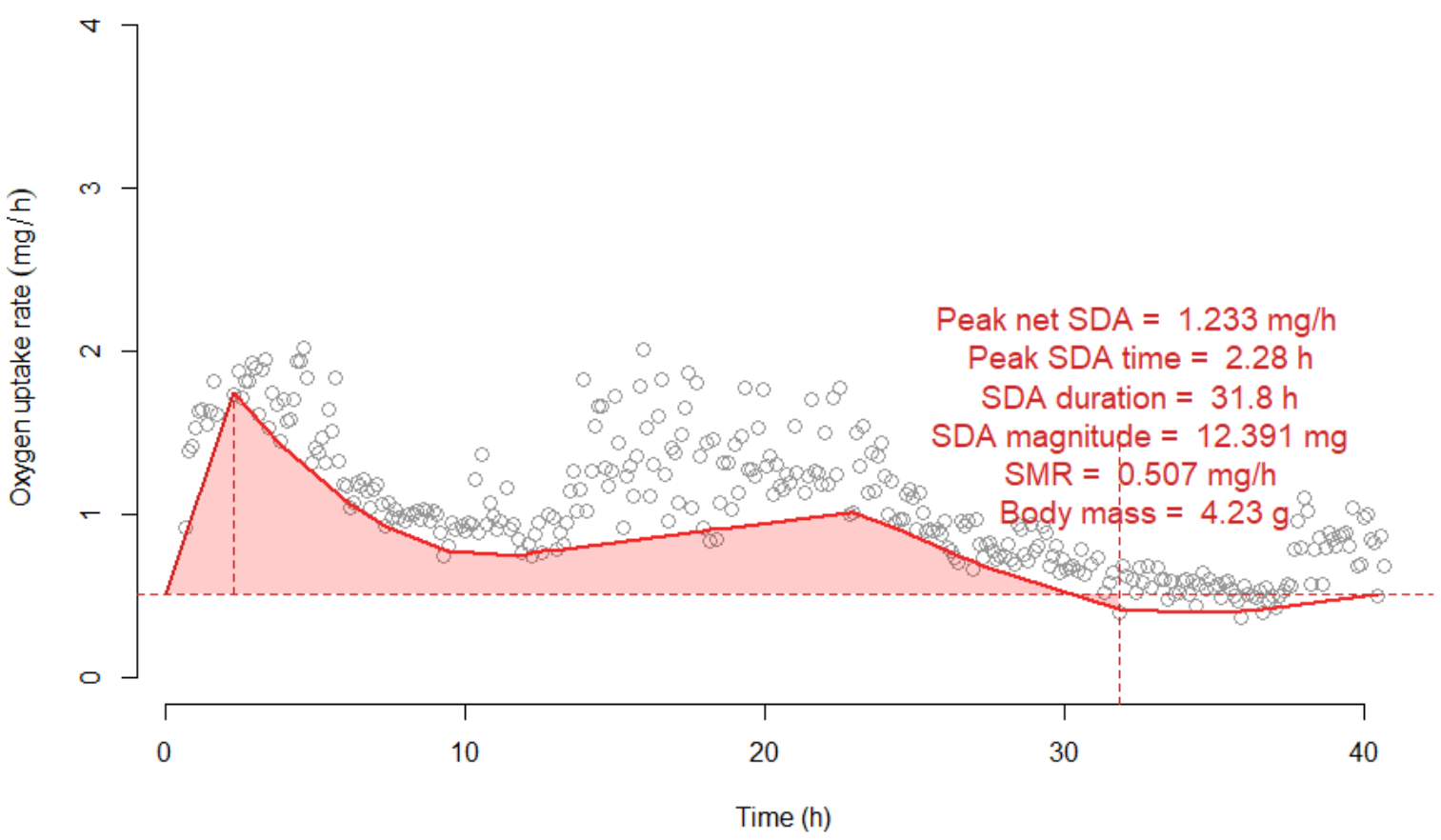




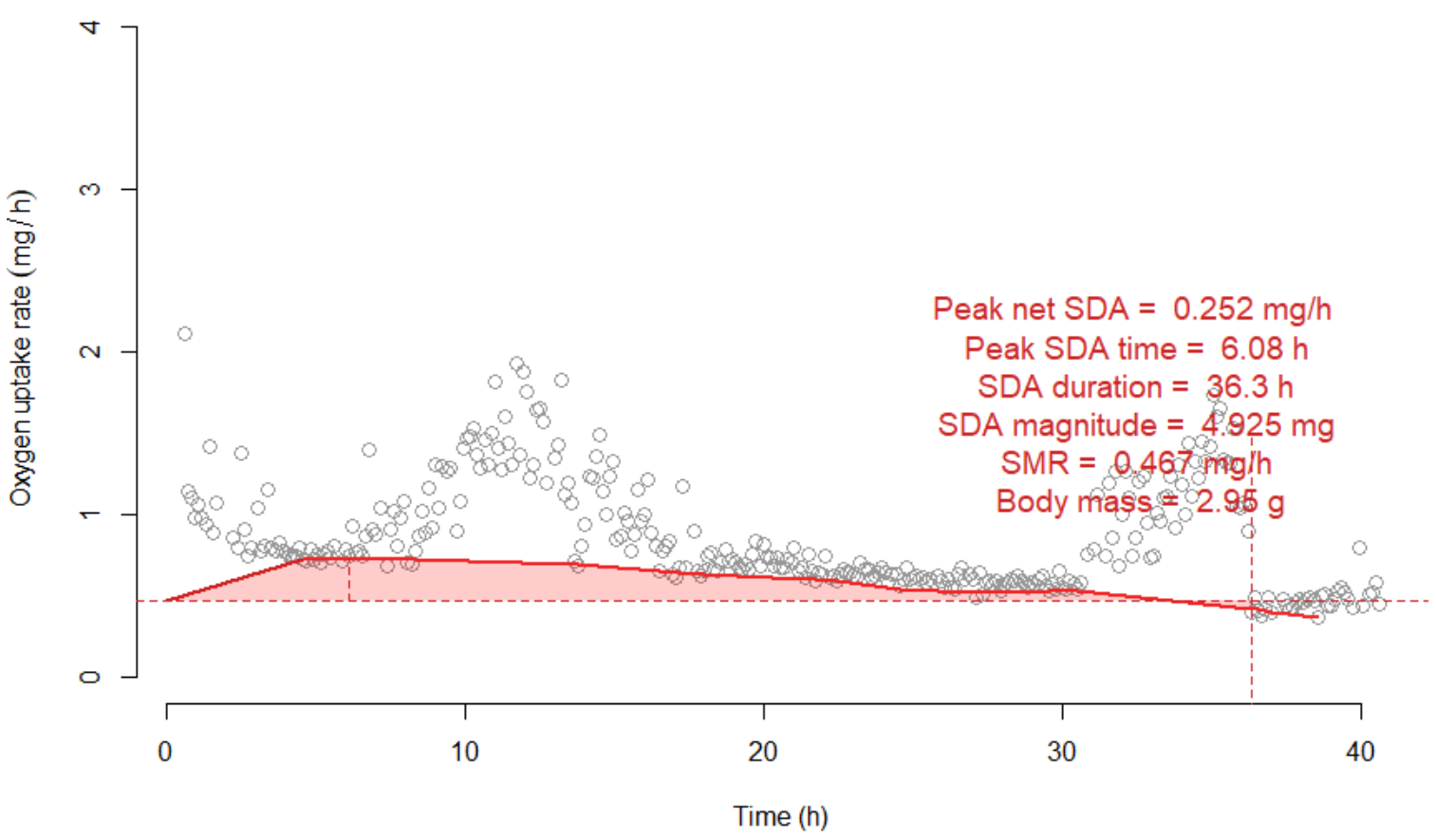

4_250617

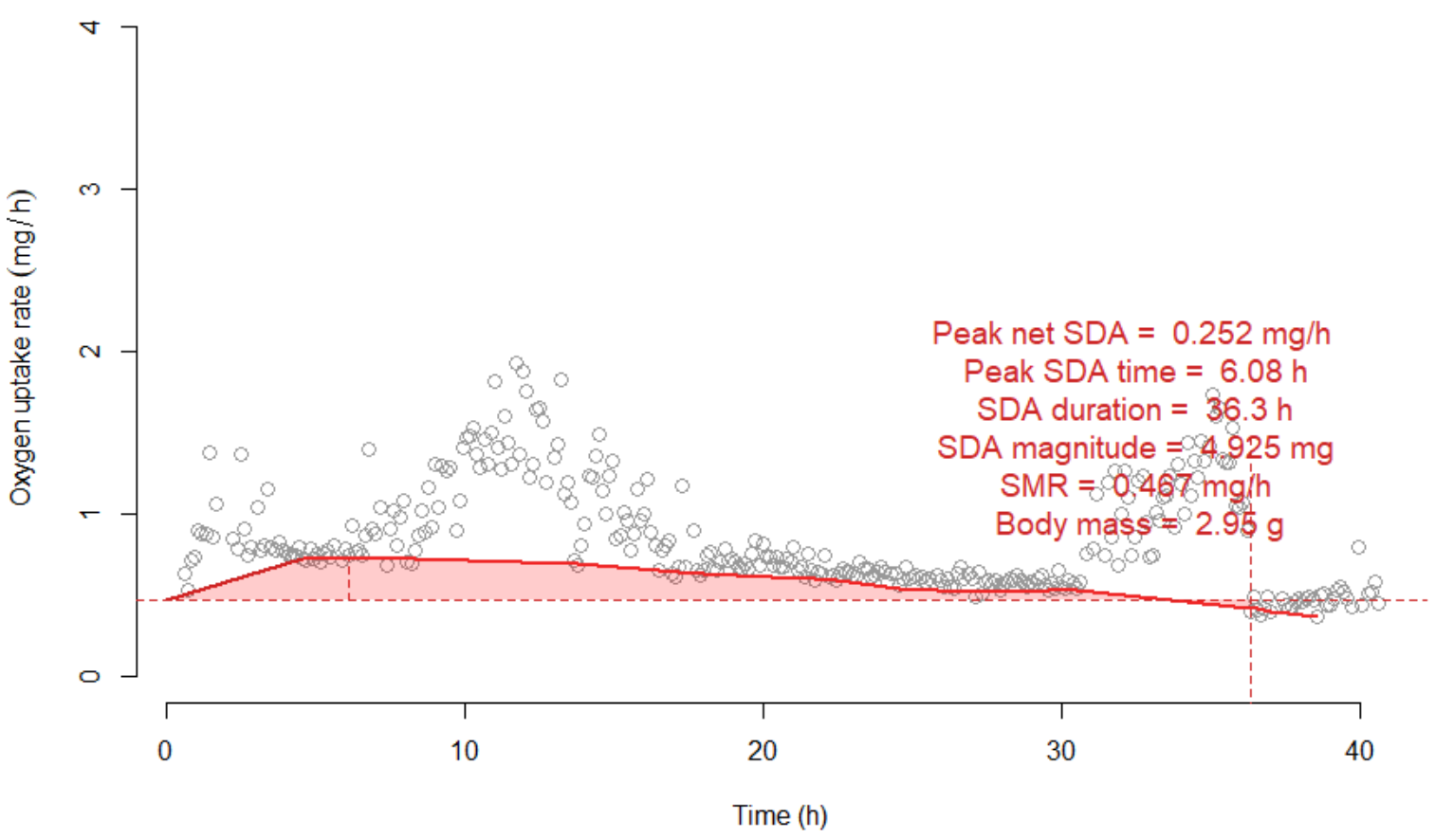




\section{5_250617}

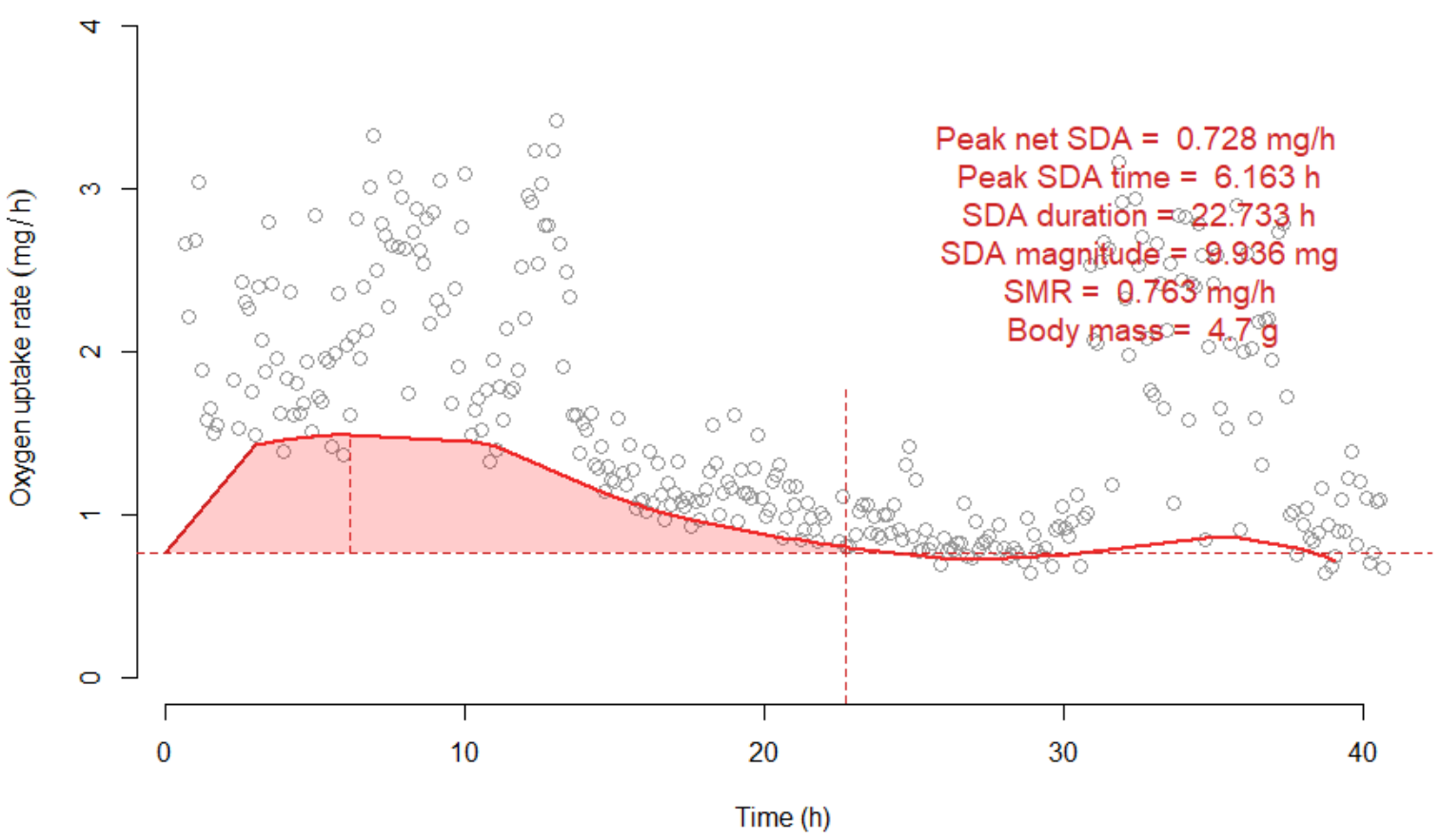

5_250617

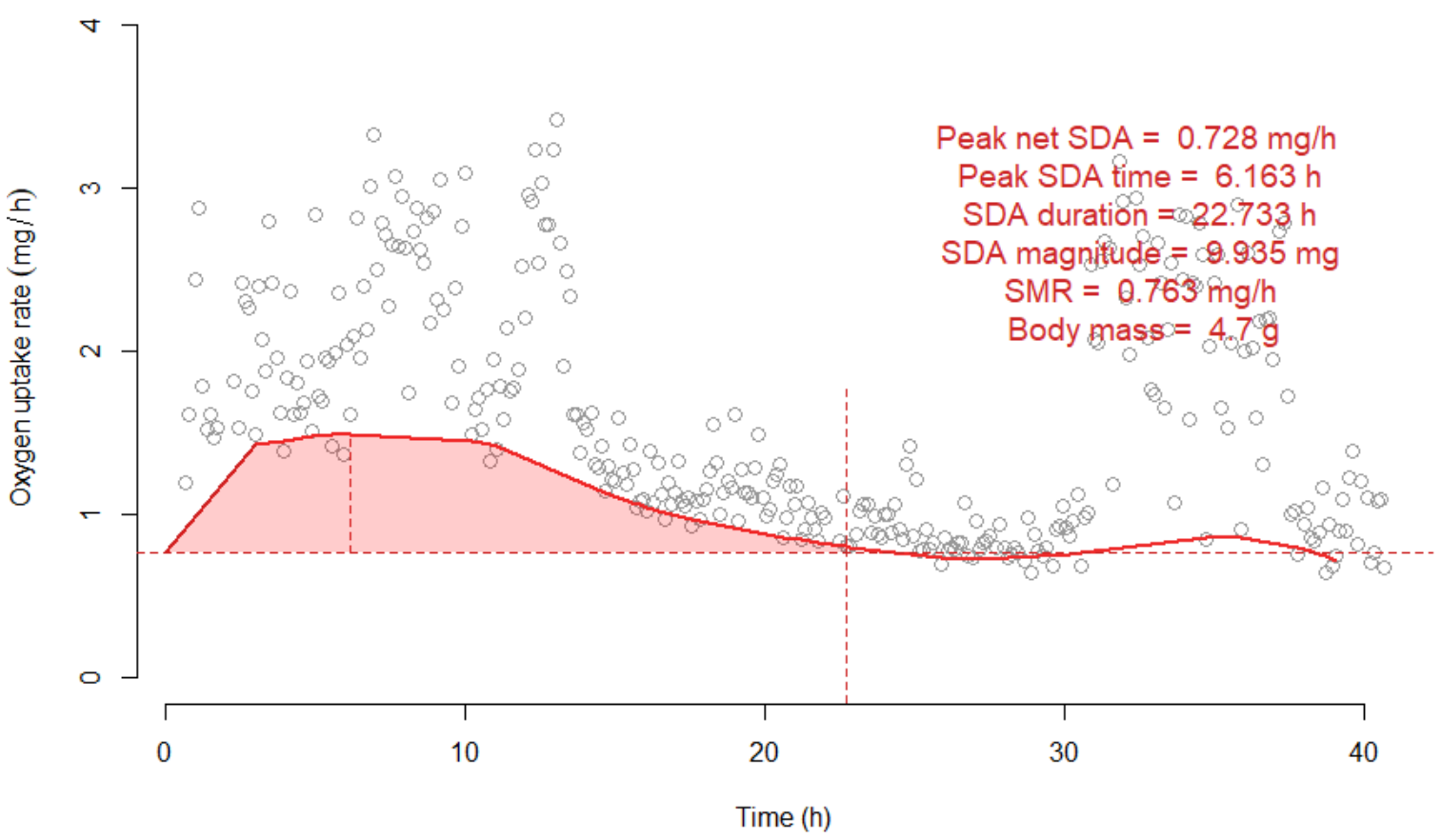




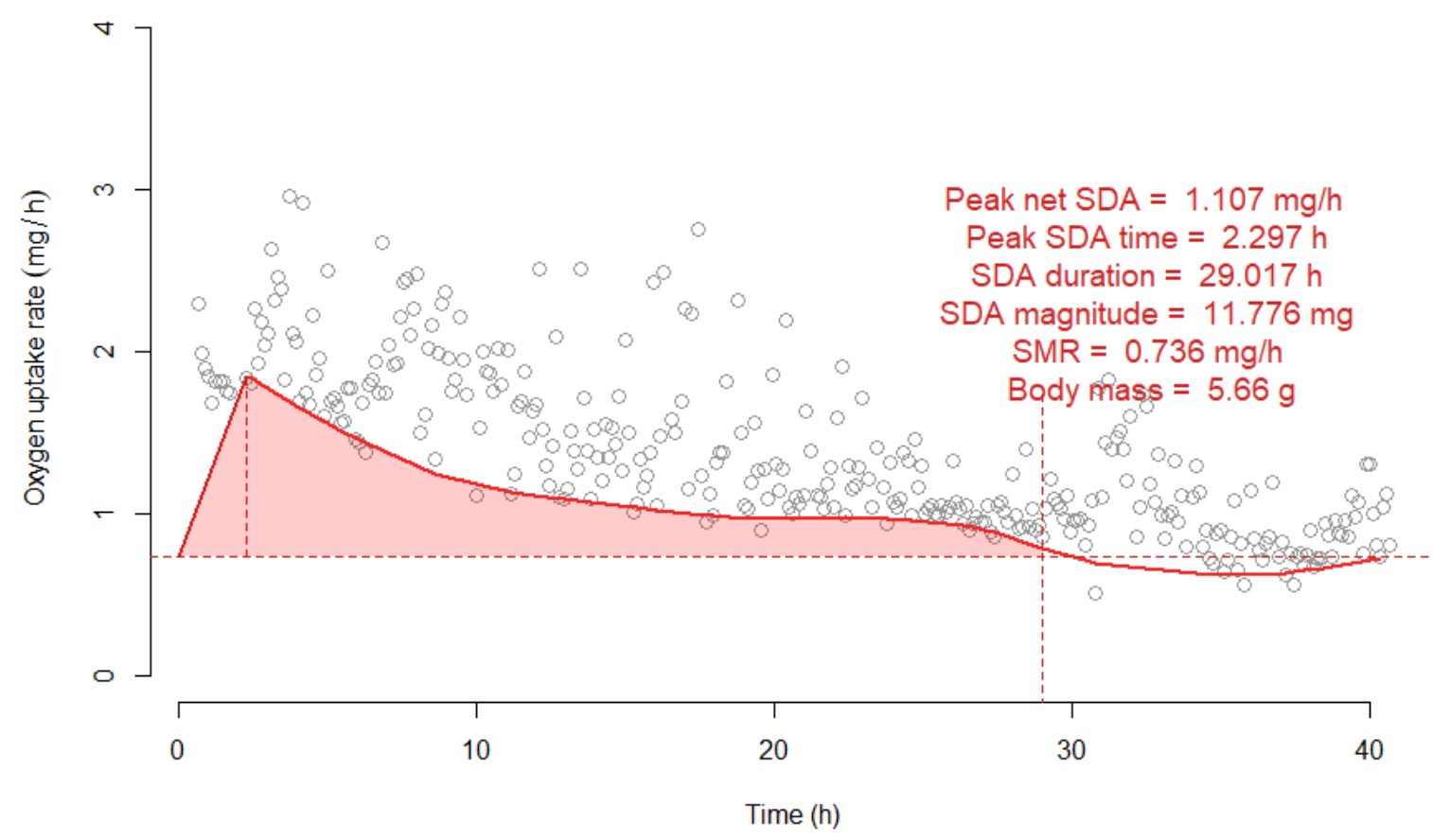

6_250617

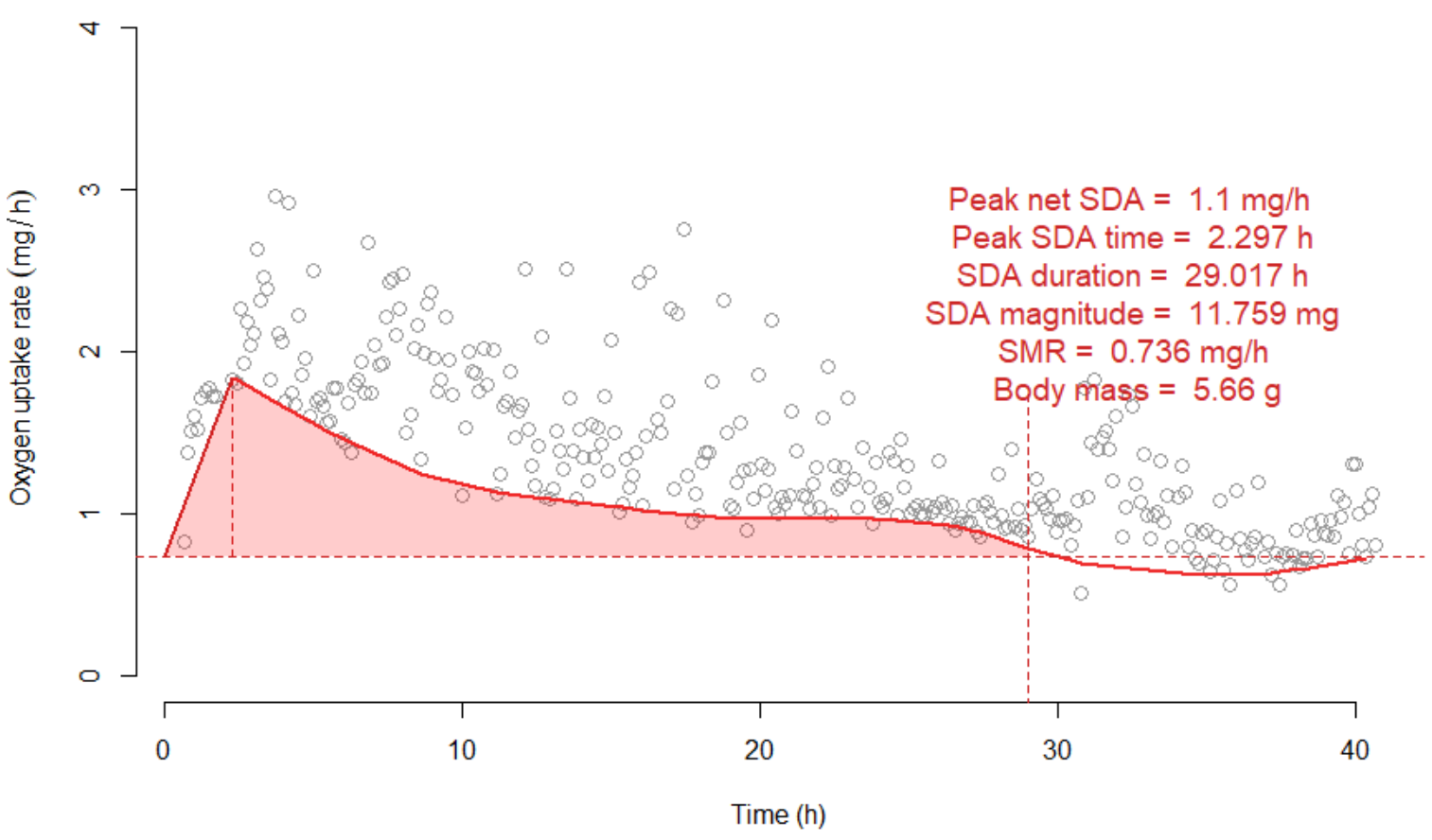




\section{7_250617}

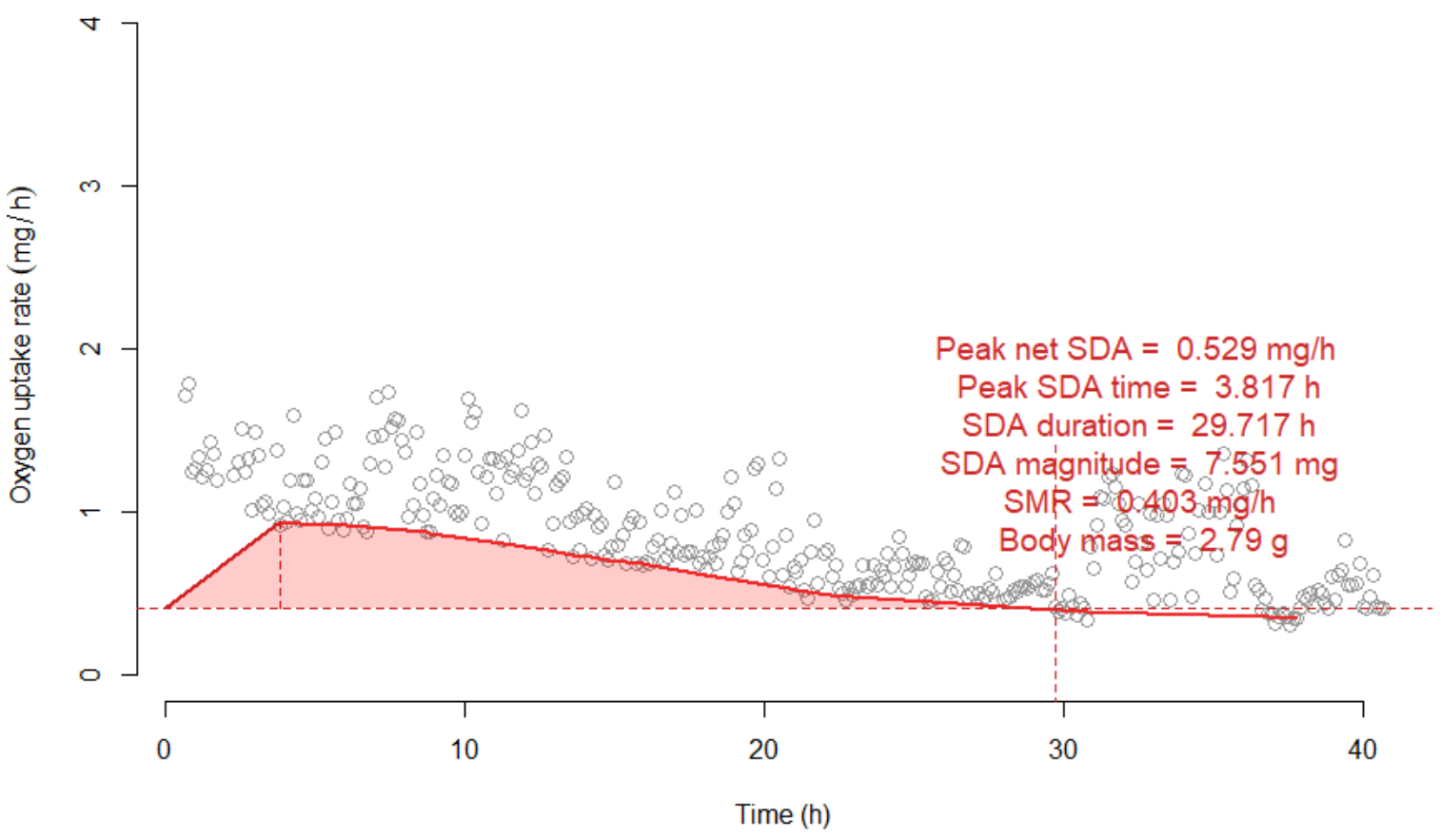

7_250617

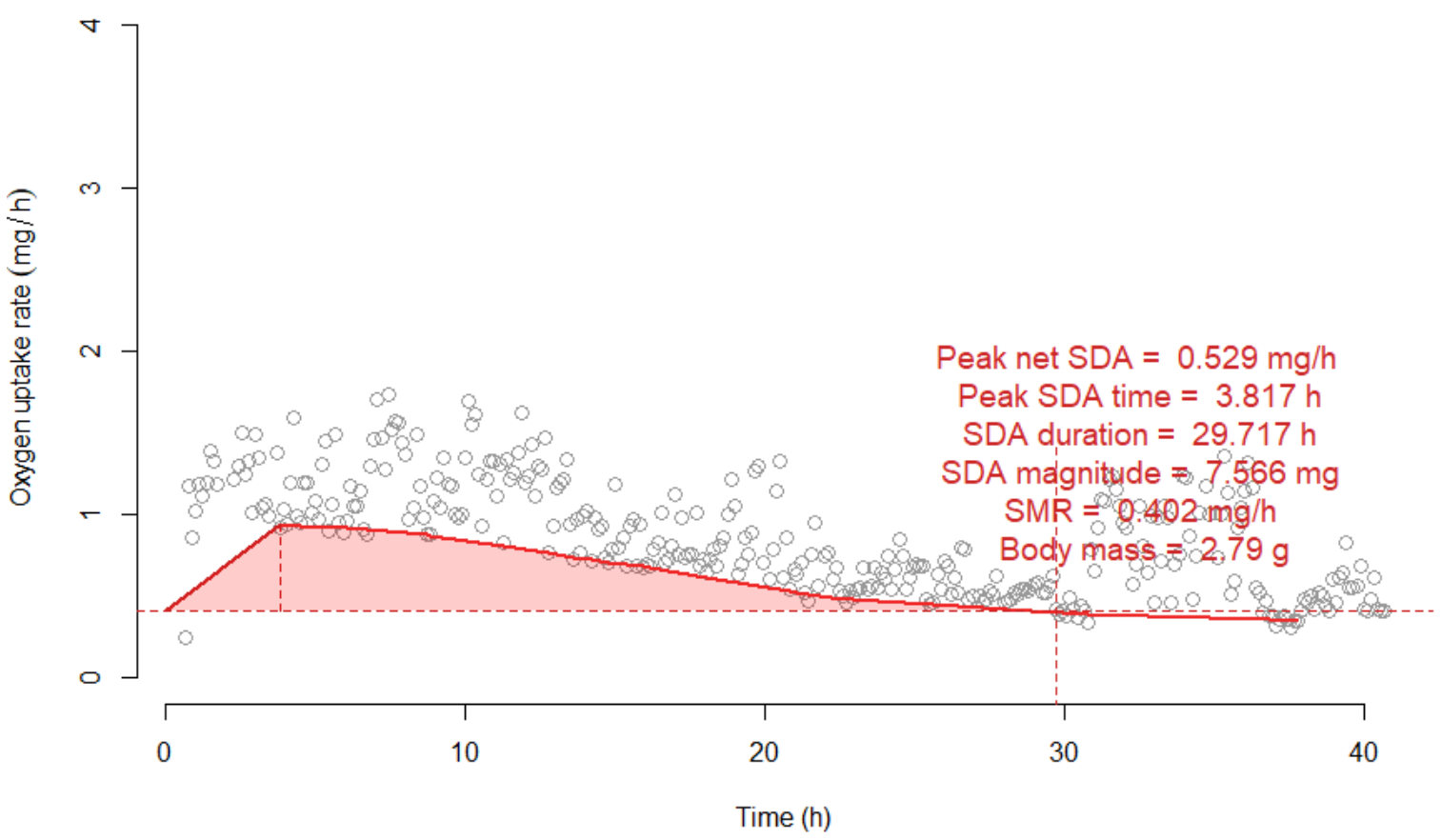




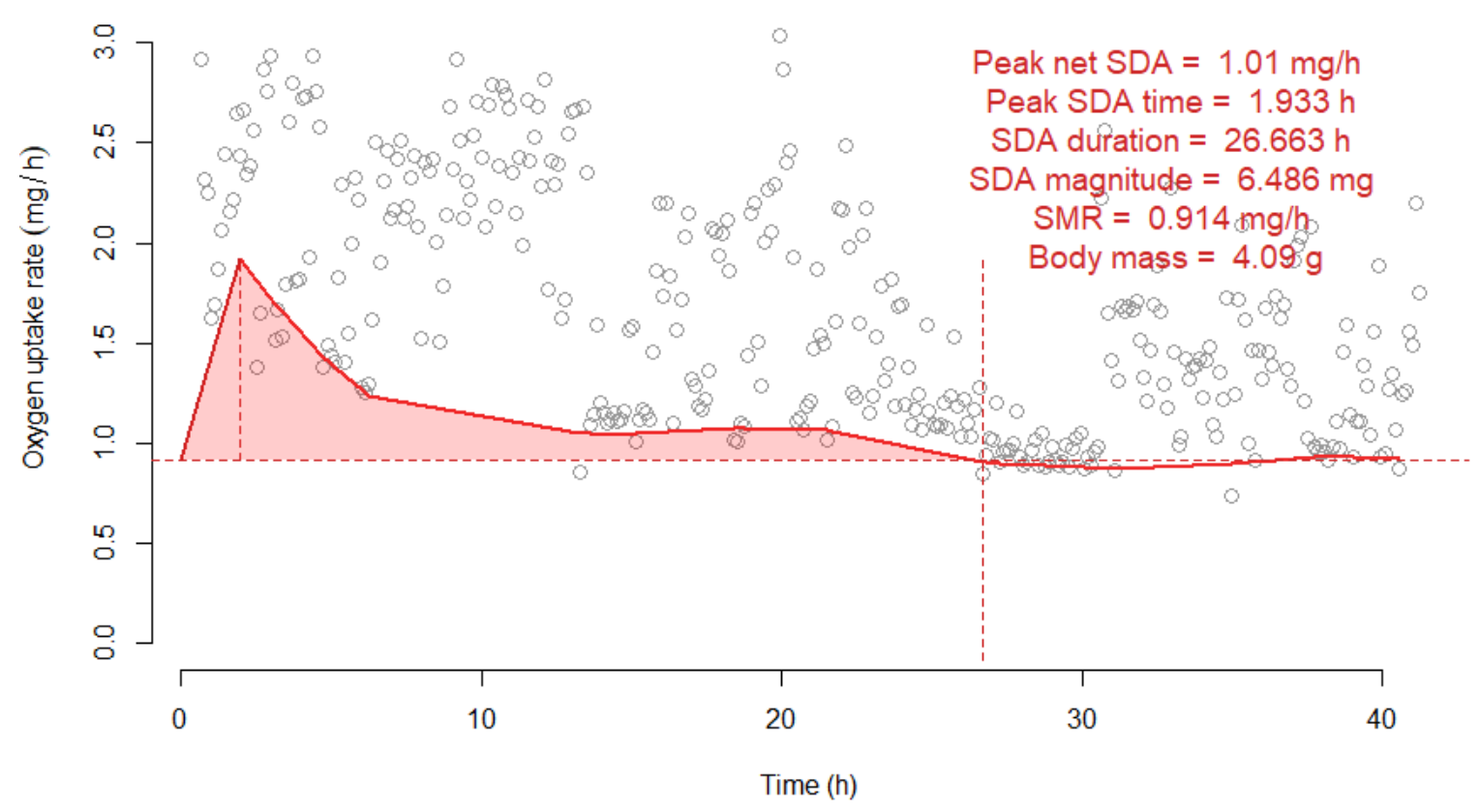

2_290617

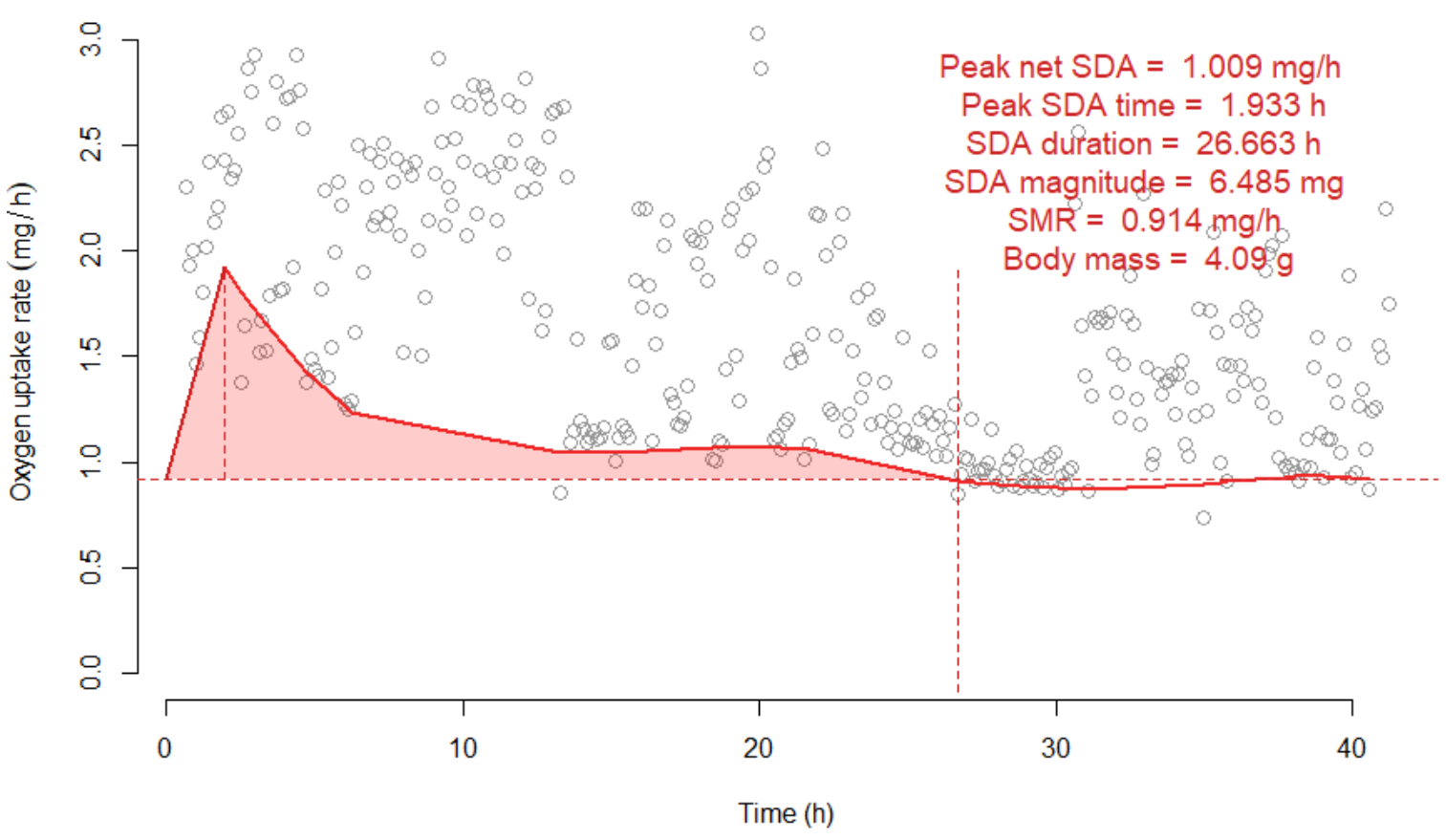




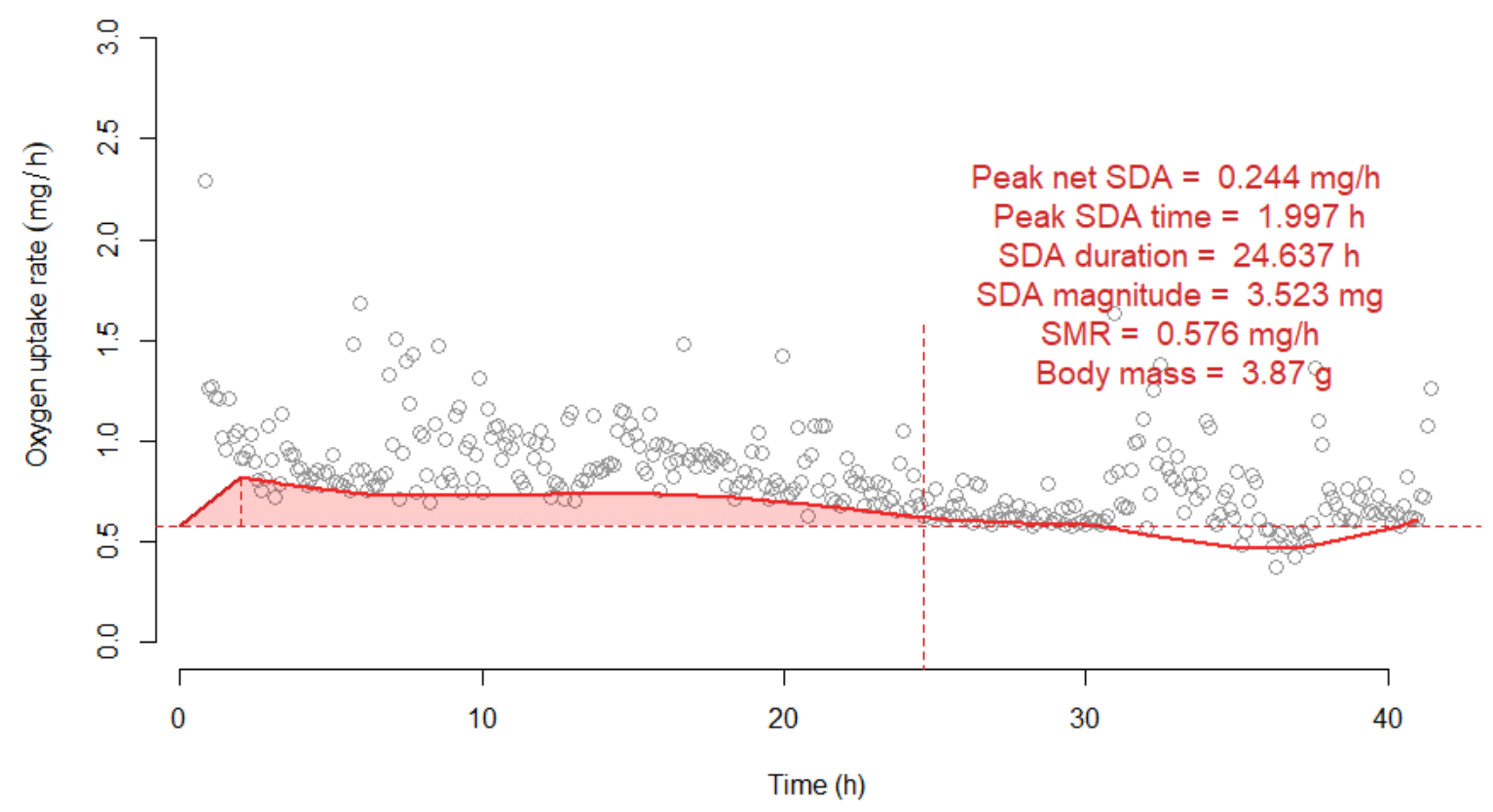

3_290617

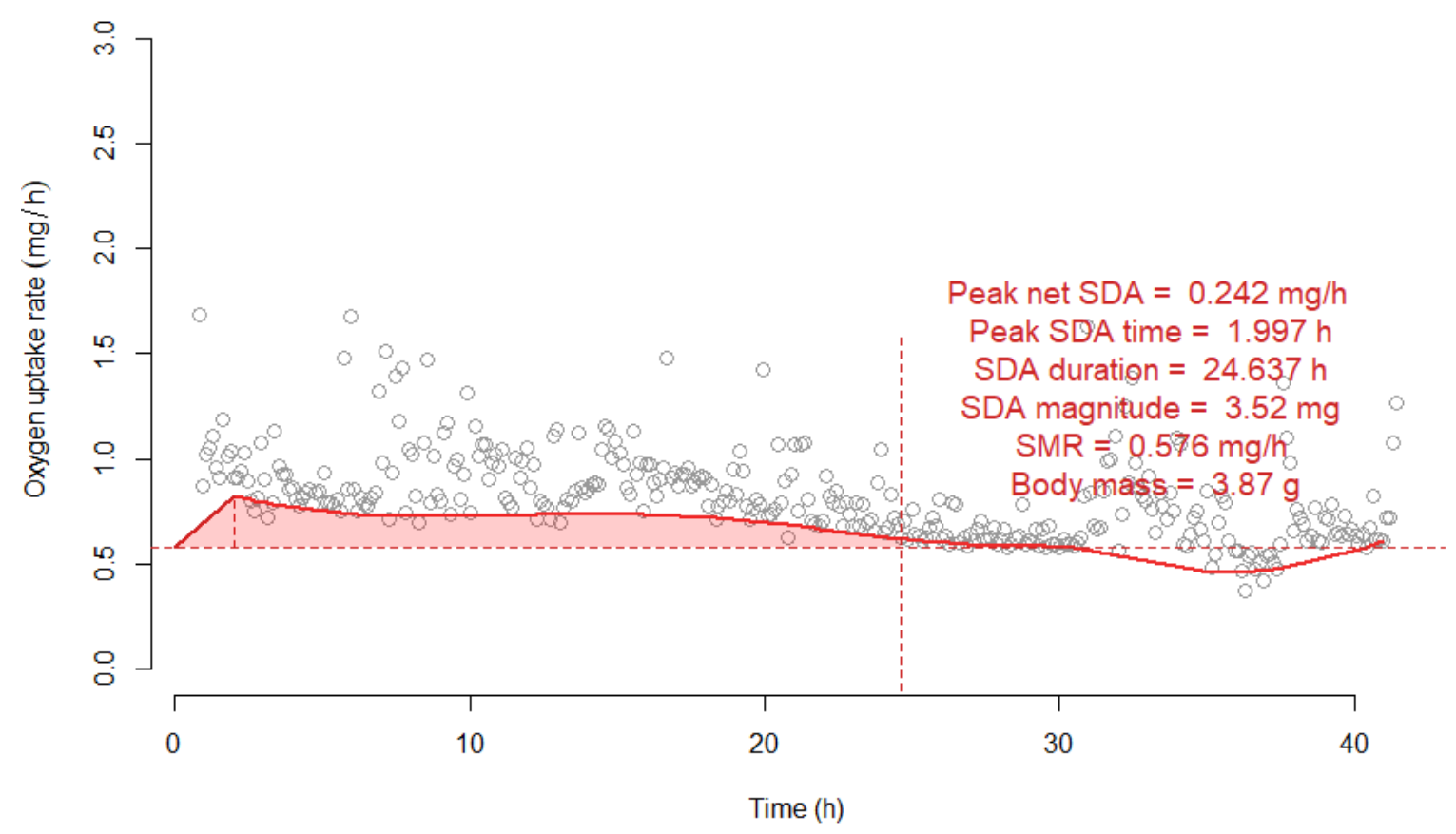




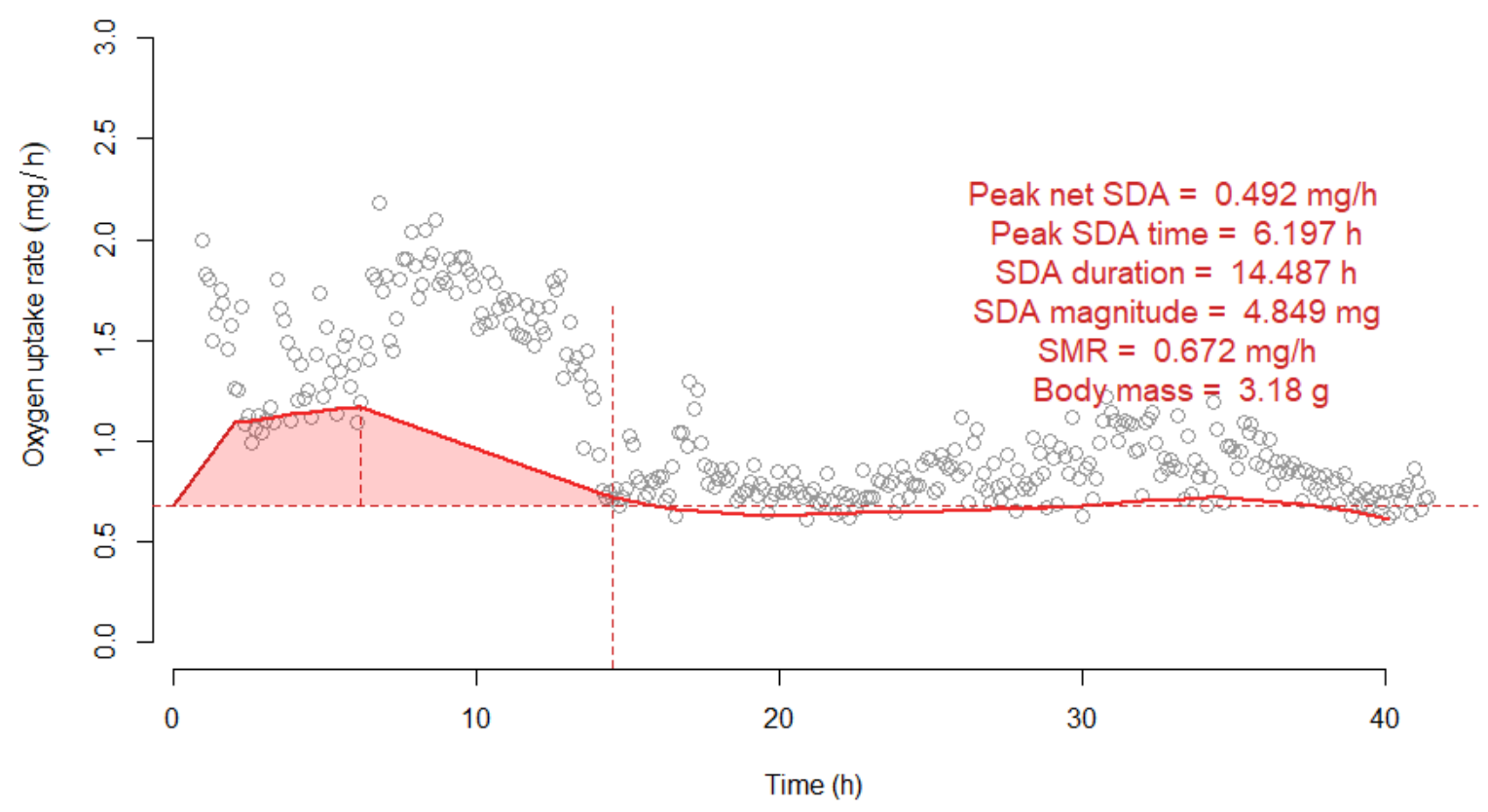

4_290617

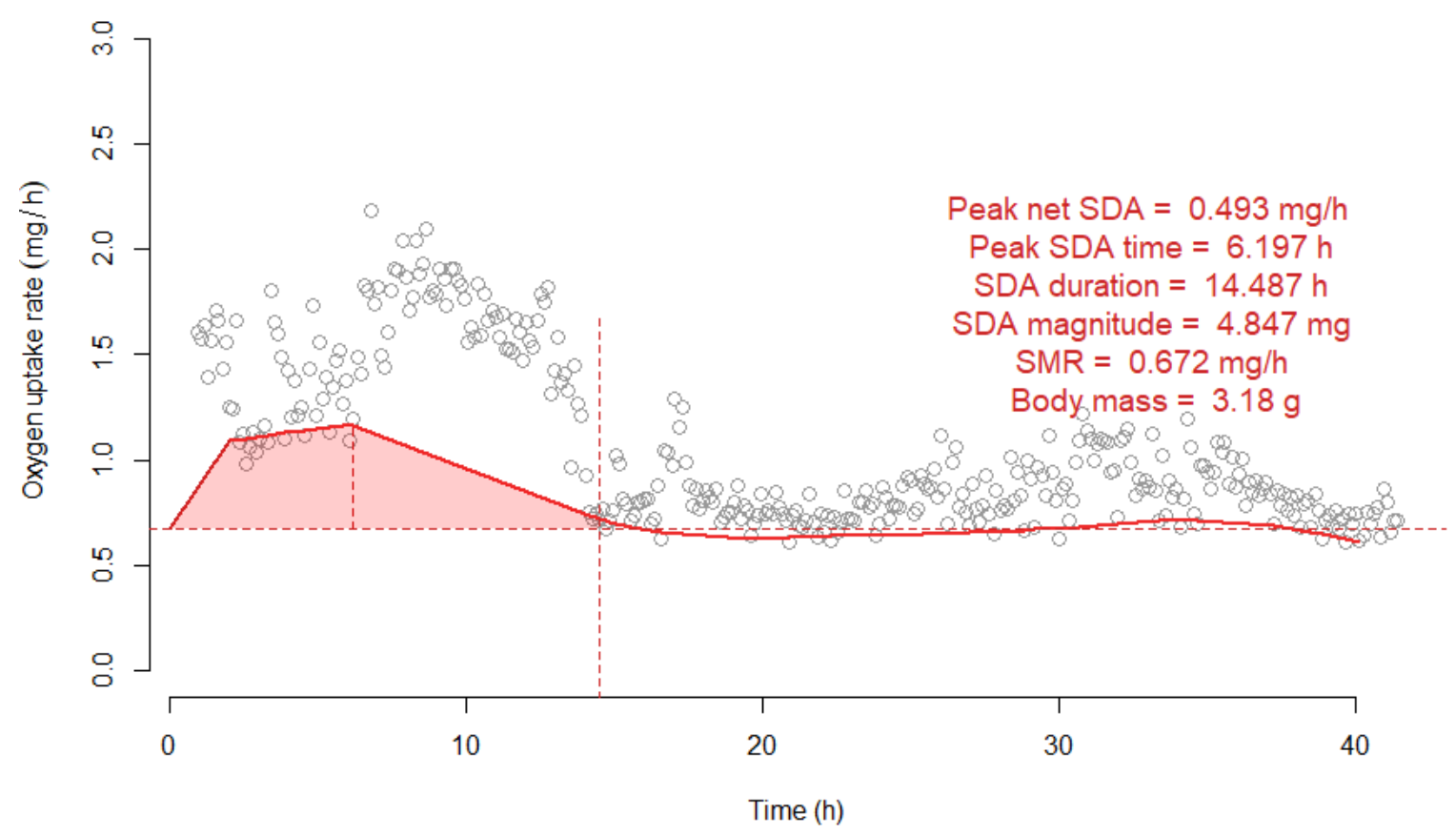




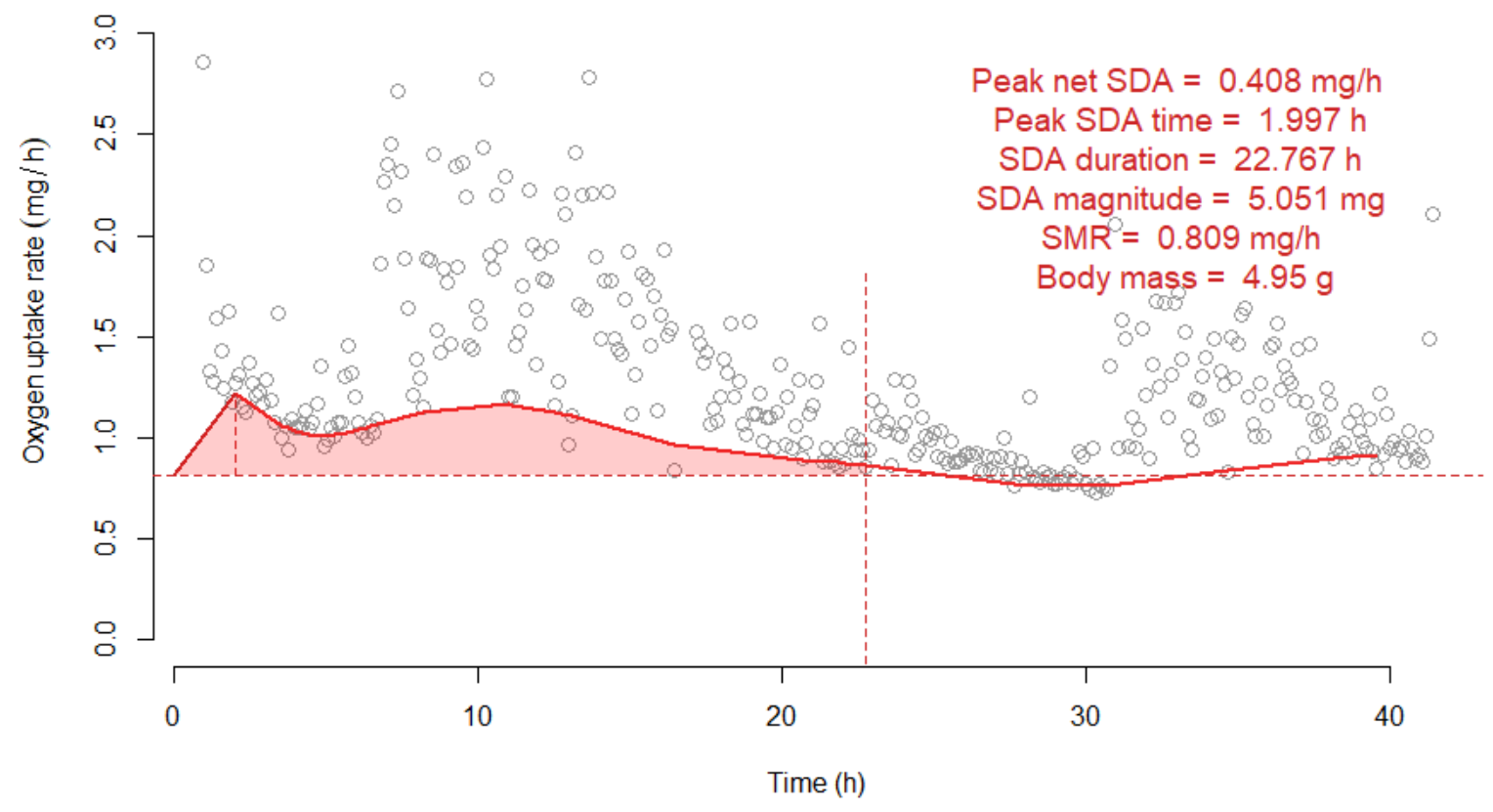

5_290617

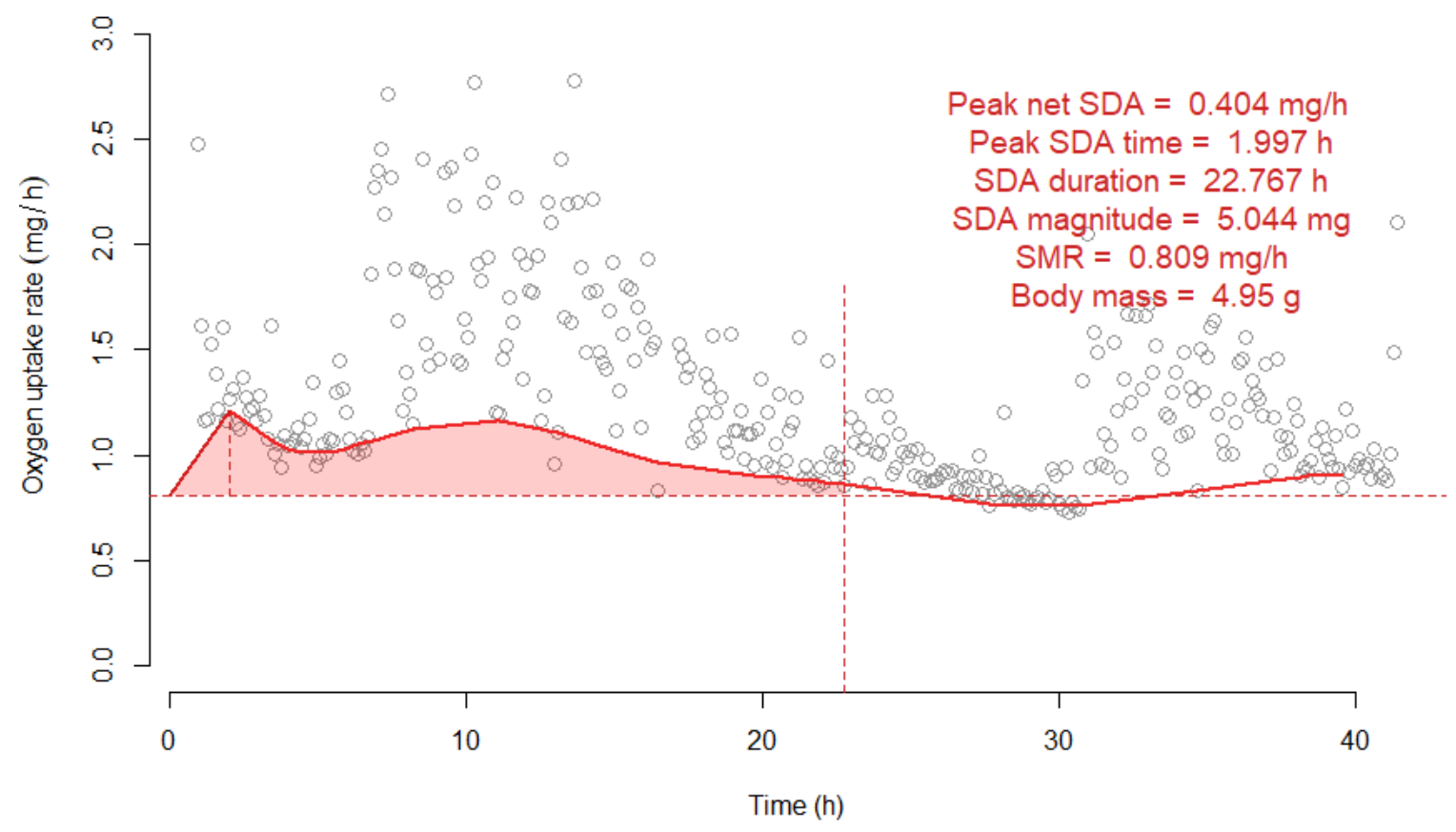




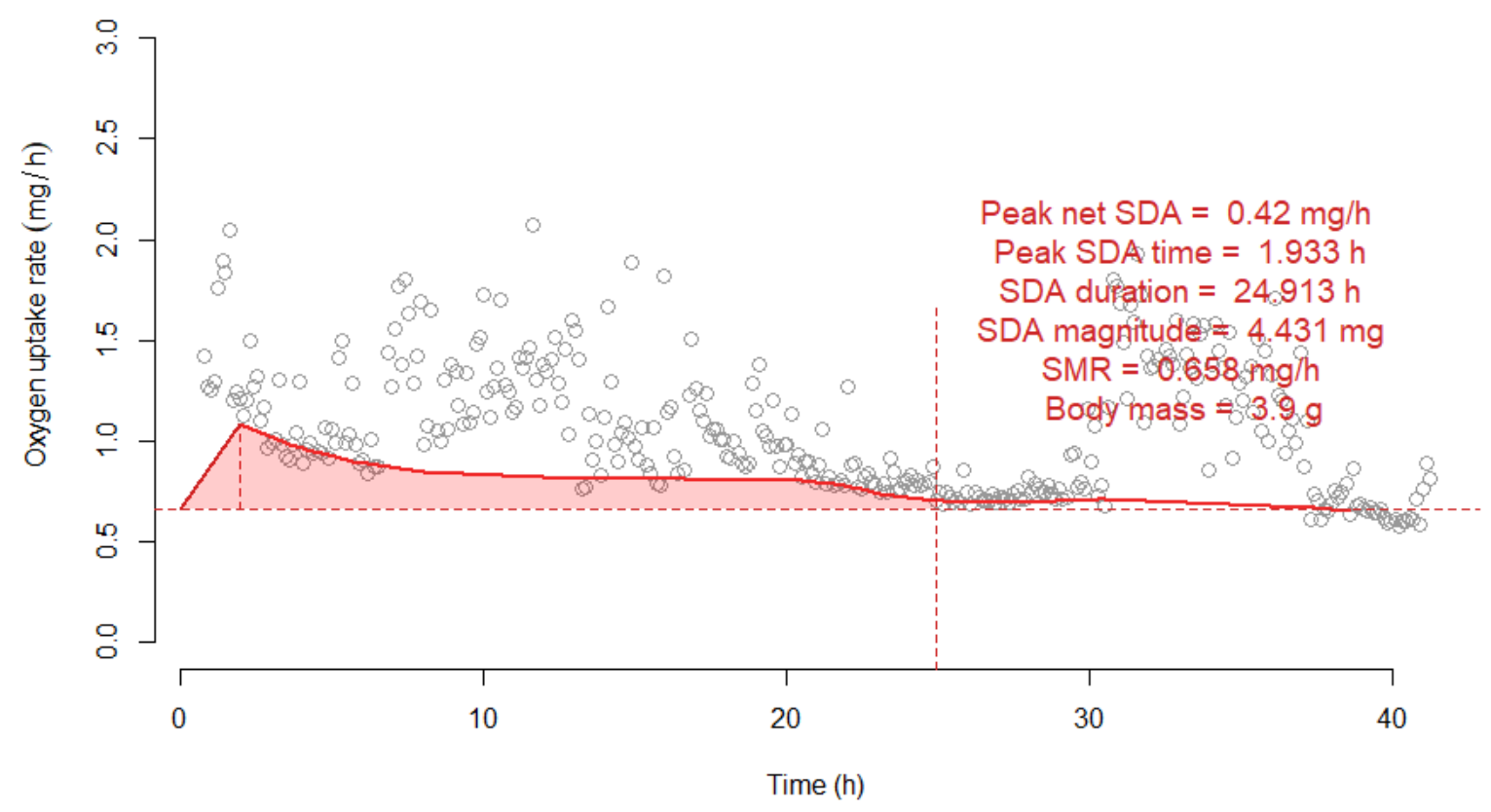

6_290617

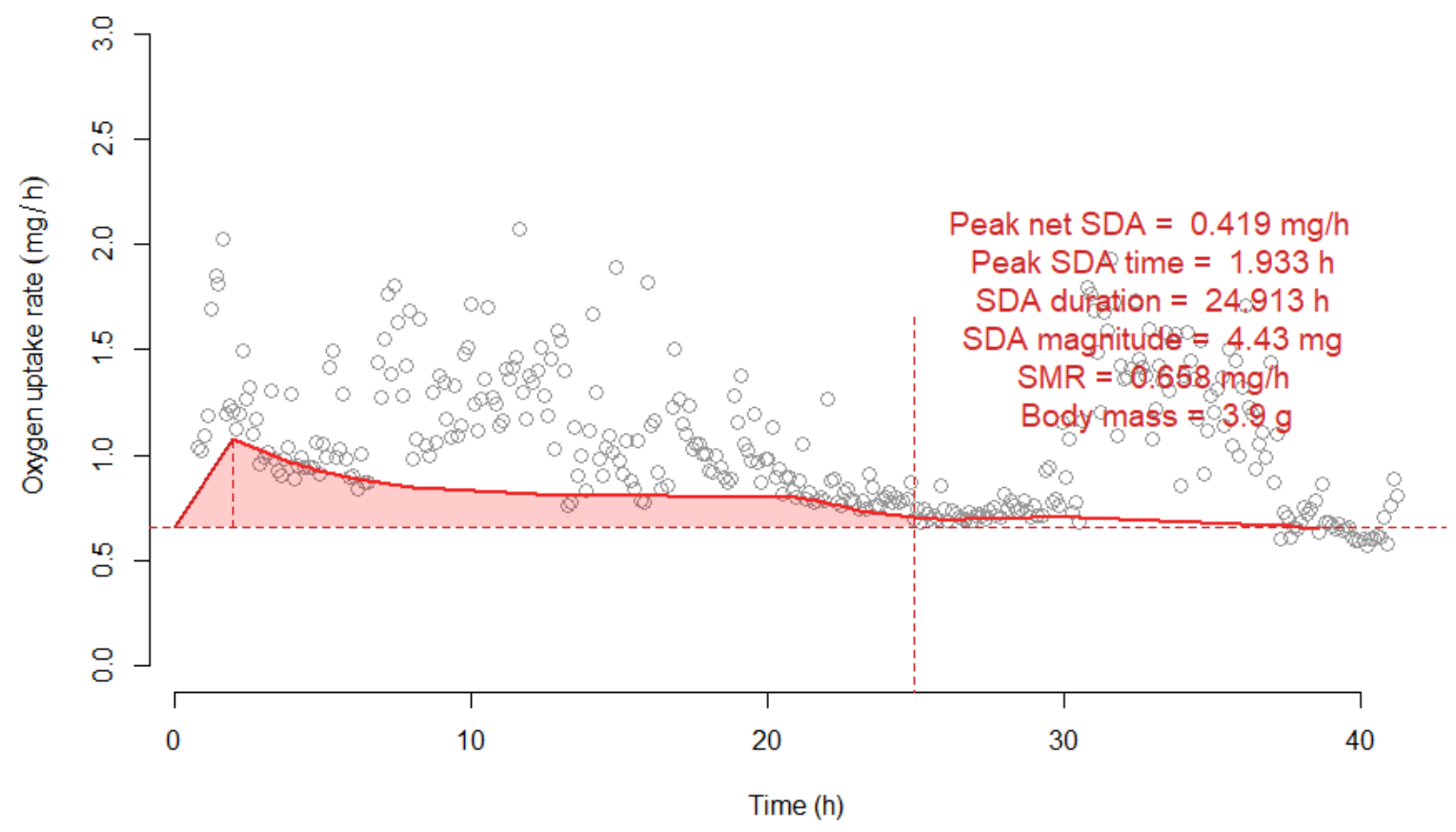




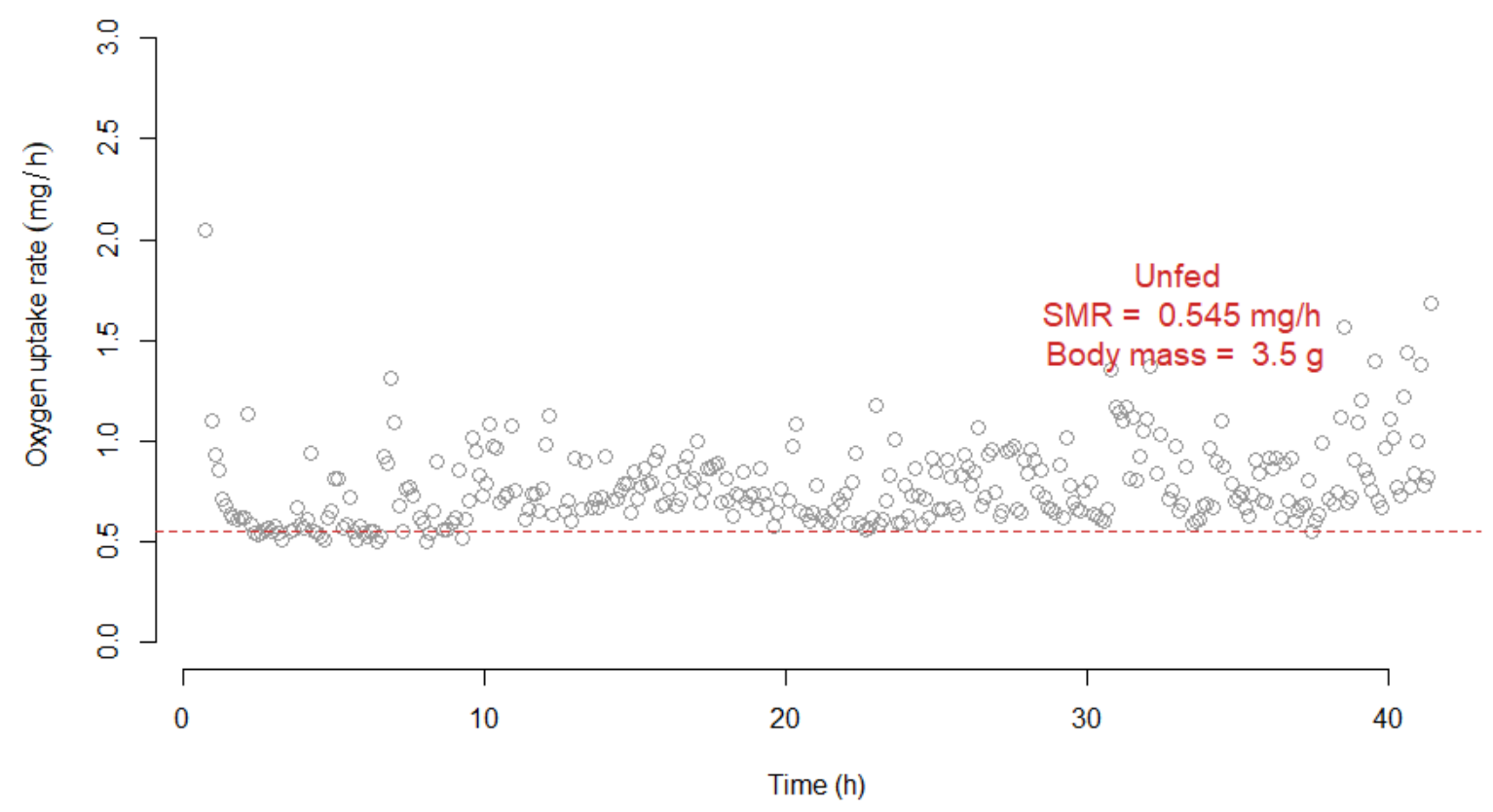

7_290617

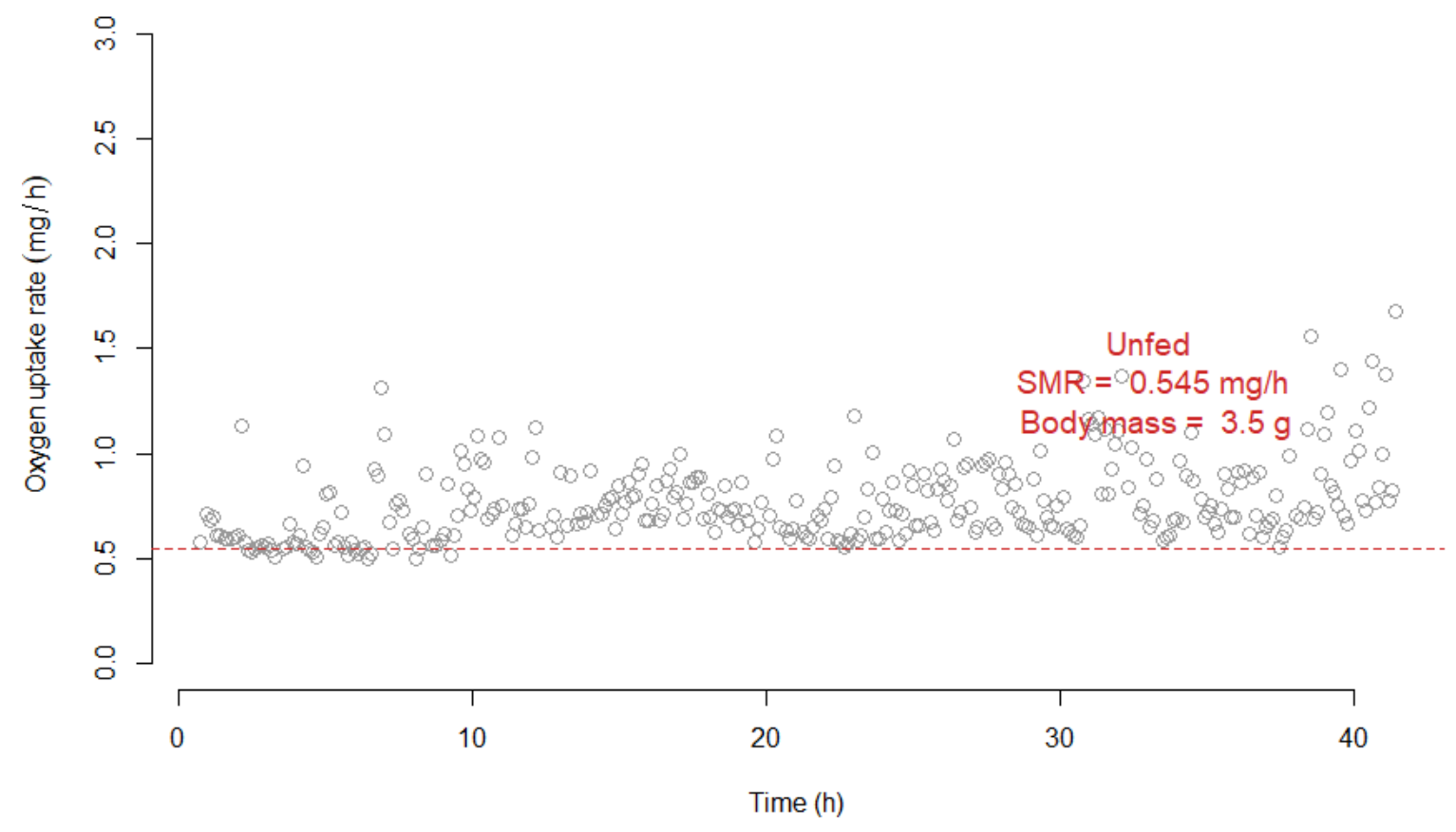




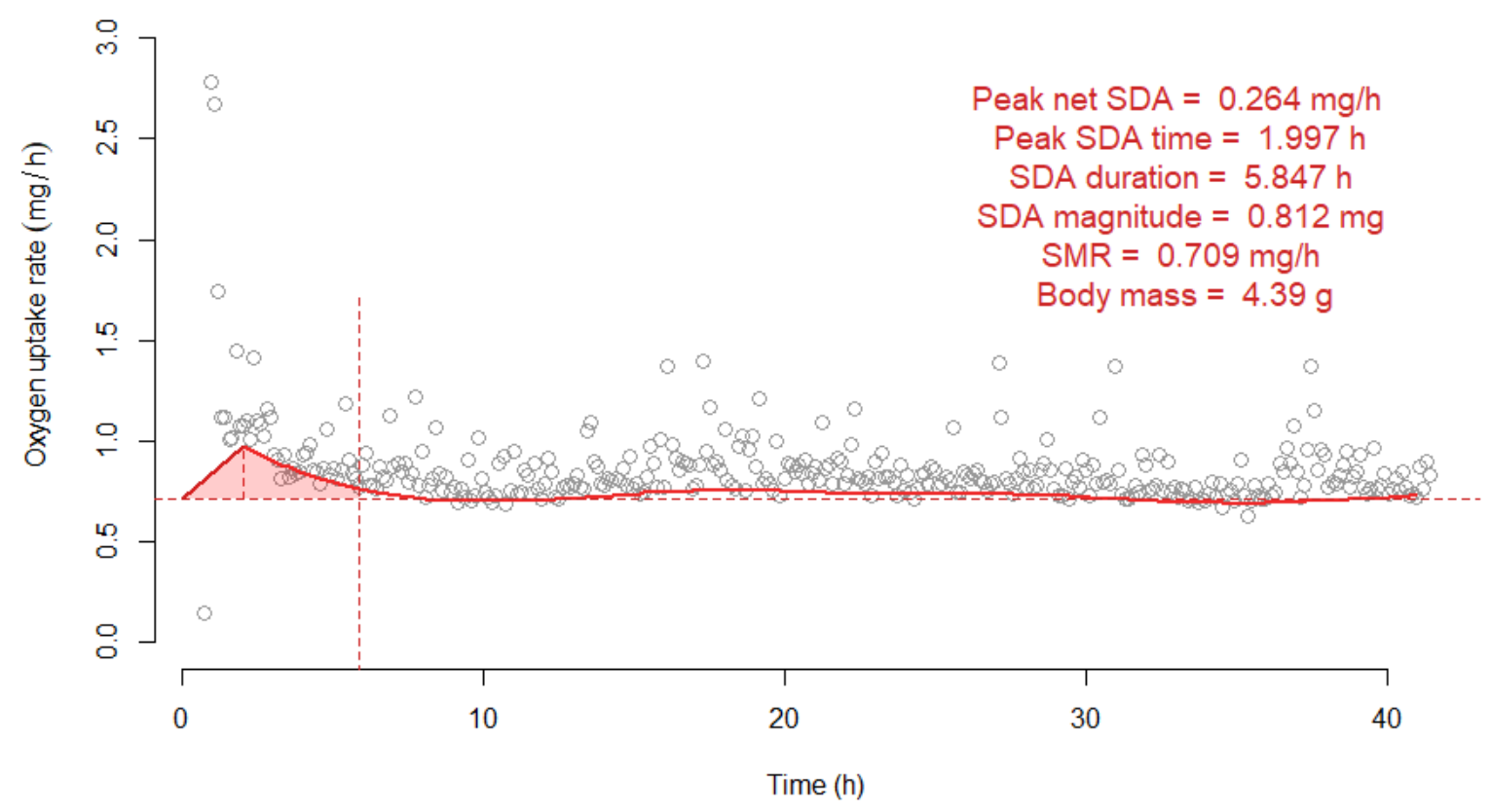

8_290617

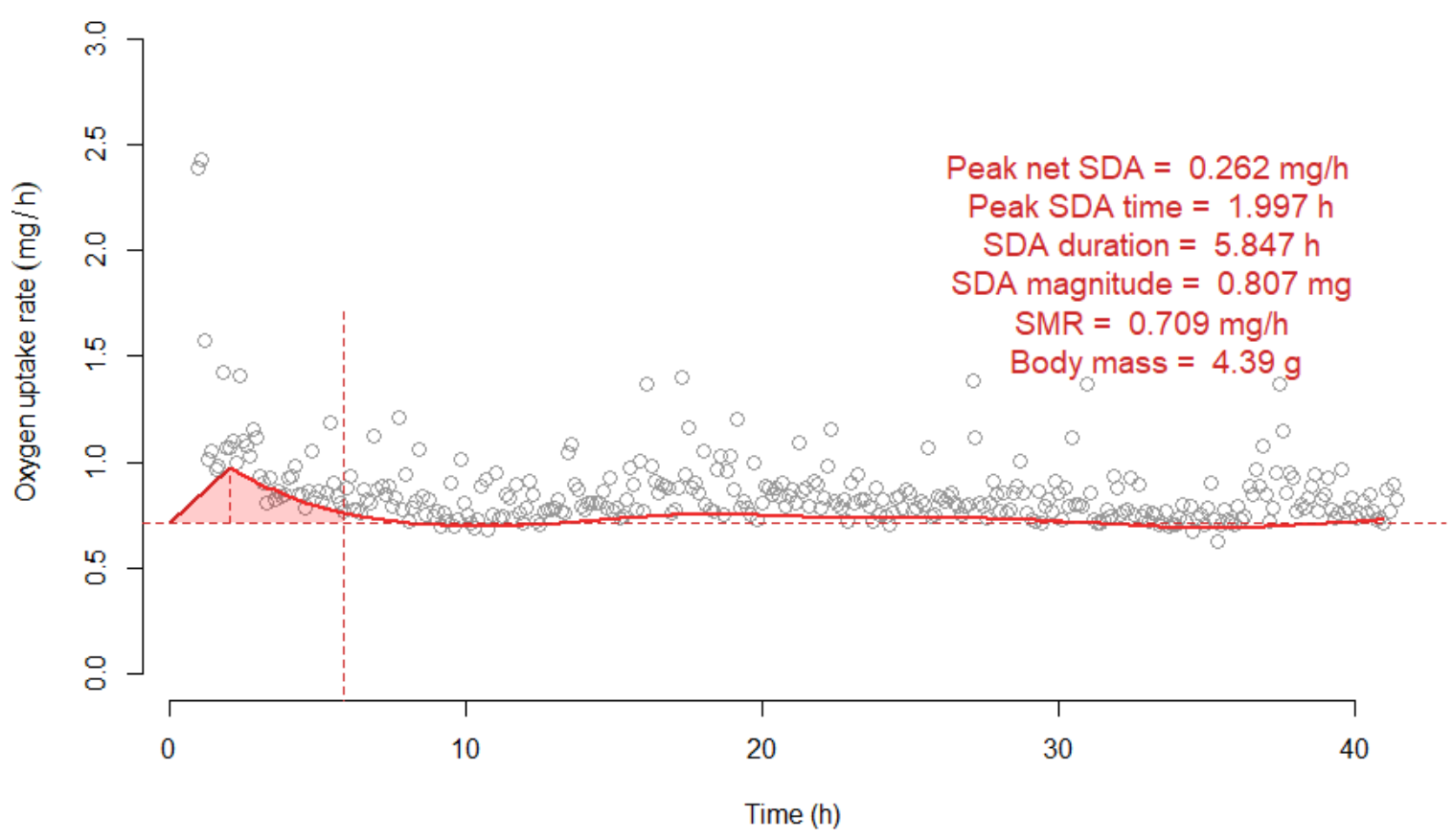




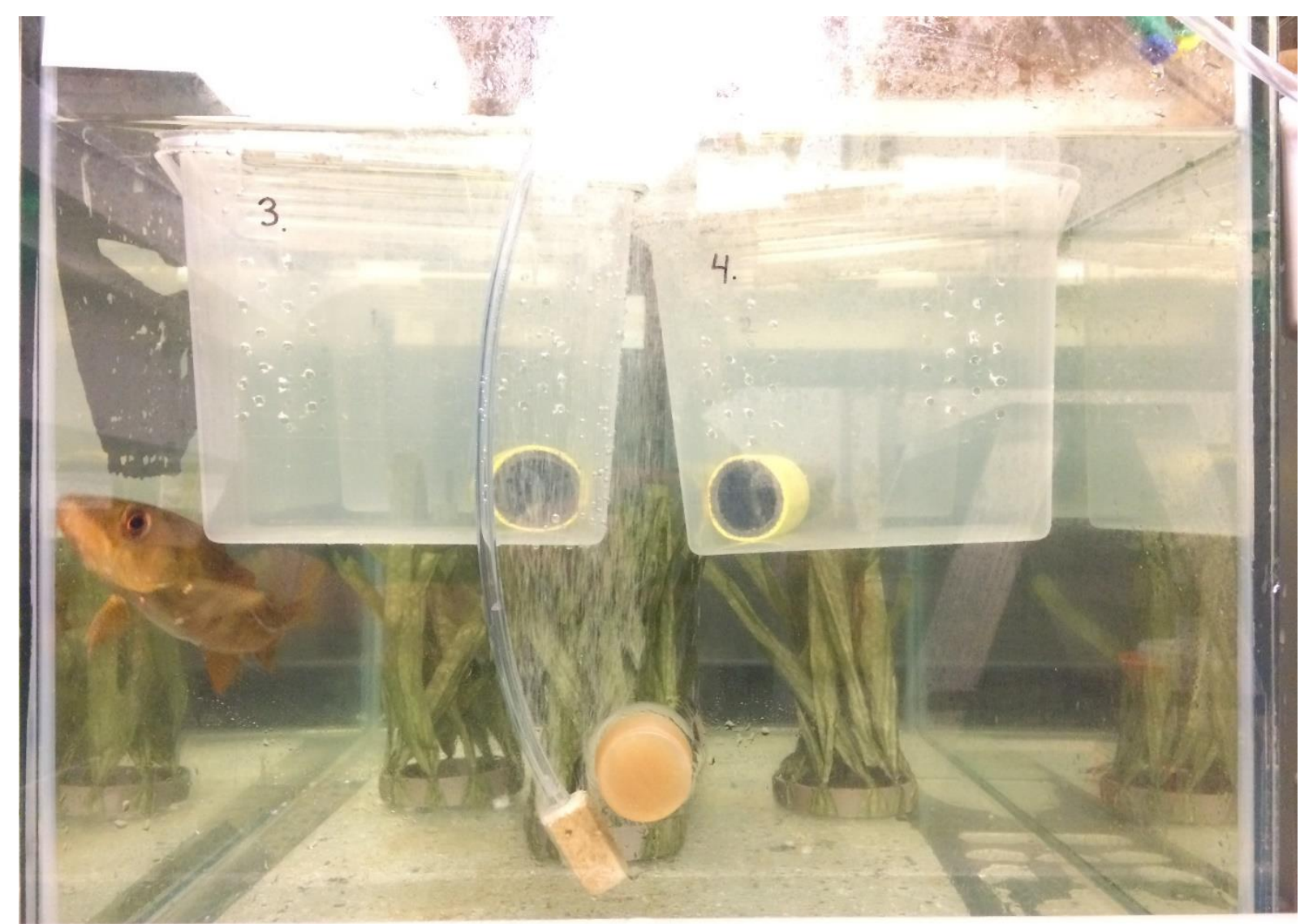

Figure S2. Photo of one of the six holding tank setups comprising a glass aquaria containing either a cod (predator treatment; shown here) or no cod (no predator treatment) and four smaller, perforated plastic boxes containing one wrasse each and a shelter (yellow tube). 


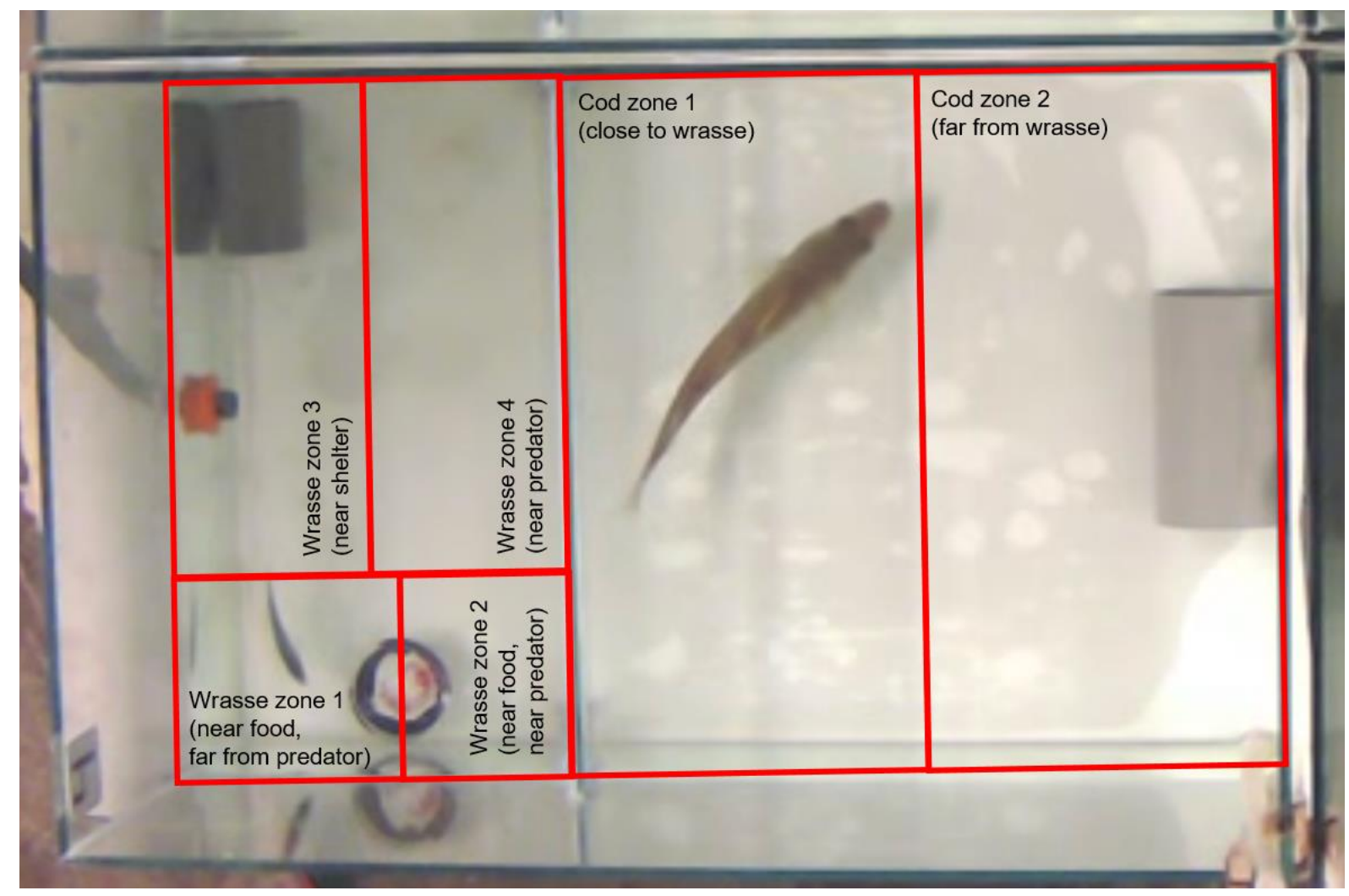

Figure S3. Photo of one of the four behavioural arenas containing a wrasse (left) and cod (right) separated by a glass wall lifted $3 \mathrm{~mm}$ above the floor of the arena to allow water exchange between prey (wrasse) and predator (cod) sections. The grey tubes are shelters. The different zones mentioned in the main article are outlined here in red squares. 


\section{References}

Chabot D, Koenker R, Farrell AP (2016) The measurement of specific dynamic action in fishes. J Fish Biol 88:152-172. 